Portland State University

PDXScholar

\title{
Las Pioneras : New Immigrant Destinations and the Gendered Experiences of Latina Immigrants
}

Angie Pamela Mejia

Portland State University

Follow this and additional works at: https://pdxscholar.library.pdx.edu/open_access_etds Let us know how access to this document benefits you.

\section{Recommended Citation}

Mejia, Angie Pamela, "Las Pioneras : New Immigrant Destinations and the Gendered Experiences of Latina Immigrants" (2009). Dissertations and Theses. Paper 1910.

https://doi.org/10.15760/etd.1908

This Thesis is brought to you for free and open access. It has been accepted for inclusion in Dissertations and Theses by an authorized administrator of PDXScholar. Please contact us if we can make this document more accessible: pdxscholar@pdx.edu. 


\section{'LAS PIONERAS:'NEW IMMIGRANT DESTINATIONS AND THE GENDERED EXPERIENCES OF LATINA \\ IM'MIGRANTS}

by

ANGIE PAMELA MEJIA

A thesis submitted in partial fulfillment of the

requirements for the degree of

\section{MASTER OF ARTS}

in

SOCIOLOGY

Portland State University

2009 
The abstract and thesis of Angie Pamela Mejia for the Master of Arts in Sociology were presented October 3,2008, and accepted by the thesis committee and the department.

COMMITTEE APPROVALS:

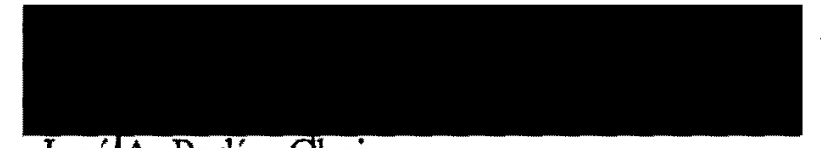

JosélA. Padín, Chair

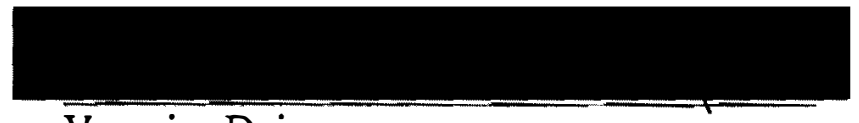

Veronica Dujon

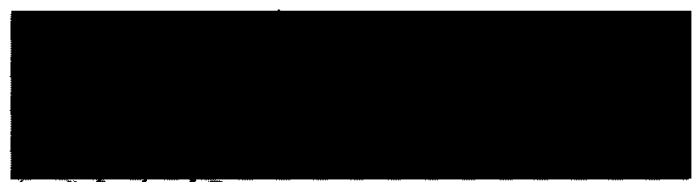

J hagnna Brenner

Michele R. Gamburd)

DEPARTMENT APPROVAL:

Veronica Dujon, Chair

Department of Sociology 


\begin{abstract}
An abstract of the thesis of Angie Pamela Mejia for the Master of Arts in Sociology presented October 3, 2008.
\end{abstract}

Title: Las Pioneras: New Immigrant Destinations And The Gendered Experiences

Of Latina Immigrants

Are experiences with migration affecting culturally specific gendered practices, roles, attitudes, and ideologies of Mexican women and men? Which experiences reinforce patriarchy? Which experiences transform patriarchy? This thesis proposes that Mexican immigrant women will subscribe to and enact different gendered behaviors depending upon their perception of gendered gains. Various factors, such as time of arrival, previous experiences with negative machismos, and workforce participation af fect how they construct gendered identities. The context where bargaining occurs - whether it, was the home, the community, or the workplace - inform women of what strategies they need implement in order to negotiate with patriarchy. This study employs two models, Deniz Kandiyoti's concept of the patriarchal bargain and Sylvya Walby's theoretical position of patriarchy fomenting unique gender inequalities within different contexts, to process the different ways Mexican immigrant women perceive and perform gender. 
The author analyzed data collected from participant observation activities, focus groups, and interviews with women of Mexican descent living in new immigrant destinations. Mexican immigrant women's narratives of negotiations and transformations with male partners indicated equal adherence of traditional and nontraditional gendered behaviors in order to build satisfactory patriarchal bargains. In addition, data suggested that identity formation was the outcome of migratory influences; it also indicated that progressive ideas about gender were salient before migrating to the U.S.. Findings also suggested that reassured masculine identities, due to the stable work options open to Mexican immigrant males in this area, became a factor in the emergence and adherence of distinct gendered attitudes, beliefs, and perceptions by women in this study. 


\section{DEDICATION}

For Slice and Kelsey. You are everything to me.

Para las fabulosas mujeres de Sea Prairie, por su sabiduria y su valor. 


\section{ACKNOWLEDGMENTS}

I would like to thank my husband and son, you for always cheering me on, putting up with my moods and for their love. Thank you to my family for their support and their life lessons. To my technical team, Pete, Stacy, and Renee, for their support and fast turn around when I needed it the most. This work would not have been finished if not for Dr. Brenner and Dr. Dujon, for always looking out for my welfare. I want to thank my chair, for allowing me the opportunity of carrying out research in Sea Prairie.

Bahar, my cohort, and the Sociology crew, you rock, as always. Dr. De Anda, for his wisdom and support. Lastly, I want to thank Christina Nicolaidis, for being there during the last minute of the race. 


\section{TABLE OF CONTENTS}

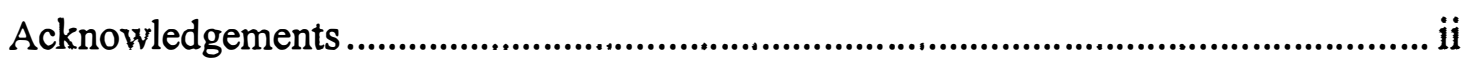

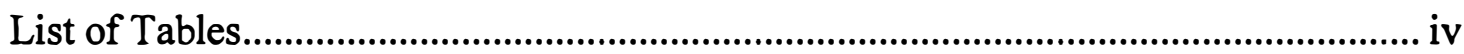

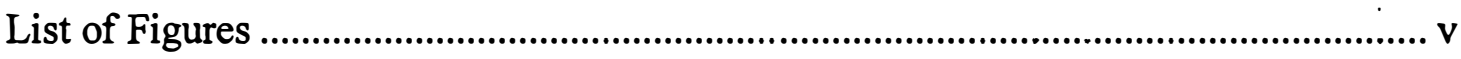

Chapter I: Introduction .......................................................................................... p.1

Chapter II: Literature Review .................................................................................... p.6

Chapter III: Methods ............................................................................................... p.28

Chapter IV: Cuando viviamos en Mexico: Pre-migratory experiences with patriarchy p.52

Chapter V: Aqui No Es Como En Mexico: Challenging Mexican patriarchy in the U.S. p.65

Chapter VI: Gendered Negotiations and Identities p.123

Chapter VII: Discussion p. 145

References p. 160 


\section{LIST OF TABLES}

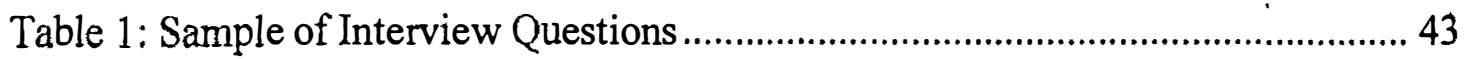




\section{LIST OF FIGURES}

Figure 1: Kibria's Model of Migration and Patriarchal Renegotiations ....................... 9

Figure 2: Patriarchal Bargain within Structures .......................................................... 22 


\section{CHAPTER I}

\section{INTRODUCTION}

How are immigrant-sending areas' gendered practices, roles, attitudes, and ideological stances renegotiated in the U.S.? While many Mexican women participate in migration due to an array of social factors, such as family reunification, we cannot ignore their motivations to migrate because of other gendered gains, such as economic autonomy. Consequently, work in the U.S. may produce different gendered processes inside the immigrant household. For this particular study, the area in question is a mid-size near coastal town located a couple of hours away from the Portland metropolitan area, an area that migration scholars are now calling high immigration destinations.

A high immigrant destination is characterized by the sudden influx of immigrants to non-metropolitan areas, prompted by labor recruitment of low-cost deskilled labor, migration spurred by the fracture of Latin American economies, and changes of U.S. migration policy. These new destinations are found in every region of the U.S., and Oregon is one state experiencing rapid Latino demographic growth (Durand, Massey, \& Charvet, 2000). These areas are negotiating and adapting to new immigrants differently, with some welcoming the economic revitalization that immigrant labor has promoted, others questioning and outright opposing rapid change of the racial and ethnic social landscape.

As these immigrant women create lives and their children are incorporated into U.S. society, questions regarding policy and assimilation are at the forefront. The bulk of work on new immigrant assimilation focuses on traditional gateway cities and 
states. This thesis shifts the focus to a new type of destination of growing importance. How are new destinations treating these female proletarians and their families? How are these families, and the place of women within them, changing?

For this research I build upon two theoretical frameworks, Silvya Walby's (1999) theoretical perspective that takes into account processes inside structures as being patriarchal in nature, thus illuminating practices that foment gender inequality. I couple her analysis with Deniz Kandiyoti's (1988) understanding of patriarchal practices as culturally dynamic, allowing men and women to negotiate their gendered roles and responsibilities, what she calls patriarchal bargains. Patriarchal bargains may transform the gendered worlds of women while at the same time compelling women to either embrace or resist such changes.

As a feminist researcher, I lay out an analysis of how patriarchal changes in one structure, one of them being waged labor, affect the patriarchal bargains inside another structure, such as the household. I steer away from a "gains" in one sphere and "losses" in another sphere argument. I propose that one must disentangle specific factors that negatively or positively affect women's status in the receiving community in order to understand their actions. The argument of women as secondary migrants or spouse followers may be partially correct. However, gendered processes before, during and after migration illuminate different motivations that women may have when they undertake a journey that challenges both patriarchy and themselves. 


\section{Sea Prairie}

I conducted a six-month study in the small coastal town of Sea Prairie, Oregon ${ }^{1}$. Since the early 1990 's, this area has been attracting immigrants from various regions of Mexico, with a majority hailing from western Mexican states such as Michoacán and Nayarit ${ }^{2}$. The most prominent marker of Mexican migration is the number of children attending the area schools and the visibility of family activity in other areas, such as institutions, recreation venues, and various other public spaces.

Sea Prairie has a few other markers that indicate a growing Mexican population: a few Mexican restaurants, Mexican food lunch trucks, and the small Mexican store located downtown. These few markers of a new culture are swallowed by other established storefronts such as a boot and hat shop, small repair shops, coffee shops, office supplies stores, fraternal meeting halls, family restaurants, and bars. Sea Prairie's downtown also boasts signs of a community identity immersed in its pioneer past by the location of its museum right next to governmental buildings.

Sea Prairie was an excellent site to conduct research on new destinations due to its distance from Portland, $\mathrm{OR}$, its food processing businesses and their attractiveness to Mexican immigrants looking for work, and the specific non-Hispanic White working-class character of the community.

\footnotetext{
${ }^{1}$ Pseudonyms will be used for the names of easily identifiable Oregon cities localities.

${ }^{2}$ Pseudonyms will also be used when speaking of easily identifiable settlements and small towns and cities in Mexico.
} 


\section{Food Processing and Immigrant Labor}

The food processing sites that employ Mexican and Central American immigrants are a couple of privately owned beef processing plants, a national seafood processing and distribution company, and various area hotels. The undesirability of some of these jobs creates an opportunity for employers to recruit minorities, often living side by side (but not interacting) with the Anglo area residents (Fink, 1999, p. 136). Immigrant men and women seek these employment opportunities once they perceive the need for their labor. By using third-party contractors and current employees to find their new laborers (mostly Mexican women), and maintaining substantial control on the shop floor while exacting maximum productivity from their employees, these food processors, subscribe to the industrialization of the food processing industry. Champlin and Hake (2006) state that meat production and processing increasingly relies on the labor of Latino workers. This successful "industrialization of meatpacking" is dependant upon an army of Latino workers with no control of the pace of the labor process. Cheap, immigrant labor not only increases gross earnings, but also benefits industries by disallowing employee unionization and collective bargaining.

\section{Key Questions}

The main goal of this study was to capture the specific nature of the gendered worlds of Sea Prairie Mexican immigrant women, not to generalize the gendered nature of immigrant women's worlds. With this in mind, the following questions drove my study of these Mexican immigrant women's worlds and experiences: 
- Are experiences with migration affecting culturally specific gendered practices, roles, attitudes, and ideologies? Which experiences reinforce patriarchy? Which experiences transform patriarchy?

- Are immigrant networks reinforcing patriarchy? Are immigrant networks transforming patriarchy?

- How does identity change as a result of these processes?

\section{Organization of Chapters}

Chapter 2 provides the conceptual model and background literature review using various works in the social sciences: Chapter 3 discusses methods used to collect and analyze data. Chapter 4,5 , and 6 discusses the findings of the study and the closing chapter discusses the initial guiding questions in light of the findings and poses recommendations for future studies. 


\section{CHAPTER II}

\section{LITERATURE REVIEW}

This thesis studies experiences of immigrant Latinas in a new high immigration community in Oregon. Using their participation in gender-segregated occupations as a focus, this research investigates how social processes inside the workplace rearranges patriarchal relations in the home, and how changes on the domestic front in turn affect patriarchal relations in the community. In this review of the literature, I identify the theoretical and conceptual frames that will shape the rest of my study. I place a strong emphasis on two theoretical concepts: Sylvia Walby's position of patriarchal processes within structures, to understand how one structure may affect the other, and Deniz Kandiyoti's theoretical use of the patriarchal bargain to take into account cultural nature of patriarchal practices, and to illustrate how bargaining creates new gendered processes.

In addition, I emphasize three aspects of migration: (1) immigrant women's use of networks, (2) women's labor participation, and (3) identity formation. Although I examine experiences of immigrant women of Mexican and Latin American descent, whenever applicable, I cite research based on or about immigrant women of other ethnicities.

\section{Patriarchy and Patriarchal Bargains}

Walby (1991) defines patriarchy as “... a system of social structures and practices where men dominate, oppress and exploit women"(p. 20). Among the structures that enforce patriarchal processes Walby identifies: 
...the patriarchal mode of ... [household]... production, patriarchal relations in paid work, patriarchal relations in the state, male violence, patriarchal relations in sexuality, and patriarchal relations in cultural institutions..." (Ibid).

Furthermore, Walby states that structures have the potential of causally affecting other structures, and her multiple structures framework allows for a more complete understanding of where changes are occurring and whether or not women benefit from such changes.

Due to the potential divergences between cultures, Deniz Kandiyoti (1988) posited that patriarchy, as a concept, needed to be culturally and historically sensitive to the different systems of male domination. She coined the term "patriarchal bargain" in order to illustrate the array of constraints that women experience in their lives and how these constraints uniquely corresponded to the specific patriarchal practices within their culture. A patriarchal bargain will consist of an arrangement between the genders, informed by existing rules (whether founded on ideology or practicality) about how men and women should act, but flexible enough to be modified when affected by a multitude of factors, such as legal, historical, social, and economic transformations.

Patriarchal bargains are susceptible to changes and women under different patriarchal cultures will develop different strategies to resist gender oppression and new ways to respond to an uneven bargain. She posits that these changes, whether as a normative change, like a decrease of wife beating, or a change in practices, like women's entrance to the workforce, will also affect these women's gendered idea of themselves and allow them to employ new strategies that challenge the new bargain. 
Kandiyoti (2002) emphasizes that women's attachment to a specific patriarchal order may derive from the "...certain positions of power available to them" (p. 147). For example, patriarchal practices that encourage women's domesticity in the context of an extended kin-network may seem attractive to women, due to ability to share household labors with other women. Thus, they may perceive a change from an extended family household to a nuclear one negatively. The latter dilutes any of these women's existing positions of power, spheres of autonomy or strategies that they could have capitalized under the old extended family model. Whereas the old arrangement permitted women to delegate domestic labors to other female kin, the new patriarchal arrangement burdens women with inability to do so. Additionally, women may be forced to retreat into disadvantaged positions due to the inability to find alternatives to compensate for previous gains in the old bargain. In this case, the only way to regain any of past gains would be to outsource household duties.

Kandiyoti (1988) exemplified women's resistance to changes in the patriarchal order by “...claiming their half of the bargain ...[men's] protection in exchange for submissiveness and propriety..." (p.283). Women's position on a particular stance derives from what works for them at that specific moment, even if at face value it resembles their complete subordination, or what we may think of as a submerged or false consciousness response to their current realities.

Migration is a response to economic and political changes in one's country of origin, and depending upon certain conditions or institutional contexts, may affect women and men differently (Pessar, 1999). As Kibria (1990) puts it “...shifts in the 
resources of women and men that have accompanied the migration process have thus created the potential for a renegotiation of the patriarchal bargain..." (p.14). Kibria argued that the patriarchal order was disrupted by women's increased control of resources and allowing them the ability to renegotiate existing patriarchal givens.

\section{FIGURE 1}

\section{Kibria's Model of Migration and Patriarchal Bargain Renegotiations}

Patriarchal Bargain (area of origin) $\rightarrow$ Migration $\rightarrow$ Shift of resources available to women (U.S. context) $\rightarrow$ Renegotiation

We can then argue that women's migration to the U.S. opens up opportunities for a better bargain, giving Mexican immigrant women the ability to renegotiate less than desired positions, or allowing them to bargain for further benefits under a slightly more beneficial patriarchal instance. Figure 1 presents a systematical argument of this renegotiation, by illustrating how renegotiation is now possible due to the resources available to Mexican immigrant women in the U.S. receiving area.

\section{Patriarchal Bargains in the Domestic Sphere}

Traditionally, on their pre-migratory bargain, Mexican women's sole dedication to the domestic space and acceptance of heavy patriarchal control was offset by series of returns, such as economic protection by a male partner and social and community status as wife and/or mother. Their limited participation in other public spheres was offset by the cultural importance of motherhood and/or marriage. Mexican masculinities were reinforced and nurtured by positions of power that benefited men over women. Under this patriarchal arrangement, economically sustaining a housewife took care of a male's need for heirs (a source of labor), partial 
fulfillment of his (hetero) sexual needs, and secured his status as a provider.

Furthermore, men's greater participation in other structures in the public realm allowed them to fulfill a culturally ascribed role. In sum, both parties were bound by a set of rules (even when taking into account the power differentials) and both men and women had the ability to create a positive identity within those patriarchal parameters.

Historical transformations, such as laws giving Mexican women various legal rights, (i.e. right to divorce and property ownership in 1917); social transformations, (i.e. decline of the extended family ruled by a male patriarch); or economic changes like industrialization of the country attracting women to work in newly industrialized Mexico city, or the more recent economic transformation driven by the 1982's peso crisis $^{3}$; compelled men and women to modify the existing stipulation of the past patriarchal bargain. A household where the male partner's wages do not sufficiently cover household reproduction costs makes women's entrance to paid work necessary (even favorable), but this becomes a source of conflict within the household. Thus women and men will negotiate privileges and entitlements, resources and responsibilities. This negotiation occurs within the existing patriarchal bargain, which continues to define how women can gain certain benefits (whether by resisting changes outwardly or subtly working "behind the scenes"), or defines how women can recover a social right under the old patriarchal bargain. For example, negotiating entrance to the workplace may create conflict in the household, even during economic hardships, and women may rationalize their entrance to the workplace as a way to

\footnotetext{
${ }^{3}$ For brevity, I only discuss historical changes lightly, in or der to illustrate the dynamic nature of patriarchal bargains.
} 
provide for their children's necessities (Segura, 1991). Thus, this entrance to the workplace is rationalized in light of the patriarchal bargain that sees women as their children's primary caregiver, instead of seeing them as individuals wanting to eam a wage in the market economy.

Migration as an economic transformation will force both parties to renegotiate roles and responsibilities, such as women being allowed to go to work in order to move forward economically in the new area. Men may need to renegotiate their role as sole economic providers and increase their participation in household labor in order to maximize a wife's income. Women's pre-migratory roles and responsibilities may have been strictly domestic. These agreements may have allowed women to work in tune to their lifecycle, or may have dictated their specific behavior in certain social situations (such as going out accompanied by male relatives only, etc). Their entrance to the workplace may have been episodic and control of her income or how her income was allocated may have been dictated by a stricter patriarchal code, with her decision-making abilities applied to household matters.

Post-migratory gendered negotiations in the transnational space, such as immigrant women's workforce participation, may point to a more or less equal division of labor, (Ybarra 1982), one that allows for a decrease of her domestic duties and gives her the ability to more say on household finances. Hondagneu-Sotelo's (1994) study of a cohort of Mexican immigrant women's migration and settlement in a Los Angeles neighborhood observed very egalitarian household labor participation by some of the husbands of her informants. She concluded that these egalitarian practices 
arose because of their experiences as Bracero migrants, forced to do their own housework while their wives stayed in Mexico. But these changes are not automatic or even comparable across the literature. When she documented the experiences of women who had migrated after the Bracero era, she did not find the more egalitarian house chore division described above, attributing it to post-1965 male migrants' opportunity to reside with kin, extramarital cohabitation with other women, and/or access to a community of co-ethnics.

Menjivar's (1999) study of Guatemalans in Califomia suggested than when a woman is the only one employed, the home-keeping responsibilities may also become her exclusive domain (p.116). She examines how this strategy may soften conflict in the home by women letting men know that "they [as men] still hold authority" (p.117). In short, immigrant women's participation in the labor force may not always bring emancipation from traditional housework duties (De La Torre, 1993; Zavella 1988). When women decide to renegotiate their role in the public space, they will still be bound by their private space duties and roles. This observance of traditional domestic duties but active participation in the public sphere as workers violates traditional gender constructions but also reinforces them. Women's conformity to this double burden may serve as a way to maintain a sense of stability amidst the severe changes that the act of migration brings (Baker, 2004). This renegotiation between gendered notions and actual necessities has also been observed among Puerto Rican women socializing “... their daughters to uphold traditional gender expectations... while learn[ing] how to 'take care of themselves'..." (Toro-Morn and Alicea, 1999, p. 206). 
Among Hindu immigrants, women's migration and eventual employment becomes acceptable due to the "...redefinition of male and female honor...", one that occurs once the family resides in the U.S. (Kurien, 1999, p. 261). While some of the sending areas may have women actively participating in the workforce, some forms of male domination will remain ideologically anchored to aspects of the old gendered order. For example, Dominican women's participation in export-oriented industries may have allowed for control over the household income, yet "... women continued to recognize men as el jefe... "(McClenaghan,1997, p. 29). In areas like Zamora, Michoacán, where women's entrance to the salaried workforce is no longer seen as a deviation from their gendered roles, “...[some community members still]... interpret women's mobility and the growing input from wives and daughter in household decisions as signs of loss of respect..." (Murnmert, 1994, p. 208).

\section{Patriarchal Bargain in the Workforce}

Pariarchal structures such as the economic sector, where men are better positioned, influence the view of women's earnings as supplementary (Kanaiapuni, 1998), dictate how women may negotiate that entrance to the workplace by maintaining the position of males as the primary earners. Women's position as secondary earners forces them to uphold their part of the bargain by performing domestic duties. Their earnings may allow for further bargaining power, but may not lead to the complete transformation of the ideological foundation of a patriarchal bargain. Thus, Wilson (2003) criticizes the simplistic view that "work participation equals autonomy", arguing that even if Mexican women may challenge economic 
dependency on their men by obtaining paid employment, but by entering the work force they encounter another form of patriarchal control, sexism, and their subordinate position is maintained and enforced by their sexuality. She cites various case studies illustrating male domination in maquiladora work, where women are objectified and sexually accosted by either supervisors or other males, the outcome being the creation of a passive workforce made primarily of women workers. I suggest that this maintenance of patriarchal codes that sustain men's control of women's via their sexual attributes reproduce masculinities that are in tune with that patriarchal bargain. Women's interest in remaining passive are anchored to the fact that their economic earnings are a form of power in the household, even though they are constantly attacked in the work sphere (whether sexually or economically).

Workforce participation is the result of economic forces that create and further exacerbate male underemployment and increase women's economic responsibility, but do not challenge (McClenaghan, 1997) the current gendered arrangements dictated by that patriarchal bargain. Casique's (2001) national study of Mexican couple found these women's labor participation increased feelings of autonomy but it did not signify changes in ideology and gendered nornns. These Mexican wives did not find men increasing their participation in the domestic arena even when controlling for education and earnings.

Relationships in the immigrant home may be negatively affected with husbands negatively responding to wives' employment by withholding earnings, (Chant, 1991, p.212) physical abuse, policing the type of work the woman may be 
involved in, mismanagement of household funds, and abandoning the home all together. While women may see their workplace as a sphere of autonomy (due to the ability to bring wages, forming friendships, or even learning new skills), working in

the U.S. may pigeonhole them in less than desired positions, whether they are seasonal or part-time positions, or significantly lower paid non-seasonal work. Their status as immigrant workers means that these positions of economic insecurity may become an impediment to their potential bargaining power in the household, due to their dependence on their male partner's wage, and other structural barriers imposed by the U.S.

The economic sphere is constitutive of patriarchal practices that relegate women's earnings as secondary, and subject women to other forms of gender domination. While earnings may facilitate bargaining, economic participation may brings additional factors that can temper any changes to the patriarchal bargain.

\section{Patriarchal Bargains and.U.S. Receiving Communities}

Hancock (2007) argues that Mexican immigrant women are allowed better access and increased utilization of resources for their family's well being in the U.S. context. Patriarchal arrangements may also be influenced by various receiving areas factors, such as local, state and/or federal benefits that immigrant women may be eligible for. At the same time, several factors may cancel out any gains already made.

Immigrant women may find that the ability to access social service resources in the receiving area equalizes gender relationships with male spouses and other kin (Kibria, 1990). These benefits include the ability to apply for some state and federal 
benefits, such as food stamps and TANF (Temporary Aid for Needy Families). Women's procurement of social services and private aid may alleviate some of the family's financial burden, especially if they are substantial. Mexican women perceive the U.S. legal and social framework as protective of women and as a possible detractor of male control (Barajas and Ramirez, 2008).

At the same time, various features of receiving areas may jeopardize the would-be rearrangement of the patriarchal bargain. Issues such as lack of extended family to help with childcare (Easter et al., 2006); undocumented status of family members (Fix and Zimmerman, 2001); labor market and wage earning obstacles (Perreira et al., 2006); fear and ambivalence towards institutions such as schools (Fontes, 2002) may bar women from renegotiating aspects of the patriarchal bargain. Gouviea (2005) argued that Latina immigrants in Nebraska are affected by traditional gendered duties, along with inconveniences such as lack of transportation (disallowing everyday responsibilities such as going to work, buying groceries, or picking up children from school). In comparison to Mexican immigrant women residing in more traditional Latino destination sites, those living in new destination areas are limited not only by their educational background, economic and social position as undocumented persons, (Hancock, 2007) but also by the community's relatively small number of coethnics residing in these new destinations. The difficulty created by gender roles and various institutional forces is also noted in Williams, Alvarez \& Hauck's (2002) study

\footnotetext{
${ }^{4}$ In states such as California, immigrant parents with U.S. born children may receive means-tested, cash benefits such as TANF, "child only" cases make up to $40 \%$ percent of their caseloads. Other areas such as Nevada and New Jersey have a modest number of immigrant families receiving benefits on behalf of their children's "child only" case status.
} 
of high school Mexican girls in the Midwest. They argue that families' cultural expectation of these girls as household helpers lessened opportunities to socialize or hold jobs, consequently thwarting prospects to practice and refine their English.

\section{Networks and their Impact on the Patriarchal Bargain}

Extant literature provides us with the myriad of changes brought on by migration and how it may affect the pariarchal bargain in different ways and consequently, women's lives. Resources are a form of capital that allows women and men to negotiate their lives in this space; among those resources that men and women tap into I would emphasize social networks. Networks provide information and ways to navigate the host community, serve as a form of emotional support, job referrals, and shelter, and becomes the central "...means through which migration takes place..." (Chavez, 1997, p.137)

Due to the gendered nature of migration, networks will steer men and women to make use of them and be affected differently in both the home community and the U.S. community (Curran and Fuentes, 2003, p. 290; Livingstone, 2006). Men's favorable position as migrants has resulted from their domination in numbers in the migration stream (Cerruti \& Massey, 2001; Donato, 1993; Hondagneu-Sotelo, 1994; Kanaiupuni, 2000; Livingstone, 2006) and their advantageous position of power in a highly patriarchal culture (Hondagneu-Sotelo, 1994). Nevertheless, the explicit effects of women's networks on female's decisions to migrate to the U.S. cannot be overlooked and need to be understood as part of the process that chips away at old gendered beliefs and creates pressure for a renegotiation of the patriarchal bargain. 
Kibria's (1990) study of Vietnamese immigrant women and their experiences with the patriarchal bargain is exemplary. She found networks being vital to the formation of a more autonomous female identity, informing women not only of strategies for the economic survival of their families (employment opportunities, maximization of human and social services, etc), but acted as a collective force of female empowerment and agency by "...protect[ing] the interests of individual women who were in conflict with male authority..." (p. 12) Hondagneu-Sotelo (1994) explains that even though Mexican women may not have initiated plans to migrate, they may be motivated by female migrants' enticement and offers of financial, social ${ }^{5}$ and emotional help. This is because the sources of information about jobs and resources may be heavily feminized and geared towards women's incorporation in the receiving area (Hondagneu-Sotelo, 1994) ${ }^{6}$. Some research finds that female networks will have a "...stronger influence on the choice of female destination than the location of male migrants" (Winters and Davis, 2001 p.21 my emphasis). Parrado and Flippen (2005) found that female friendship networks allowed women to be less isolated and garner information and resources that may equalize gender relationships. Specifically, social support from friends resulted in women having increased input on and control of household finances and experiencing a lighter load of household due to male partners' increased help. Networks composed of women's own kin may facilitate women's migration and partially aid women to renegotiate less favorable bargains (Hondagneu-

\footnotetext{
${ }^{5}$ Hondagneu-Sotelo speaks how women may help the potential migrant by negotiating with fathers, spouses, or male heads of household.

${ }^{6}$ Conversely, men's job prospects may not aid women to find employment or find resources like child care, schools, social services; resources are germane to their expected roles as caregivers of children.
} 
Sotelo, 1994). Additionally, workplaces may also be spaces where women's friendships may be activated (Zavella, 1988). A highly feminized workspace may be even a more fertile ground for these friendships to form and allowing women to build a gendered capital that may facilitate bargaining inside the household. In sum, while female networks challenge the sending's areas patriarchal order by motivating women to undertake the journey North (sometimes defying spouses), by increasing the number of female migrants in the receiving area (thus maturing female networks), and by providing material resources to female migrants, we cannot ignore how networks themselves also complicate the patriarchal bargain by disadvantaging women.

Female networks may boost negotiation power in the household, but in order to undertake the journey successfully, Mexican women may still be constrained by the need to make use of men's networks. Planning the journey and reaching the U.S. safely may require the aid of males more developed knowledge on border crossing (Davis and Winters, 2001) or dealing with coyotes. Livingston examined the job outcomes of Mexican immigrants using networks (kin or friend based) in comparison to non-network means like newspaper ads, etc. to find employment in the formal sector. Even when possessing documented immigrant status, women still relied on non-kin friend networks to obtain employment leads (instead of family networks), leading to the possibility that patriarchal forces still shaped occupation segregation and outcomes due to kin's reluctance of sharing job leads with them (2006).

While I emphasize the importance of family networks, Parrado et al. (2005) research on migrant Mexican immigrant women and relationship power in Durham, 
NC found that family networks in the receiving context were "...significantly and positively associated with emotional dissonance... [since] ... it often imposes burdens on women that reinforce patriarchal demands." (p. 366). Family members from their partners' side reinforced less egalitarian gender practices ${ }^{7}$. For example, additional boarders in the immigrant house (whether these guests are relatives or not) will create more demands on women's domestic labor output (Hondagneu-Sotelo, 1994).

Moreover, having a gender ratio disparity of more immigrant males to immigrant females may reinforce traditional patriarchal practices that lessen the chances of bargaining for fairer gender practices.

These findings show how migrant social networks can "...facilitate and constrain migration opportunities for women and men..." (Hondagneu-Sotelo, 2000) with some studies suggesting that networks weaken patriarchal control at home, while others suggesting that networks reinforce less favorable patriarchal agreements.

\section{Identities and Motherhood}

To understand how Mexican immigrant women may be reconciling paid work in the receiving area with traditional ascribed gendered roles, we must subscribe to a reconceptualization of motherhood that attributes women's increased participation in paid labor as part of their duty as mothers. In spite of Mexico's economic transformations in the last three centuries, motherhood has been an important source of identity for Mexican immigrant women. The continued importance of motherhood

\footnotetext{
${ }^{7}$ Parrado and Flippen also stated that challenges to patriarchy may be more acceptable in Mexico than in the U.S. Understanding the patriarchal bargain as a continuum instead of thinking of it as an static concept may help us understand why in some cases, women are better positioned to make patriarchal bargains in the sending area, instead of the making them while residing in the U.S.
} 
as a form of a positive source of identity has been attributed to the cultural representation and impact of the Virgin of Guadalupe in the historical and political collective consciousness of the country. This synchronization of women's roles as mothers and the Catholic imagery of a selfless, abnegated virgin mother, allowed women in a Morelos community to engage in grassroots work by "fitting in" politics as part of a positive mothering identity (Martin, 1990). Extreme economic barriers affect women and men's identities differently, leaving women with no other positive identity but motherhood, while men have several other avenues of identity formation, such as (hetero) sexual conquests, participation in sports, or other forms of affirmations of masculinity in the public sphere (Neuhauser, 1990). Fitting in paid work or other unorthodox gendered scripts as part of a mother's "duty" may allow women to better renegotiate existing arrangements without overtly challenging patriarchal control. The reproduction of the household, the caretaking of children may still be central to their identities, and entrance to the workplace, far from a liberating force, may well become part of mothering (Tiano \& Ladino, 1999).

\section{Conclusions and Expected Findings}

Mexican immigrant women's experiences with paid work in the U.S. may equally reinforce or alter existing patriarchal bargains both within waged labor, at home, and those patriarchal bargains found in the other structures. In order to understand how these women are positively or negatively affected by these changes, we must understand how this negotiation takes place, what resources are available in 
order to compel a renegotiation, and whether acts of renegotiation affects women's and men's gendered identities.

We can argue that migration may produce changes in the household's patriarchal bargain and within those patriarchal structures that shape women's status outside the household (i.e. paid work.) Framing women's gendered experiences within the household or the workplace as a series of bargains activated by changes may allow us to see that changes in the patriarchal bargain in one structure may affect not only one, but several structures simultaneously, as illustrated in figure 2.

\section{FIGURE 2}

\section{Patriarchal Bargain within Structures}

Patriarchal Bargain within Structure " $A$ " $\rightarrow$ Change $\rightarrow$ Patriarchal Renegotiation of Bargain within Structure " $A$ " (and B) $\rightarrow$ Renegotiation

Renegotiated bargains may take an equitable aspect where there are moderate to significant changes to past patriarchal practices. I will term them equitable patriarchal renegotiations. I term inequitable patriarchal renegotiations those instances when women's ability of renegotiation is thwarted or lessened, where premigratory patriarchal practices remain, or when renegotiations with spouses fail to bring desired gains.

\section{Equitable Patriarchal Renegotiations}

Immigrant women's negotiated entrance to paid labor may lead to control of her wages, thus allowing for a more equitable financial decision making process inside 
the household: e.g., deciding how part of the money should be spent or how financial responsibility for certain obligations is divided. Martha Roldan (1988) sees it as a difference between the wife's "...managerial role in handling a very limited money pool...”, (p. 234) and the joint economic decision on how the total earnings from all workers should be spent. The change from a limited to a joint decision-making model may allow for the renegotiation of patriarchal behaviors in other areas of the public sphere.

Work hours and shifts may allow for women to decrease their household duties, while men may rationalize their domestic labor participation as a way to not deplete household funds. For example, if the male partner works during the night, and his female partner works during the day, his duties may require of him the caring of young children while she is out at work, instead of outsourcing domestic duties. The lack of extended family labor may also motivate husbands to be flexible and take on some of these household labors.

Changes in the household patriarchal bargain, such as the increase in women's participation in decision making may allow for a decrease of patriarchal acts of control of Mexican immigrant women's physical mobility. For example, by learning to drive or taking public transportation in order to go to work, women may justify that they are relieving their male partners of added responsibilities, while at the same time questioning what she is and is not permitted to do under certain instances, thus, allowing her to challenging further patriarchal restrictions. 
Labor participation in a U.S. workplace may also affect how men and women are permitted to behave; being a new country may require the adoption of a more guarded attitude regarding what is an acceptable behavior towards women in this new community. Participation in a U.S. workplace that discourages and outright prohibits patriarchal behaviors could mean a different way that women and men behave and go about their daily lives, how men attempt to "masculinize" that space, and in the case of some areas where Mexican masculinities are not permitted, how women react to this absence of patriarchal behaviors.

Receiving communities may also allow for resources that benefit women's ability to negotiate the patriarchal bargain, such as those provided by the various networks available to them in the new area. These networks range from the emotional support of their own kin to financial resources available to them as mothers, and to forms of financial and in-kind support provided by outside social support agencies. In addition, friendship networks create an alternative to kin networks that may hold patriarchal beliefs above kinship ones, and may allow women the use of additional resources when renegotiating the patriarchal bargain in the household (Parrado and Flippen, 2005).

I would also argue that that the loosening of patriarchal control due to the renegotiations of patriarchal bargains may trigger different ways of women seeing themselves vis-à-vis their male partners. They may try on new identities or discover ways of remaking an identity already in place. They may act in ways that may have been prohibited or frowned upon in their regions of origin. 
While these are just potential outcomes, I argue that certain situations and experiences will create a better bargain for women, and that in turn, these experiences may change how the relationship between men and women is structured in a variety of settings. Factors that allow for a creation of a less detrimental pariarchal bargain for women in the U.S. are as follows: (1) Women's participation in paid wage, since it allows them to balance the decision making process at home (and allows lax understanding of women's public space presence); (2) Mexican immigrant women's greater participation in various parts of the public sphere (institutions such as schools and banks), since it permits them to exercise decision making outside domestic matters, further compelling them to negotiate their domestic roles and that of their male partners; (3) new resources available to women in the U.S. context; and (4) the way new gendered identities are affecting these various domains in order to maintain or further improve the patriarchal bargain.

\section{Inequitable Patriarchal Renegotiations}

Conversely, the net impact of migration may enforce certain aspects of the old patriarchal bargain, which may end up in benefitting immigrant males over immigrant females. Transnational female laborers may recognize the migrating arena as a form of autonomy, and the ability to access material or normative resources as equalizing the gendered order. Yet, in order to keep cultural traditions alive amidst changes created by a capitalist economy and U.S. cultural institutions, they may be compelled to keep old traditional bargains alive. Their male counterparts may revert back to pariarchal 
behaviors once they see the migration experience turning sour, or co-ethnic institutions such as the Catholic Church may encourage the adherence to old patriarchal codes.

If some of the previous mentioned factors (paid work, household distribution of labor, public sphere participation, decrease of patriarchal acts against women via their sex, resources, etc) are absent, not available, or play out in a different way, then the traditional patriarchal arrangements may be reinforced rather than loosened. Wage earning may be beneficial to women when they encourage a more reasonable distribution of labor and increased financial decision-making, but some types of employment may simply not have enough impact to tilt the balance. Many occupational opportunities available to Mexican immigrant women are limited to temporary, deskilled, and low paid occupations. Immigrant women may also be forced to take additional jobs in order to financially break even while simultaneously being solely responsible for the household labors. Conflict with spouses is also a great detractor of the potential renegotiation and may be manifested in a variety of forms. When immigrant women increase their participation in other institutions or accumulate resources, this may threaten Mexican masculinities, and trigger a defensive reaction. Their work participation also detracts from family time and clashes with motherhood as a source of positive identity and individuation for Mexican women.

While women's own family support may be beneficial, either psychologically or logistically, kin support may also be detrimental, and I strongly suggest that women 
without their own family support may have a harder time negotiating with male partners than those with existing kin networks. Since familial patriarchal practices also affect women (some women in fact, may have been subjected to less than ideal patriarchal situations under the care of male kin) the lack of non-kin networks, whether created at work or other domains, may compound that inability to renegotiate aspects of the patriarchal bargain.

Migration as a social force, and the myriad ways factors associated with it, interact to makes a significant reorganization of the pre-migratory patriarchal bargain possible. However, the impact of this change is not set, and can vary along the spectrum between the two ideal-typical outcomes that I introduced in the last section of this chapter. Factors that allow and encourage for better patriarchal bargaining opportunities and resources, and factors that completely negate the ability to do so, are tied in to the specific local character of the areas receiving immigrants, and may have diverse effects on how women use opportunities to challenge aspects of the patriarchal bargain. My approach in this thesis will be to develop an account of the multiple ways women negotiate these bargains; of their view of what a sensible but still just gendered bargain looks like, while being attentive to how structural forces affect women's ability to challenge instances of patriarchal behaviors that are detrimental to them. 


\section{CHAPTER III}

\section{METHODS}

\section{Introduction}

This research aimed to show how Mexican immigrant women negotiated gender once migrating to a new destination area. In this chapter, I discuss the complex experience of insiderness and how negotiation of that role became a new to understand the community, and then I lay out the steps I used in collecting and analyzing data. The chapter also details the development of my coding instruments and the steps that I took to analyze data.

\section{Participant Observation and Researcher Insider/Outsider Status}

The challenges in the field is captured in this passage from my personal journal:

... I was confident that rapport would easily emerge as I am Latina, I migrated with my parents as a teenager, and I was in touch with the Portland Latino community as an activist. As my time in the field progresses, I am now aware of the difficulty of truly being accepted... staying in and being trusted enough to remain an insider ... the possibility... that neither the language nor the migratory experiences that I share with them would be sufficient to allow me access to their realities... well... what can I tell ... it bothers me and frustrates me to tears. ... It could mean no one showing up to my focus group! I am immobilized by this situation... this whole maestra (teacher) deal has to stop soon... (Diary entry)

My experiences as a researcher differed greatly from what I expected as a "pan-ethnic insider." The learning outcome was to finally understand that I was neither inside nor outside, and that my status would always remain influx. As my time in the field 
progressed, it created a set of issues that needed to be dealt with in order to collect data. My insiderness was determined by location and context, as I was the outsider when I was translating for the teacher, but was an insider when I was trusted with a mother's fear of her son not really knowing how to read in Spanish or English, how she wished not to tell the teacher just yet. My time as a participant observant was made more interesting by the supposed insider status that I thought would facilitate entrance into the community. Instead, it became a more difficult and frustrating mẹthodological barrier, one that opened my eyes to the infinitely difficult task of other qualitative researchers.

\section{Participant Observation}

My work in Sea Prairie County began as a continuation of a working research partnership of the School District and my thesis chair. We discussed how my work as a school volunteer could facilitate future data collection. For example, parents would eventually see me as a familiar face around the school and not see it strange or feel unsettled once I asked them to participate in future data collection activities. My thesis chair advised me of not overemphasizing my role in the school. He warned me not to announce myself in any meetings or emphasize my association with the University. In sum, I was to be unassuming and remain in the background, and not be seen as a social service provider. I was to be a translator, an office helper, a classroom assistant, a playground helper and overall, a volunteer. This worked well in that I was able to meet with some of the parents, or via their children, I would build what I call "rapport by proxy". Having the ability to talk to kids during the school day would 
help me greatly when it came time to recruit for focus groups. When I met parents, I told them that I was planning to have a series of platicas (chats) with Latina mothers in order to collect opinions on school services. During parent activity nights, I served only as a translator and hung out with kids (who had already gotten to know me as a classroom helper) and their families. When I made calls to students' homes, I was courteous and was able to talk to parents about their children. I made myself available to answer questions and come as go-between by reading school forms and helping parents fill them out, by calling parents whose kid may have been absent or sick, and by translating/interpreting forms and school letters.

The challenge was to remain separated from the school while performing volunteer services for the school, and this was made difficult by my role as a translator. Before I began translating (whether it was over the phone or in person), I would tell parents that I would be translating word by word what the secretary wanted to know from them, and that I would also translate word by word what they wanted the secretary to know. I make sure to indicate that my "duty" as a translator was done by making casual conversation with the parent about something that was coming up or by commenting about something that her son/daughter may have said during ESL class, etc. In order to show the parents that working with the school did not mean I was an employee or a person in a position of power, I was always needing to indicate that I was only translating and not forming opinions about their kids' behavior or academic progress. I was also sensitive enough to not show agreement when school paraprofessionals demeaned or misunderstood any cultural behaviors from kids. At 
first, I thought it would be easy for them to see that I did not behave like the staff from that school, given that my interactions with everyone were ones full of cordialismo $y$ respeto (being cordial and respectful), a welcoming aspect of our culture comes naturally when interacting with others who share your language. Each time I would ry to make their experience of dealing with me as comfortable and pleasant as possible, since I understood the difficulty of having to come to a front desk that would be staffed by monolingual employees, and because my interaction with parents was a welcoming change to the isolation that I felt during fieldwork. Parents at the school always had hard time communicating with school, even with the presence of a bilingual secretary. In short, I reated these parents like my parents would have liked to be treated when they visited my school, and did not recreate any of the negative behaviors that school staff may had unwittingly used in order to interact with these families and their children.

Working with a school with no bilingual educational assistant meant that I was asked to remain part of the day in the ESL classroom assisting the ESL instructor. This would eventually complicate an aspect of doing insider researcher, which may often be overlooked, something that I may have taken for granted when I thought thesis work would mean, "studying my own culture". Due to my three days per week availability, it often became my duty to work intensively with the newcomers. Since I was constantly helping these kids, often times twice during the day, many times making up curriculum on the spot, they began calling me maestra (teacher). In our countries, a maestra not only teaches the academic basics, he/she integrates daily 
lessons on behavior and morality y cultura (morals and culture). A maestra was respected by everyone and not to be questioned by students, and even parents defer to with he/she may have to say. This was not going to make subsequent research activities any easier. I often corrected the kids by telling them that I was still a student in college, so there was no way I could be a maestra. One day I overheard a parent outside telling her daughter that she wanted to speak with the maestra who spoke Spanish. This continued for a while, with my numerous attempts of demoting myself from maestra to volunteer not helping at all, and with my worry that the next aspect of data collection would be affected by this trend.

After a month and a half of having some of the parents get to know me a bit better, there was an understanding that I was not there as an employee of the school. My informal way of dressing and the front staff's tendency to forget my scheduled days (and some days, even my name), coupled with my slow withdrawal from the school site, took me out of that educator role that the students and parents had ascribed to me. A few weeks after I started renting a room from one of the families, I felt that those obstacles that compromised my entrance were no longer damaging to rapport. I was still an anomaly to the community and my presence in events was still seen with a mixture of uncertainty and interest. The day that I was invited to come to Catholic Mass, many people kept murmuring to each other and glancing where I had been sitting. It was not until one of the church lectors came to greet me that I felt more comfortable being there. The next day I asked Dania (the babysitter from the focus groups who became my informal cultural host and broker) why people seemed so 
uncomfortable with my presence there, and she told me that they never had a teacher come to either Spanish mass, not even bilingual teachers from the other schools. It took a bit more time than I thought it would, but by the time I began the interviewing phase, most of the people from the elementary school had either heard from me or knew me personally.

Since I was living with one of the families for part of November, December, and January, I was also invited to go out with them for dinner or visiting their family members. I had many informal conversations with people in the community and kept notes of these various interactions. My stay with this family would end the middle of January, since an uncle would be coming from Nayarit, but maintained contact with them via telephone, and had dinner with them and my family while I finished the interviewing phase. I also have kept in contact with an interviewee who moved to Vancouver, Washington due to her husband finding a better job.

\section{Focus Groups}

In order to gain a better picture of this process, three qualitative data collection methods were implemented: focus groups, interviews, and as previously discussed, participant observation. For Mexican women, idealized and specific normative duties attached to a mothering identity may deviate from their current experiences as immigrant mothers. Furthermore, patriarchal restrictions disallow voices of immigrant mothers to surface. Focus groups were used as an initial data collection method, it also became a way to validate, empower, and level the field between participants and myself. Focus groups were preferable to face-to-face interviews in situations where it 
is important to create a more comfortable space for participants to share thoughts and experiences while one-on-one interviews may be intimidating (Madriz, 1997).

I conducted focus groups with Latina mothers during the first week of November 2007. During my brief time as a school volunteer, I befriended and established rapport with many of the parents that participated in the focus group. This greatly eased recruitment, facilitation, and as I will later explain, interviews.

\section{Procedures and Sampling}

I sent a letter in Spanish, signed by the school principal, introducing myself to those who may not have met me. It also let parents know that I would be calling them to set up group talks. The letter informed parents that these group talks would aid the school in understanding their specific needs as a Latino community, and indicated that mothers were the ones to attend. It also gave the approximate date and time that some of these focus groups would be held at, but also informed parents that I would be flexible in working with their schedule. Letters were sent via mail and as a school communication. I was given the opportunity to send my own letters and was allowed to use school lists to gather this information. Letters went to 110 families and using school data, I contacted a total of 60 participants in order to obtain a decent enough sample of Latina mothers who were also employed or had been recently employed. I overbooked by signing up 11 participants for each focus group. To assure that I would have enough mothers showing up, I called one day ahead to remind the person and also called an hour before the start of each focus group. 
All of the focus groups where held in the library of Dairyland Elementary School. I thought that the setting would not be conducive to people wanting to show up, so during calls I informed parents that only myself and the co-facilitator would be in school grounds on that night.

In order to accommodate working mothers schedules, all groups where held after 5:30 p.m., and a light dinner was held for the participants and their children. A high school senior served as a babysitter for children, except for the two infants that where present in the room during two of the focus groups.

I had asked parents to arrive half an hour before each of the focus groups, to have dinner and talk a bit about what I am doing. During this time they met the cofacilitator and got acquainted with me in an official-free environment. It also gave them a chance to ask questions and was a great way to start signing consent forms. Consent forms were read out loud since the literacy of participants could not be determined. By the end of each focus group, the co-facilitator was sure that each person was literate and that they had understood the informed consent process. We also asked participants to respect each other's privacy and not share with others what was discussed in the group.

I conducted 3 focus groups, with 23 participants in total. My aim was to ask mothers to share their experiences as immigrant mothers, work matters, family dynamics, relationships, community of origin experiences, and also learn about their suggestions to the school on how to better serve the needs of Latino families. Thus, a smaller group ended up being a better forum for gathering information, and 
participants had more time for sharing their feeling about particular issues in more detail, something that may not have been feasible if the group was larger. Speaking of immigration and motherhood may sometimes be a highly emotional topic, and the smaller setting created a more comfortable atmosphere by allowing people to take their time in collecting their thoughts.

As a community organizer, I have gained extensive experience as a group facilitator and have had the opportunity to act as a moderator in a variety of ways retreats, panels and board meetings - and have been exposed to a range of various group dynamics and processes. I have also completed various graduate courses on focus group interviewing and analysis. I also had the opportunity to assist my thesis chair as his focus group note taker and transcriptionist.

The focus groups were, to some extent, homogenous, common characteristics shared by all participants were that of gender, ethnicity (Mexican descent), and parentage, but each of them had varied work histories (employed or previously employed). As a moderator who not only shared the participants' language and panethnic background, but also their status as a mother of a child who attends school, these similarities increased their willingness to respond to the questions. Some of the participants knew each other from participating in previous school events, living in the neighborhood, or working together. Half of my participants had met me already during school events or when they picked up their children from school. Many of 
those who had not met me, knew of my work as a school volunteer. My co-facilitator of two of the three ${ }^{8}$ nights was also Latina.

Although I was looking to interview working mothers, I invited mothers who may have been previously employed or whose work history could not be ascertained over the phone. I did not stress that mothers wanting to participate needed to be currently employed since the rationale behind the focus group was to stimulate conversation around the issue of patriarchal relations at home and the community. In any case, all of the women who participated were currently employed, previously employed or working for pay inside the home. Only one of the participants worked seasonally for 2 months out of the year.

Due to external scheduling conflicts, I could not segment the groups by employment sectors, but each of the sectors ended up being equally represented in the three focus groups. I later learned that this ended up being advantageous, as many of the people who in some of these sites have tense co-working relationships, and may not have been so candid with their responses about workplace experiences in this group setting.

When a topic veered off, I subtly reminded some of the participants of wanting to hear all sides and/or their answers to all questions. My co-facilitator and I minimized potential class differences by dressing down in jeans and sneakers, and wearing our University logo sweatshirts. Our informal manner distanced us from

\footnotetext{
${ }^{8}$ The other co-facilitator was bilingual and had worked with the community before.
} 
being with DairyLand Elementary and created a more comfortable atmosphere that was conducive to dialogue and sharing.

Focus groups were lightly structured to allow my initial questions to be answered, but also to allow the participants to voice issues that were important to them. Since my research plan would employ these focus groups as a starting point in understanding a range of opinions, and not to be compared across groups, the questions were broad in order to allow for the emergence of themes. Probes were used when needed, but the original questions allowed for a lively discussion. In order to create consistency and to have an easier time during analysis, I chose to use the predetermined set of questions instead of a list of topics.

After working closely with my professor on the structure of the focus group schedule, I tested the questions on a group of Portland Latina mothers who attend one of the churches where I have been working as a social justice organizer. They helped me by pointing out areas where I sounded awkward or where a probe was too confusing. I also showed the focus group instrument to the Mexican mother who was renting me a room in the area. She gave feedback similar to the group above and had offered suggestions on what I should ask on later interviews.

Focus groups guided participants in voicing their opinions on the issues of gender relations, expected role responsibilities and their experiences as mothers living in the Sea Prairie community. The order of the interview questions moved from broader topics based on opinions to more specific questions based on experience. 
These focus groups were extremely important since they served as an informal introduction to these mothers about my study and my presence in the community, and created a list of interested interview participants. They also allowed me to develop additional probes for the interview topic list that I was to use on later interviews.

\section{In-depth Interviews}

All interviews were conducted in my native language of Spanish, and even though I was born in Honduras, no great misunderstandings occurred. My Mexican participants used a few words that may have been used colloquially in my country. Words such as acoplar (roughly translated, to connect) encompassed more than my understanding of this particular word, and in time, I came to understand the specific cultural meaning of acoplar and how it relates to these new gendered identities and experiences.

\section{Sampling}

Some interview participants were recruited after attending one of the focus groups. I located the rest by asking earlier participants to give my information to interested mothers, or by informally talking to parents during my time as a school volunteer. I informed them that I would be calling later to share interview transcripts with them or to ask clarifying questions. Most of the time, former participants contacted me and suggested names and numbers of those interested in talking with me.

Due to the size of the community, snowball sampling was the most effective way to reach for more participants, and many times people recommended those that I had previously interviewed. 


\section{Procedures}

Each participant was given an informed consent form, which I read aloud since I could not always determine participants' levels of literacy. They were asked to sign if they agreed to participate. Consent forms indicated that the study aimed to learn about the varied experiences of Mexican immigrant mothers within institutions such as school, the family; workplace, and as community members. It also indicated that their participation was voluntary and they could opt out without penalty from the school district or the university. Twenty out of twenty-six of my initial contacts agreed to be interviewed.

To assure confidentiality, I conducted interviews in participants' homes, and many times, I would work around schedules in order to have some privacy from husbands or other family members. This was the case only some of the time, but I was not so strict about smaller children in the background. Older kids often hung out but after the third question regarding work routines, they left the area, bored. Younger children were immediately distracted by a bag of toys that I brought with me. I also asked people not to discuss details from their interviews, unless they wanted to, to other people in the community. This came as a relief most of the time, since participants were initially hesitant to participate if they thought I would share their responses. Once I read the consent form and asked them to give me a "stage name", the participants felt secured to open up and discuss things candidly.

I then transcribed all interviews, and the audiotapes were immediately erased. I also called back participants and asked them if they wanted me to share the 
transcripts with them. While most of them said no, a few of them said that if I had questions about what they said, I could call them and ask. For the three participants who wanted to see transcripts, only one of them had some reservations about what she said and asked me to erase large portions of the transcript. She said that she had changed her mind and did not want most of the information out there. I went ahead and erased what she had crossed out from my transcripts.

\section{Nonparticipation and Attrition}

I had six nonparticipants during the interview phase. Three of them were not literate and did not know if they should sign, while two of them could not meet with me due to work schedules. One of the participants wanted to interview but due to weather and road difficulties, I was not able to reach her. In addition to these six, four women had given me their numbers but then decided not to participate.

\section{Interview Instrument}

The interview component of my research plan allowed me to understand in more detail the gendered world of my participants. Since all of my participants are working mothers, the interview needed to be finished within an hour. I needed to be flexible enough to not only meet their work schedules, but also to understand that their role as laborers in the home sphere was substantial.

I approached the interviewing phase with a list of questions that would cover all of my issues, making sure a level of consistency remained, but kept the conversational spirit throughout the whole hour. This approach also facilitated my 
ability to make quick decisions on what to ask next, for what to probe for and whether or not the question was relevant.

When I spoke with potential interviewees, I gave a one minute explanation of what the interview would be like (at their home, their choice of time), the nature of the questions (work and family), and what I was interested in learning la vida cotidiana de las madres (the everyday life of mothers).

Patton (1987) outlined the types of questions that make up a well-crafted interview schedule. The content of my interview contained 5 out of the 6 types of questions that he categorizes:

1. Questions about behaviors and experiences, “... what a person has done...” (pg. 115),

2. Questions about opinions and beliefs,

3. Questions about emotions and feelings “...emotional responses of people to their experiences and thoughts..." (pg. 118),

4. Questions about knowledge, such as factual responses, and

5. Demographic questions.

The interview schedule divided the questions into various groups, making sure that a section transitioned well into the next. However, my intention was not to make the order and sequence of categories fixed, but to give me a way to subtly transition from one aspect of the inquiry to the next. The categorization of the questions into work issues, community issues, and household experiences, organized and illustrated the theoretical reasoning behind my argument of the work sphere rearranging the 
patriarchal practices inside the household, without ignoring the specific ways labor migration rearranges that community's unique forms of patriarchal domination; how work networks are formed and if they transcend into the work sphere. It also aimed to discover how women obtain resources to equalize their position within the patriarchal bargain, and it allowed me to determine their active position as migratory actors.

\section{TABLE 1:}

Sample of Interview Questions

\begin{tabular}{|c|c|}
\hline Interview Question & Inquiry \\
\hline $\begin{array}{c}\text { How does your husband feel about you } \\
\text { having to work outside the home? } \\
\text { Would his opinion differ if you worked } \\
\text { in Mexico? }\end{array}$ & $\begin{array}{c}\text { Patriarchal relations - Waged Labor and how they } \\
\text { affect the household }\end{array}$ \\
\hline $\begin{array}{c}\text { Who makes the financial decisions at } \\
\text { home? Have they changed from how } \\
\text { they were negotiated in Mexico? }\end{array}$ & $\begin{array}{c}\text { Patriarchal relations - Household (Sending and } \\
\text { receiving areas) }\end{array}$ \\
\hline $\begin{array}{c}\text { Are there episodes of sexism or } \\
\text { inappropriate male behavior at work? } \\
\text { Probes: Flirting, inappropriate } \\
\text { touching or verbal acts, etc. }\end{array}$ & Patriarchal relations at work \\
\hline $\begin{array}{c}\text { Are you a member of a religious } \\
\text { organization, transnational } \\
\text { neighborhood group, or school } \\
\text { leadership (PTA)? Please explain why } \\
\text { your participation in any of these } \\
\text { organizations is important. }\end{array}$ \\
\hline $\begin{array}{c}\text { When one comes to a new place, } \\
\text { people always need someone to help } \\
\text { them find resources... } \\
\text { Probes: WIC? Or the clinic? Who was } \\
\text { that person that helped you? }\end{array}$ \\
\hline $\begin{array}{c}\text { Do you have the ability to talk to } \\
\text { coworkers? Do you maintain contact } \\
\text { with coworkers during off hours? }\end{array}$ \\
\hline
\end{tabular}

The interview schedule began with questions on what a typical workday looks like, with probes on specifics, such as hours, routines, and co-workers. It also 
encouraged reflection on their previous work experiences (if any) as Mexican workers - difficulty of finding or maintaining a job, etc. Some of the inquiries were knowledge questions (how did they find out about their current job), but most of them were either opinion and/or experiences, with more experience questions at the beginning to provide a good transition into an opinion question. For example, after asking about a daily work routine and the friendships that may be forming during work hours, I posed the questions about potential conflicts occurring at work, such as sexist behaviors by coworkers of the opposite sex and whether they experienced any racist and prejudiced attitudes from coworkers. In this section of the interview, conflict in the workplace emerged easily, since people were given the opportunity to initially talk about their daily work routines and then talk about the social aspect of their group.

In order to transition into the next section about possible networks forming, I asked for a more descriptive narrative about their place of origin. I then allowed them (or probed them, if needed) to tell me how their place of origin compared with Sea Prairie. This allowed me to determine whether co-ethnics live in that specific neighborhood or if they resided somewhere else in the county. I also asked whether these relationships existed before migrating to the area. The narrative of family and friends allowed me to continue talking about how they helped the person who is coming from their area of origin. This created the ability for me to ask about a more difficult question along the lines of who do you ask for help, with the person having reflected on social relationships that facilitate migration previously. Often times, the 
question of who do you ask for help transitioned to their experiences asking for help and who they went to. I finished this section asking about other groups they belong to, and probing them if this groups were important for them, and if so, how much.

I then transitioned to their experiences as newcomers, having them reflect on who helped them obtain resources that facilitated mothering. I followed up by having them compare the ease or difficulty of mothering in Mexico and the U.S., that is, what remains the same and what changes? From the experience in the focus groups, the gendered bargain changed greatly, and women spoke about these new experiences, liberating and perplexing at times, in the new area. One of the questions that I had as tagged as a sensitive question, was the issue of who helped with the decision to come here. Often times, a participant had answered this question already, but if not, they had gotten a feel for what I wanted to know and answered straightforwardly and sincerely, even when it came to issues that could reveal their documented status ${ }^{9}$.

The last section dealt with the home and their relationship as spouses. I often told them that their conversations mentioned all of these things having to do with women's worlds, both at work and the public sphere, and that we did not want to forget about relationships with male partners and other males. The question about men and their opinions on wives working was already asked at the beginning, so I pressed them to help me understand why men change when they come to the U.S. and why. My available probes here are many, and after having conducted focus groups, their answers did not only touch upon the issue of negative patriarchal practices at home but

\footnotetext{
${ }^{9}$ Documented status or anything that may have revealed a participant's status was erased from the tape and transcript.
} 
spilled over into the public aspect of machismo and men's experiences in the community. Issues on money management and housework did not need any probing. My closing questions asked them to imagine their families having the ability to maintain a comfortable lifestyle on the husband/male head of household income. If this was possible, would they continue working or would they prefer to stay home. One of my probes took into account whether they were taking care of small children and asked them to imagine that their kid is no longer that young. My final question leaves it open to their suggestions or if they want to speak about. any issue that I may have neglected to ask.

Probes were used in order to elicit more detail, to ask for clarification, or to elaborate on a subject with which I may have been unfamiliar or something that my status as an insider researcher may have overlooked.

Many times, I used verbal and non-verbal cues to show how the interview was progressing, detailing why I was asking a certain question, or why I did not ask for a certain piece of information. For example, after a long narrative, I would assure the person on how a certain statement answered one of my nagging question, and my appreciation for their time.

I was also extremely cautious to maintain rapport but to also stay neutral to any answers that may have been extreme. At the beginning of the interview, I told my participants that I wanted them to be candid, and as detailed as possible since everyone's experiences and backgrounds are unique. Many sensitive topics did end up surfacing because, I believe, not asking leading questions and not over-using my 
probes allowed women's own voices to surface. I am certain that I achieved that position of empathic neurality that I was looking for.

During my first five interviews, issues such as work injuries, community "tranquility" and racismo entre Latinos (racism among Latinos) were salient. This often came up on every interview, so I decided to integrate them as probes.

I also found that knowing the person beforehand (i.e. having met them in the school setting or having them participate in the focus groups) allowed them to feel more comfortable with me. Once people found out that I was living with someone in the community, they then spoke more candidly of their experiences, or were more receptive to further probing. I also realized that they were open to having me come back and ask more questions.

\section{Sample Description - Interview and Focus Group Participants}

Mexican immigrant mothers interviewed were employed or previously employed in one of the following: Happy Cow Meat and Snacks Processing Co., Placid Sea Seafood Company, a shrimp and bait company and in various hotels and inns that stimulate the area's tourist flow. Almost half of my interview sample listed various regions inside the Mexican state of Michoacán as their place of origin, with a few others listing Nayarit, Sinaloa, Aguascalientes; Tlaxcala, and Jalisco as their home states ${ }^{10}$. The age of participants ranged from 20 years old to 64 years old. Educational attainment ranged from attending only the $2^{\text {nd }}$ grade to 2 years of college completion.

${ }^{10}$ Most of the focus group participants listed the state of Michoacán as their place of origin $(n=10)$, with a few others listing Nayarit $(n=4)$, and the rest listing Sinaloa, Puebla, Veracruz, Guanajuato, Guerrero, and Jalisco as their home states. Some of them listed their specific region of origin, while others felt more comfortable listing their state of origin only. 
Years in the U.S. ranged from 2 months to 20 years of residence, with the majority having arrived from Mexico to Sea Prairie County and not residing anywhere else in the U.S. Most of them were either married or living in a common law marriage, with 2 living separated from their husbands and one widowed since 2005 .

\section{Minimization of Researcher Biases and Other Challenges}

The use of multiple methods, such as focus groups, participant observation, and interviewing helped minimize any bias. However, due to the qualitative nature of the inquiry, one potential threat to validity was my status as an insider researcher, that threat of seeing what one wants to see was magnified by my position as an ethnic researcher. I minimized such risk by keeping a personal journal to critically reflect on potential biases. I also discussed my difficult position as an insider by debriefing with graduate students in my cohort and committee members about my research difficulties and concerns. I also discussed issues of bias with other graduate students on a closed membership graduate support internet forum.

My extended, albeit interrupted, stay in the field also helped minimize bias. Since I was able to live with one of the families in the area, I was able to observe the way different settings affected how people acted. This gave me an idea why something was happening and whether this was a one-time occurrence or a recurrent one. In one instance, I had a hard time understanding why my participants spoke of their household labor as easy and fast, since all I observed was long work hours with sole responsibility of a large amount of domestic tasks. This was punctuated with wives talking about their husbands helping or willing to help when I never observed 
the husband of one of the two sisters I lived with help with hardly anything. This became clearer when I was shown family pictures of their life in their small rural township. They told me that their idea of housework over there was not only reproductive work inside the home with no appliances such as washing machines, taking care of small children from the extended family but tending to animals and somehow finding a way to make some money before, during, or after doing all of what I described.

I also engaged my participants to actively help me clear areas of miscommunication. This occurred during subsequent trips to interview more participants. I revisited with informants to look over their transcripts in order to ascertain that the transcript reflected what they wanted to say.

In sum, due to the small sample, the uniqueness of the research site and the diversity of all participants, generalizations about what is found cannot be made. As the findings will reflect, the site is distinctive due to its sex-segregated occupational opportunities, and if my findings are valuable, it is not because they are representative of new immigrant destinations elsewhere.

\section{Transcription}

I transcribed each interview and focus group in order to get to know my data and to revisit any preliminary memos and field notes. This created a very mechanical task into a preliminary analysis of sorts. Transcribing each of the focus groups also allowed me to pinpoint any areas of the interviews that may have been underdeveloped and also helped me generate further probes for later use. 


\section{Coding Instrument}

The coding instrument was developed in the following way: I began by looking at each question of both my interview and focus group instrument, then listed each possible answers for that particular question. I then looked at each of the codes and eliminated any that overlapped or substantially repeated the function of another code. I was also able to decide whether any codes needed merging into one, or if any one code needed splitting into two.

Other codes that did not completely capture or fit were either re-coded or put aside for further inspection afterwards. I then revisited the literature and developed a list of free codes, keeping a careful eye for any codes that may have repeated the earlier version of the coding instrument. I often discovered unanticipated types of answers that required adding new codes or sharpening an existing one. I have kept a record of each code sheet as it changed

\section{Analysis}

I entered the codes (and notes on each specific code) into Atlas.ti, instead of just using a hand coding strategy. Atlas.ti software capabilities permitted me to efficiently manage large chunks of data and allowed me to better order and retrieve codes, quotations, and memos. I carefully coded each ranscript and then revisited coded transcripts a week later.

I also kept a list of analytical memos while I coded and revisited the coded transcripts. I classified these memos as either theoretical memos or general memos. Theoretical memos helped me revisit and apply the theoretical ideas from the literature 
while those general memos noted any descriptive analysis or general questions for later inquiry. I attached most of the memos to codes, quotations, or data chunks.

The next step was to classify my codes, transcripts, quotations, memos, and other notes into groups. I used Atlas.ti features (grouping data into "families") in order to maximize this step. The "families" feature allowed me to classify all of my data into different categories that replicated the themes explored in each of my research questions. I made use of the querying features of Atlas.ti to analyze the numerical frequency of each code, how each code was represented in each of the families, and how each code was attached to a certain text segment. While looking at data pertaining to my questions, I made an effort to keep in mind any alternative explanations for each expected finding. I also took note of any unexpected findings. Each of the themes reported in the findings section are those that showed the most strength in explaining the particular issue. 


\section{CHAPTER IV}

\section{“CUANDO VIVIMOS EN MEXICO ${ }^{\prime \prime}$ ": PRE-MIGRATORY EXPERIENCES WITH PATRIARCHY}

This chapter captures participants' lives as gendered subjects back home. Their words introduce a picture of how they perceived the patriarchal bargain at the household level, how they experienced patriarchy as paid workers in Mexico, and how the lives of female kin before them laid out a different understanding of what their roles as Mexican women should be. Mexicanas experiences allow us to see the possible patriarchal character of their regions of origin, and their retelling of these patriarchal processes within institutions can help us decipher aspects of the postmigratory patriarchal bargain, and in part, aid us in measuring the effects on their lives as transnational actors.

\section{The Domestic Worlds of Mexican Women}

What do you men know [about cooking]? Why, your own father never even entered my kitchen. Isn't that so, Narciso?

I don't even know what-colors the walls are, the Grandfather says, chuckling.

-- Sandra Cisneros, Caramelo o Puero Cuento.

The majority of those participating in this study would agree with Cisneros' fictionalization of males and their distance from the domestic sphere. It also hints at the reality of their inconstant participation in said domestic affairs. All of those participating in the interviews and focus groups stated that they had been solely responsible for household duties back home, whether as married women or single women still living at home. In many of the cases, the only waged work opportunities

\footnotetext{
"Translation; When we lived in Mexico
} 
available to them were mostly seasonal or tended to be agricultural. Others did state that the Mexican division of labor was a reflection of the way things had always been for men and women. One of my more outspoken participants framed this division as the "unfairness of being a sister":

[men that come from ranchos], are not to do anything [related to housework]. They [mothers] do not want the young boy to touch a plate, and if he has a sister available to do it, then he does not get that plate done. He still has to work outside the house, like my brother did, with his father, but so did I. I helped my dad with work en el monte (in the countryside) as well having to help my mother. Marta, aged 34, Zitacuaro

While a very small number did state that they received help around the house from husbands, they attributed these men's openness to helping out in domestic matters as the result of being men raised in very non-traditional environments. Below, Trina describes her husband's contribution to household labors as unique:

And he, thank god, was differently raised, [his experience as a young boy] was not as regular as other [Mexican men] and yes, he participated in housework, and knew how to do [domestic] things alone, so when we started living together [in Mexico] we both knew how to [do household duties] I did not have to be fighting with him when it came to the house...

Trina, aged 33, Aguascalientes

While being interviewed, she stated that in Mexico his domestic labors consisted of occasional help on the weekends, but did say that her husband "was most likely the only man in Aguascalientes that washed more than one plate". Even when other women did mention that male partners helped at home even when they were a married couple in Mexico, the help these women received was not an equal division of 
domestic duties. For those that did elaborate on what it was their partner helped with in Mexico, it was mostly taking care of children:

To help me, well, only taking care of the girl. [toddler], meaning, take care of her but not diapers or bathing her, only watching her, making sure she doesn't eat anything off the floor...

Amalia, aged 20, Michoacán

Most of the women in my sample had been married women in Mexico. Those who were not had shared substantial household responsibilities with other female family members. Here Sandra gives us a glimpse of her daily life as a young girl having to balance her portion of the housework, outside employment, and secondary school education:

Over there, every day I had to grind [corn], and make tortillas, every day, and then also, before leaving for school, I studied over there via telesecundaria (secondary school via television access), and before leaving for school, I had to leave the plates already washed, sweep the house, the beds made, and everything... after school I took care of children [for pay] and then I arrived home to help cook... Sandra, aged 33, Jalisco

Those participants from rural areas recounted the difficulty of domestic routines in Mexico, emphasizing how a sink or a washing machine would have facilitated housework duties:

P4 Over there, nothing of washing machines or dryers,

P5 And also, you have to wash everything by hand, and [find a place] where there is water...

P1 Where I am from, if you want to go wash [clothes] the [public] washing station [is located] behind some hill, you also have to carry you dirty plates to wash them, and here, rain or thunder, you have a sink inside your house Focus Group participants 
Whether they attributed this to the practicality of women doing domestic work or to the patriarchal driven socialization of Mexican men and women, overall, household duties remained their sole responsibility. None of the Mexican women from more rural regions expected (nor required) the participation of males in unpaid household work, and those women from more urban locales were thankful for any help received from their male counterparts, but did not expect steady cooperation from their male partners.

\section{Participation in the Mexican Labor Force}

Whether it was informal economy employment, working at home, agricultural work, or factory work, most of the women participating in the interview had been part of the Mexican workforce. Three of the women interviewed did not work in the paid economy but had mentioned working in household subsistence activities by maintaining crops or taking care of animals. Of those involved in agricultural activities, their being hired depended on the season of whatever crop was harvested in the area and whether there was a need for laborers. Of the six participants who worked in urban areas with a large presence of manufacturing industries, all were employed year-round. Taken together, everyone participated in wage-earning activities, even if those who worked - in the informal economy, at home, or raising crops to subsidize their husbands' income - did not label these pursuits under work.

I did not find that these women's entrance to the work sphere had been a cause of conflicts or disagreements with male kin in their lives. While their gender and their perception as sexual objects limited their entrance to certain industries and the 
positions available to them, their labor participation did not cause heavy renegotiations with husbands, fathers, or brothers. As one of the women in the focus group said, "I worked more as a married woman than as a single woman", and as all of them indicated, their labor participation in Mexico was affected by the lack of work opportunities in some areas of the country more than men's prohibition of said labor participation. However, men's reactions to women's labor participation remained culturally entrenched in patriarchal beliefs that ascribed women's ideal position as household workers. A portion of my field notes details a telephone conversation that I had with an interview participant. I had called Marisa to go over part of her transcript and the conversation had veered into the territory of como eran las cosas en Mejico (how things were in Mexico). Her narrative allows us to understand men's common reaction to women who work in agricultural pursuits in her Michoacán rancho:

For a woman, in this rancho, they see a certain woman working over there and they 'le hechan la burla' (make fun of her) 'look at her in that tractor, she is going to fall', they laugh, or they say that 'she will run some animal over', or they treat her less than nice, they tease her. and make her feel uncomfortable, or they [women] are told [by supervisors] that there is no more need for people at the tomatillo 'come back tomorrow', when you know that they would not say that if your brother had gone to look for work that same day. Field notes

While the individual responses of men may be motivated by patriarchal ideologies,

Mexican industries are gender-blind when it comes to recruiting women laborers:

I worked as a young girl [and not as a married woman] but where I am from, many older women worked at many hotels, and they [labor recruiters] look for workers, and [these older women] leave in a small van [owned by the hotel]... even if they are older women, well, I think is good that they are giving them work Focus group participant 
Where I worked, they only wanted male personnel, very few women [workers]... [and also] over there [maquiladoras] they give you an exam, only to see if one cando sums or be able to multiply, or read and write, but in the place where I worked, they would give people that did not read and write employment...even when one [as a worker] needs to be filling out a report, a form, to make sure that you checked that the product passed many points of inspection, and there was a woman who was very advanced in age that did not know how to fill it out, and [supervisors allowed] one to help [these older women] to fill out their forms... even when they [hiring managers] said they wanted to hire men, or people that needed to know their letters, they would take everyone...not just men Sandra, aged 33, Jalisco

Just as Wilson (2002) stated, these Mexican women's entrance to the workforce meant leaving household patriarchal ties and myriad forms of domestic control of women by men, but then they were subjected to different forms of patriarchal control in the workplace. To paint a better picture of this patriarchal shift, I asked those interviewed to describe their work experiences in Mexican industries, and to narrate instances of any behavior that made them feel unsafe or uncomfortable. Many of them talked briefly about how men accosted women, even supervisors touching their body while they worked. In an interview, Silvia spoke about being constantly judged by what women wear, even when are hired to work in a factory setting. She also described the difficulty of getting used to the working culture of the U.S. Below she tells me how getting dressed for work in Mexico required a more formal approach than what a U.S. employer may want from a woman worker:

Over there [Mexico] you dress better than here, I do not know why I am judging how people dress [she laughs] [When I began working here, I started coming with]...polish in my nails, and... [Happy Cow supervisors], they reprimanded me all the time... I wore my high heels, I could not leave them, because over there [Mexico] even if you work at 
the cheese, I worked at a cheese factory in Mexico, I needed to be [dressed] in that manner... over there... you go meet a [prospective] boss [for an interview] and... they say 'this person I will need', for your business you will need that certain person... but if you see that she has a small wrinkle... they [do not fit in] in your business... even if you are going to have that person [working] in a factory [setting]...And I think that people feel bad, they feel that they lacked something... because over there, your worth is not what you have in your head, but the outside, that you look good...

Silvia, aged 37, D.F., Mexico

Women's entrance to the Mexican labor market entails the fulfillment of a certain set of requirements, said requirements dictated by the patriarchal practices of the Mexican manufacturing industry, with her being allowed to work if she meets these requirements. Female workers are controlled by employers' enforcement of a pleasant visual female appearance and my participant understood that this is what her employer required of all women workers. As an exchange for allowing her entrance to his workplace, she is required to remain looking her physically best, wearing make-up and maintaining a perfectly coiffed hairdo. The patriarchal practices enforce a gendered belief of women as sexual objects, while informing women not only of their role in this in structure, but delineating their part of the patriarchal contract. The contract may or may not be perceived to be fair, but with no other alternatives, women have to accept its' often unfair stipulations.

Patriarchal bargains act as a blueprint that informs Mexican women those expected behaviors in the public sphere. Consequently, women's ability to cope with what is demanded of them is culturally specific, and often times limited to acceptance and deference to patriarchal rules. This illuminates a better understanding of why Mexican women may "work with" the boundaries of that specific bargain. Having 
stated that women enter the Mexican industry as sexual objectified actors, and their expected behavior shaped by the cultural understanding of how a Mexican woman should act, we should be aware how women uphold the bargain. Their part of that agreement not only by becoming a passive sexualized object but by being compelled to follow an often deleterious cultural script of womanhood that dictates "correct" behavior.

One of my interviewees worked in a factory in Culiacan before arriving to Sea Prairie and explained what she believed to be "correct" women's behaviors, and her thoughts of those that deviated from that script:

In the factory that I worked at, was [made up] of women and men, and no, inclusive, there were couples working, men and women, and... of sexual [harassment], I feel that, if one respects one self, they will respect you, and if one gives way to be disrespected, they will disrespect you no matter what, like the saying goes "the man goes where the woman allows" if the woman stops [his advances] and you tell him you know what, I do not like this" they will need to respect you...

[Researcher: So, you saw women putting themselves in that situation?]

Yes...well a lot of women, that, well not as many as that, in fact, they were three or four that would go out on dates, knowing that the man [that they were dating] was married, or they would send him notes....

[So you think they started this?]

Yes.

Yadira, aged 32, Culiacan

Their entrance to the workplace is facilitated by their role as sexual objects, while at the same time, bound by a specific behavior shaped by that patriarchal bargain. In this case, being sexually accosted was part of the trade-off of being 
allowed to work. Adapting to these behaviors is part of that bargain, and deviating or taking advantage of the situation to start personal relationships with the opposite gender was perceived as breaking contract rules. This belief of needing to act in a certain matter to be respected, and this idea of a "solely female" culpability echoed every interviewee's narrative of work in Mexico, and as I will later on report, their experiences as U.S. laborers.

The experiences of women in the Mexican labor force point to the importance of the different patriarchal beliefs in each of these structures and how they affect the patriarchal bargain at home. Men's responses to women's labor do not affect the larger economic agenda of industries, they merely reflect and sustain patriarchal beliefs at home. While Mexican industries and their sex-blind recruiting techniques do not reflect their overall patriarchal nature, coupled with the economic ambiance of the country, they serve as a way to challenge men's control of women in the home. Women's experiences with sexism in the Mexican workplace constrain them into upholding traditional gendered behaviors, which in part keep deleterious aspects of the domestic patriarchal bargain alive.

\section{Our Mothers and Grandmothers and the Failure of the Old Bargain}

When speaking with women about how life changed for Mexican women, they often framed this change by remembering their lives as younger women. These narratives of "how things were in Mexico" allowed women to measure changes in their world as mothers and women in the U.S., and offered me a glimpse into what they saw as a fair distribution of domestic labor in the U.S. household. In addition, 
these narratives of how things changed took a comparative turn, by placing themselves away from what the gendered worlds of older female kin looked like.

Ruby migrated after her father filed paperwork for the family's U.S.

naturalization under IRCA. Toefilio had spent most of his life migrating for work and returning to Mexico sporadically. Ruby became very passionate when she related her mother's increased responsibilities during Toefilio's absences:

It was very difficult ... my dad, he would come here to work, and sometimes he would send money and sometimes he would not, because my mom was not working, and I would help my mom ... so we could pay things, my mom had to go and take care of animals, like goats, and my older brother did not go to school since my mom had to go take care of animals, and he was left at home taking care of the little [brothers and sisters] ones, and I leave to school, and when we needed wood for cooking, my mom or my brothers had to go up the hill to get wood, because we did not have electricity... my mom was always alone... Ruby, aged 31, Guanajuato

Maria Elisa's husband also migrated to the U.S., with irregular trips back to Mexico. In the focus group, she stated that due to his infrequent monetary remittances she was forced to do "everything that a man does in [his own] rancho... what one does in the house, and that of children..." while she worked out of the home as an agricultural laborer. Here she describes a difficult situation that occurred during the time that she did not have any monetary or emotional support from her absent husband:

My son was sick and, then they told me in that public hospital, 'your son will die'... where else could I take him, I neded to take him to a place that would take care of him... I had to steal [kidnap] my son from that hospital, because they had him there, without good care, ready to die, and I stole him and took him to another doctor, I had to sell our ranchito, because I had no one, and my husband had not sent me any 
money in a long time... but I had to carry my son, from place to place, while my husband was making a new family here, but I did not think of wanting to die, and neither did I let my son die.

Maria Elisa, aged 56, Michoacán

Amalia was one of my youngest participants, and the daughter of another interviewee.

Her mother had been forced to work as a microentrepreneur by selling prepared foodstuffs (and later, by opening an informal restaurant) after her husband left her for another woman in California. I later spoke with her about her decision to move to Oregon, citing that her husband had wanted to move to Texas instead. Amalia eventually convinced him to move to Oregon and seek the help of her relatives.

During her narrative, she succinctly disassociated herself from the way older female kin reacted to past patriarchal practices:

We are not our grandmothers that would stay there waiting until the man came from the U.S., who knows when, or if he did not come, and then our mom and us, we had to stay batallando (roughly translated: staying and fighting) and helping them [mothers]....

Amalia, aged 20, Michoacán

Women with migrating male partners found themselves fulfilling both parts of the patriarchal bargain, even when men's migration North meant fulfillment of both the breadwinner and householder role. Remittances, for whatever the reason, may not have equaled what the family unit lost in both labor power and economic sustenance. Mexican women's experiences with this failure of the old bargain may have served as a way to legitimize behaviors that run contrary to the traditional patriarchal gendered bargain. This equally affected both groups of women; older women having to subsidize what small remittances could not cover, younger women's life chances 
being diminished by not finishing school in order to help older female kin with economic activities.

If it were not for my insistent probing during interviews and focus groups, the amount of time dedicated to unremunerated work would have remained absent from these women's narratives. Many times, the idea of doing all housework under those conditions (lacking a sink) was met with humor, almost nostalgically, and was not painted as a negative aspect of their pueblo. The idea of the division of labor in Mexico did not come across as unbalanced; neither did they expect men to be socialized into helping with domestic labors. Participants attributed the difficulties of housework to what was not available to them in their place of origin, and not to those patriarchal ideologies that socialize men into being served by women.

As a focus group participant had sagely stated, "men need to realize that women also have the right to work and earn money for their children, since money for children is never enough"; it was this participation that fulfilled their bargain to their children as mothers while at the same time, supplementing the household economy. This cautious entrance to the Mexican workplace was seen as a way to "help out", and meant that old traditional gendered rules still applied to them in the public sphere. Their participation in paid labor, whether as informal laborers or industrial proletarians, was meant to subsidize the income of male partners and kin, not as a replacement. Their specific role as laboring bodies in the unstable Mexican economy is both sex-blind and sex-differentiated; women accepted for male-typed positions by 
industries needing labor, but restrained by certain patriarchal practices via their role as sexualized bodies.

Mexican men's lack of ability in sustaining part of the bargain as providers, and the subsequent failure of the alternative strategy of solo male migration, may have been met with disapproval, and may have even been perceived as an unsuccessful attempt by male partners to fulfill their side of the patriarchal bargain. Thus, Mexican women's acts of renegotiation begin before their own migratory plans germinate, and as daughters and granddaughters, they represent a collective and historical continuous state of negotiation with generations of male family members, partners, and other patriarchs. These constant gendered renegotiations are a strong component of the benefit package that the Mexican state offers the U.S. economy: immigrant women's labor. Whether Mexican women decide to take the journey North or remain in Mexico as paid workers, their labor aids the capitalist system as a whole, as well as the individual firms that employ them. 


\section{CHAPTER V}

\section{“AQUI NO ES COMO EN MÉXICO"2 : CHALLENGING MEXICAN}

\section{PATRIARCHY IN THE U.S.}

This chapter illustrates the emergence of the post-migration patriarchal bargain by centering the analysis on the experiences of Mexican women as U.S. immigrants. By focusing on who facilitated, encouraged, or imposed women's migration to the U.S. we can explore how the effects of networks informs Mexican immigrant women's ability to renegotiate aspects of the patriarchal bargain at home and the community

I also discuss Mexican immigrant women's experiences as paid workers in various Sea Prairie industries that hire immigrant labor, focusing on how their lives as workers are affected by patriarchal beliefs on expected gendered roles and behaviors. I dedicate a good portion of this section discussing the employment conditions of Sea Prairie's Mexican immigrant men working for the dairy industry. Their work in dairy farms allows us a glimpse of a post-migratory version of masculinity that emerges and affects aspects of the old patriarchal bargain. Mexican immigrant men and their participation in household labor, especially on how Mexican immigrant women perceive this participation as positive result of the migratory decision, is also discussed.

Lastly, I examine women's use of community resources available to them, and how the U.S. context may be affecting aspects of the existing patriarchal bargain at

${ }^{12}$ Translation: Here is not like in Mexico. 
home. I expand on the argument that immigrant women perceive the U.S. state as a deterrent of patriarchal behaviors practiced in Mexico.

\section{Networks and the Renegotiation of Patriarchy}

Migratory decisions are gendered and so are the networks that facilitate this migration. Focusing on social network usage is of extreme importance, not only to understand the gendered nature of the particular networks existing in the Sea Prairie immigrant community, but to understand the patriarchal restrictions and negotiations that may have influenced that particular woman's migration North. I detail the types of networks women have accessed in order to understand how they gained and maximized resources, and how those networks affected the pre-migratory patriarchal bargain.

\section{Decisions to Migrate}

Men are selected into migration by their human and social capital attributes, but this selection is also affected by the structural changes occurring in Mexico, and by the gendered expectation of earning enough money in order to maintain a household. This expectation allows Mexican immigrant men to find ways to uphold their side of the patriarchal bargain. We also have to take into account other variables, such as sending area migration dynamics and individual aspirations of the migrant. According to the literature, women will often make their decision to migrate due to a desire for family reunification, fulfilling their own part of the patriarchal bargain.

During the interviews, I asked women who was the person(s) that facilitated, encouraged, or even suggested the idea of their migration north. The majority stated 
that they made the decision to migrate as a couple, while others had said that it was husbands or other male kin that encouraged them. A small number of women had made the decision themselves with no help or encouragement of any family member. Here it is important to understand how in each of these groups, gender did or did not play out as a component of this decision to migrate.

Male family members: Two of the participants had family members with previous migrating experience and had met their husbands here in Oregon. They had arrived here at the requests of brothers as young women, and in one of the cases, she had been the last person from her extended family to migrate to Sea Prairie.

Together $^{13}:$ Nine of those interviewed did express that the migratory journey was planned as a couple, with most of their male partners having had either personal experience or a relative with experience with international migration.

Husbands/male partners: Six of those interviewed were asked by their spouse to migrate, with almost everyone having had a male partner with previous migrating experience. In only one of the cases, the participant had taken the journey after being forced by her husband to bring her kids to Oregon, but she had agreed once he promised to fulfill various demands on her part. Nevertheless, their decisions were not solely based on obeying their husbands; most of the time, women showed a strong desire to reunify the family unit.

While the main reason that they listed was the desire to have their family together or not being able to make it economically as a family in Mexico, the

\footnotetext{
${ }^{13}$ Two of the women in this sample had experience as young migrants (one coming when she was 17 and the other as a 14 year old).
} 
rationalization of migrating either together or at the request of a spouse portrayed a

more gendered aspect. Rita describes women's motivations to migrate:

As an example, my dad, when he was here in the U.S., and he would come for a year, then he would return, get some money, and then come back again, and he was ok like that, for a time, his money is spent, and then he would go back again...now, one cannot stay and wait for the husband, three to four years until they come back... first, it is easier to bring your wife with you [so she can work], and second, wives do not like staying separated from husbands, because they have seen what happens to men who are alone [in the U.S.] ... and also, is not because of that, you also want to have your small family together.

Rita, aged 33, Nayarit

Women's interests in maximizing their wellbeing surged from the economic realities, gendered lessons of what happens to men "who are alone in U.S.", and as I previously argued, the failure of the "solo male migrant" patriarchal bargain.

Independent: Three of the women in the sample had decided to undertake the journey themselves. Their individual attributes and experiences are diverse; with all of them stating that their lives and experiences were most satisfactory in Mexico than their current lives in Sea Prairie (one of them had a professional career, the other one had her own business, and the third one had a migrating husband that she wanted to have back at home). Here, one of these participants describes what drove her to migrate alone:

He would not help me economically, [or] morally...the distance was hard... there was a time that I was tired, I got fed up, and I said "I will leave to the U.S., if he left, why not me?"... [that was] bad, that was a bad decision for me, because my life was made already in Mexico, the only thing that made me come to the U.S. was him ... sometimes pride, it is bad, doing things without thinking, yes, he left, then I saw that I could also leave 
to the U.S., but I was wrong, because one thinks that in the U.S. [things are better], forget it.

Cynthia, aged 43, Michoacán

I, the truth is, I am honest, I came here following my husband after he came here, and I really was not conscious of what this pueblito (Sea Prairie) was really like. I did not come to work, I came here to follow him, and... since he had already four years that he had not come back [to Tlaxcala], I was not very happy over there [in Tlaxcala], so I came here...following him... I think that all the women that have husbands here [in the U.S.] and they are over there [In Mexico] they feel lonely, they wish they could be like the families that have their husbands present, I think that in a home there is always the need of the man... like the man needs the woman like the woman needs him...I wanted, when I got sick, to hove him here, to have him bring me a glass of water.

Mina, aged 35, Tlaxcala

We cannot discount the effect that female networks had in encouraging migration north. Female members of their own family or their husband's family facilitated some of these participants migration by convincing male family members of the benefits of bringing their family here versus having them reside in Mexico. Female kin helped them navigate whatever social services were available to them and their families, and also prepared the way for the arriving family to have immediate necessities ready (a place to stay, clothes, a job waiting for them.) I suggest that the female migrant presence in Sea Prairie was not only comforting to male migrants but an indication that family formation was a feasible endeavor. These female in-laws were often those who supported or made a strong case for the male migrant to bring his wife. Here one of my participants explains how her sister in-law encouraged her husband to permanently bring her and his kids to live in Sea Prairie: 
And we won't be helping you while you go to Mexico and return and then go back again and return, that [coming and going] we won't help you with. Better bring her here, have her work, instead of leaving her [in Mexico] doing nothing.

Rita, aged 33, Nayarit

In this example, Rita's sister in law was firm that her brother's return migration needs were not always going to be supplemented by her. She also justified her position by explaining that it was better to have Rita "do something" here than having her do nothing in Mexico. Some of the female family members who convinced their male kin to allow their wives to enter the work sphere served as examples of women who participated in Sea Prairie's labor force (seeing how many men felt about wives working in the U.S.) without compromising their reputation. They also encouraged Mexican immigrant males to let wives drive, make financial decisions, etc ${ }^{14}$.

While we can see that female kin supports other migrant women, some participants mentioned Mexican immigrant men being knowledgeable of U.S. resources that their wives would need to access. Husbands guided three of these women, with two of them having no family networks to access or other female networks to access. Here one of my participants tell us how her husband introduced her to WIC:

To this day, I am not very sure, Ino longer go [to the WIC clinic]... [when she takes the children to the clinic] I do not understand what they are telling me...my husband says he will go so I "don't get anymore confused"... so the WIC, and I did not understand! "What is this WIC?" So he told me that is where they give you a little card, and

\footnotetext{
${ }^{14}$ From my sample, those that had arrived here before 1995 were forced to make do without established female networks. Five of these women relied on monolingual social workers (4 participants), female friends ( 2 participants), or a female neighbor ( 1 participant) or another family male (1 participant). For those who came first, each of them recounted having sick children and no translators available, or having done with no help whatsoever.
} 
this little card comes every month, and you go [to the grocery] and you get what it tells you there. And he would tell me "don't get anything else, only what they tell you to buy in that card", and so I would say "no, I'd rather not go", I would need to go with someone... what would have happened if I took other things and I go over [my budget]...that was my fear... to go over... and then he said to me "Can't you learn?" Genera, aged 34, Michoacán

A male partner that is knowledgeable of the U.S. social safety net may appear as being more flexible, or being perceived as forward thinking by seeing women as successful migratory actors. At the same time, dependence on a male spouse may reverse a loosened bargain into a more rigid pre-migratory patriarchal instance. The ability to renegotiate patriarchal impositions will be trumped by dependence on a spouse who could forbid a woman access to other areas of the public space. Two of the three participants that did use male networks had other factors that may have prevented the reversal of the patriarchal bargain, such as education or normative orientations due to their positions as women from urban areas, thus preventing a negative situation in the U.S.

While most of the people mentioned being able to access family networks in cases of economic need, there were a few who had contentious relationships with either their kin or their husbands' kin. While a few women mentioned not being able to depend on their kin for favors, only two mentioned having contentious relationships with families.

Curiously, some those who had to rely on other non-kin networks had been pioneras (pioneers), who had been in Sea Prairie for nine years or longer, and had to 
make do with no support networks. In one case, the break of family reciprocity was started by a pionera after her brother-in-law abused her kindness. She had then decided that her family was not one to return favors. In another instance, a pionera's relationship with her family was further strained by a misunderstanding over her religious beliefs. Both of these women said they felt closer to their non-kin relationships. In the case of these two women, their non-kin networks (both religious) had been very important to both of them. Veronica had relied on constant economic help from her prayer circle after her husband delayed his return from Mexico. During the two months, her parish members helped her with groceries for a family of 5 and rent payments, while at the same time providing with needed emotional help. Elisa had relied on her congregation when her husband had suffered a stroke. She was helped with childcare, groceries, and money for rent. Additionally, members from the Sea Prairie congregation summoned additional help from the Portland congregation to help with medical bills and a place for Elisa to stay while her husband recuperated. Rosa $^{15}$, having only her in-laws in Sea Prairie, had gone to her comadre (comother fictive kin) for a loan, since she did not feel comfortable asking her husband's family for monetary help. This fictive kin relationship was also crucial when her brother needed a place to stay and when she had lost her job. Both of these times her comadre had helped her economically and emotionally. When asked why she would only go to her, she explained that her husband's family members were so unreliable that they had even failed to pick up her children during an early release day at school.

\footnotetext{
${ }^{15}$ This participant was also a pionera, having been here for 13 years, and serving as a network support to her female in-laws.
} 
Rosa had listed her sister in law as a secondary contact, and when the school called for early pick up, she ended up not showing up at all. In these three cases, access to nonkin networks may have advanced women's negotiation further, since the break from their networks also affected their husbands. Their partners saw their ability to access reciprocal relationships in the time of financial crises as a testament to their ability to handle difficult situations beyond the domestic sphere ${ }^{16}$.

Even though Trina could access her in-laws for a loan to repair her husband's car transmission, he forbade her to ask them or any economic help whatsoever. $\mathrm{He}$ reasoned that since they had been here for more than a decade, asking for help from his parents and brothers would not have been seen favorably. In the end, they had decided to wait until she was able to work more hours, in order to repair his car.

Women's decisions to migrate were tied to the perception of men's responsibilities under the unfulfilled patriarchal bargain; the desire for family reunification was constitutive of this patriarchal bargain. The old patriarchal bargain attributed women's positive identities as wives and mothers; their gains tied to financial security brought by the wages of a working spouse, and the idea of a family unit as an important part of their wellbeing. While some of the decisions may be attributed to their desire to reconstruct pre-migratory roles, women are making this decision in light of gains that the U.S. may offer them. While most of the gains could be perceived as economical, as I will later discuss, subjective gains (such as positive

\footnotetext{
${ }^{16}$ Three months later, I ended up visiting one of them, and I asked what her husband's thought of all her sacrifices. He then interrupted and hugged her, and told me that although it was a hard thing for a woman to experience everything his wife had gone through, he was confident that she could manage everything and make the best of what she had at the moment. "Solo me necesita para besitos" (she only needs me for my kisses), he said.
} 
motherhood) are part of this patriarchal contract. Many decisions to migrate take gendered roles into account, but in some other cases, immigrant women felt that reuniting with a spouse was an unfair trade-off to what they had left behind in their regions of origin.

Networks became initial resources for women migrants, not only for settlement necessities, they were useful source of benefits when it came to negotiate patriarchal bargains. Female family members mobilized in order to accommodate their women in-laws, so as to smooth out any of the difficulties that they may have experienced as women migrants. While networks initially served as a resource that challenged patriarchal restrictions by encouraging immigrant women's migration and settlement by evening out the sex-ratio in the immigrant community, and by increasing women's knowledge of community resources that promote renegotiation of the pre-migratory bargain, it was not the only way that allowed for a renegotiation of the contract between men and women. In Sea Prairie, it was the workforce participation of immigrant men and women that greatly affected patriarchal relations in the home and immigrant community.

\section{Patriarchal Relations in Paid Work}

Mexican immigrant women's entrance to the U.S. workplace affects how men respond to this entrance, and precipitates a negotiation in light of pre-existing patriarchal beliefs. I begin this section by discussing how men responded to women's participation in the various Sea Prairie industries that attract and eventually employ Mexican immigrant women. I also highlight the work conditions encountered by these 
pioneras and discuss their workplaces in detail. Next, by exploring the re-creation and maintenance of old patriarchal norms in these industries by the Mexican immigrant women themselves, I argue that Mexican immigrant women's participation in remunerated endeavors mainly served to sustain patriarchal codes and norms, with wage earning being one of the only resources that would be used to challenge aspects of the patriarchal bargain. Finally, I discuss Sea Prairie's dairy industries and its Mexican immigrant male workforce, and suggest that while job opportunities in Sea Prairie's dairies reinforces traditional roles for men and women, it may also be allowing for men's greater participation in domestic affairs.

Voladas (women who 'fly'): Men's Responses to Women's Labor Participation

While interviews indicated male partners were sensitive to the household burdens of immigrant women, knew of the heaviness of those jobs available to their female partners, and understood that sometimes they would not see their wives regularly due to the erratic work schedules, women stated that there was conflict over their desire to enter the paid workforce. When asked to describe what their partners thought of their entrance to work, many respondents mentioned that their husbands did not agree at first, but they often accepted their choice because they understood that an immigrant family needs two incomes in order to live comfortably. Interestingly, after wives began working or had secured a paid position, partners often reversed their initial acceptance, and reverted to rigid patriarchal positions of women's paid labor participation. 
Marisol describes her husband's response regarding her desire to work:

When I got together with him, he did not want me to work, he said that, he says when women work they become, more rebellious, more prone to anger... he said, he thought, that I was not going to pay more attention to him, and I told him no, but he said that women empiezan a volar [begin to "fly away", roughly translated as carefree and reckless with their behavior], or that a female friend may tell them to leave their husbands, but I tell him that is the one that wants, the woman that wants [to leave him], not all of us are the same, I tell him that it has happened [to other men], I do not believe it would be my case [that I would do that] ... after I convinced him with my mother, [he said] ok, I would like you to work, that way you do not stay at home enfadada (foul mood or mad)... Marisol, aged 31, Nayarit

Her husband's rationale for opposing her entry into paid work showed a fear that she would eventually be contaminated by the influences of female friends with unorthodox gendered ideas about Mexican immigrant women's roles. It took her having her mother help her convince him, almost on a "good behavior" promise, that not all women were like that and that she would never behave in that matter. He then reluctantly "grants" her permission to enter work in order to minimize or avoid her foul moods.

Ruby added that her husband allowed her to work because of the pension and social security benefits and because her younger children were already attending elementary school. She stated that he had opposed to her working several years after being employed.

Mina describes her arrival to the U.S. with plans to work and her husband not allowing her: 
The first time I started working, he behaved a bit selfish, he did not want me working, he wanted to find me at home, with his food prepared, and no, not me, I was not giving the idea [that she was discontent with the arrangement], but when he started seeing that I would get in a foul mood, and I would tell him that I needed, well, algo que fuera mio [roughly translated: something that was mine, that belonged to me], to know where I go or how I use my money, he, well he accepted that I went to work, but he did not want that... Mina, aged 35, Tlaxcala

Like Marisol, Mina stated that her husband saw her de malas (bad mood) and thus allowed her to go to work.

These same three participants had expressed very progressive gendered views on the self, a sophisticated analysis on their role as Mexican immigrant women, and understood that their position as a working mother in the U.S. differed from what her position would be from a mother working for wages in Mexico. When asked whether her husband would let her work in Mexico, Marisol stated that she did not know how her husband would act, but then stated that her friends did work over there, suggesting that she too might have worked in Mexico. Later on, Marisol shared strong views on what she sees as the experiences of women in her pueblo:

Because I have seen, like I told my husband, I cannot begin to imagine what it would have been like if I married over there... because in Mexico they [males] do not respect their wives, is what I have seen, when I went I saw, they do not respect them... they leave the woman at home... while they go to dances or to other places, to parties... and they leave [wives] at home, that I would feel that I could not stand that, and I know that here men may try to be sly... but I think here tends to be a different place, well, I don't know, I am already accustomed of going out with him, together, and over there it is not like that. Marisol, aged 31, Nayarit

Ruby talks about how she was able to curb the influence of her husband's gambling and outings with friends to strip bars: 
I al so told him, "doyou want freedom or do you a family? You decide... "And he [at first] did not believe [me], so I started packing my things, "go with your friends, I guess we've agreed to that"... Ruby, aged 31, Guanajuato

Mina also threatened her husband with a transnational divorce, since she did not want to migrate here at first, and wished to have her husband back home.

Women's egalitarian demands were tempered with acceptance of some patriarchal burdens and negotiations. Immigrant men's control of their female partners' entrance to the public sphere remains symbolic and even though there often exists immediate economic need, men justify their reactions by their perceptions of women's negative behavior. Even though most of the women participating in the interview phase of this project saw their relationships as very egalitarian, old patriarchal remnants were still deeply ingrained in men and women's identities. Each of the women quoted above had participated in the Mexican labor force, either working for pay in the fields or working in manufacturing, and all had a very progressive view of men and women's role in the U.S.

In spite of the above, these participants negotiated their entrance by subscribing to the pre-migration understandings on gender and the culturally expected role of men and women. For example, they accepted the view of women as voladas (women who fly away) by accepting and dgreeing with husbands that some women did act like that and in many cases, these women se portan mal (behave badly) knowingly. For example, Marisol distanced herself from women that she knew were portandose mal (behaving badly) by stating that if "they are allowed by their husband to work, [they should] try to behave". Her entrance to the workplace had to be 
negotiated and was gradual, stating that she started work after she felt confident that her youngest kids could handle her absence. Furthermore, she summoned the help of a female kin member in order to convince her husband that having her work was feasible. Ruby also started work well after her youngest started preschool and even though she had worked as a single woman in the U.S., her husband initially did not want her working at Happy Cow. He was eventually swayed because of the benefit packaged she would be eligible for as a full time employee. Mina's case is also important in understanding this trend, with her having threatened divorce and eventually migrating here. Nevertheless, she was still seen as a woman that is acting de malas, and had to negotiate her entrance to the workplace just like Ruby and Marisol, even when she had made the journey to the U.S. with her toddler.

As I will later suggest, Mexican immigrant women's entrance to the workplace served as a way to raise the status of their household (and also husbands), but, as I will show later, it also required them to subscribe to pre-migratory gendered beliefs on how Mexican immigrant women are expected to behave when they enter the work sphere.

Industries Employing Immigrant Working Women: Placid Sea Oyster

Participants' daily drudgery at Placid Sea became part of the tourist attraction since the processing floor is visible to those who patronize the restaurant upstairs. Rosa had this to say:

A lot of people go and see how you work, and to eat [while they look at you]. I do not like it when people are looking at me, that is why I turn my back to them... and they take pictures [when one is working]...I 
don't like it...my niece tells me "as if we were the zoo", and they [patrons] look at us chueco [rough translation: scowling]... Rosa, aged 28, Michoacán

Placid Sea started operations in the early 1940's, and currently manages distribution centers throughout the United States' West Coast and Alaska. It exports a variety of seafood (mainly shrimp and oyster) to global markers, and it imports and processes product from various international areas.

Four of my participants had previously worked in one of Placid Sea's plants located in a town a few miles west of Sea Prairie. This facility has a tourist roadside restaurant with a high visibility and known for its' regionally unique seafood plates and moderately priced delicacies. According to my participants, everyone employed by Placid Sea was of Latin American descent, with most of them being Mexican or Central American. One of the line supervisors was Latino as well, but the rest of the supervisors were non-Hispanic Whites.

To maintain product quality, live oyster processing requires room temperatures of at least 34 degrees Fahrenheit at all times, and frozen products require the same temperature in order to thaw. My informants described the work at Placid Sea as extremely uncomfortable, having to stand extreme temperatures while working up to 13-hour shifts during some seasons, (and employees are not allowed to choose a part time schedule during this time.) While there was an even ratio of men and women, the plant experienced extremely high worker turnover, with only a few people staying beyond a month or two. Sandra had this to say: 
There are people that go and work for two or three hours, and they leave, because the work is extremely heavy, and there are others that are working, but the line supervisors, if they see that they are slacking, well, they fire them... people say "no, I am no longer able to... why do I fool myself?"

Sandra ${ }^{17}$, aged 33, Jalisco, Mexico.

Those employed by Placid Sea are either paid by the hour or paid by the gallon, with those that start out working hourly, and those who have stayed longer working the contract rate. The contract rate comes out to 9.00 dollars an hour if the worker is experienced and works efficiently. Work hours fluctuate from 4-hour days to 13-hour days during some months but the plant operates year round. Workers cannot socialize while they are working as hourly employees, but are allowed if working by contract, although participants said that they would rather work than socialize if being paid by the gallon.

My informants secured their jobs at Placid Sea via friends or family members. One of my participants, Marta, having applied directly and not being called back, was later hired when her cousin spoke to the supervisor. Anglo supervisors seem to make decisions to hire someone upon personal recommendation. While the majority of those participating in both the focus groups and interviews described their Anglo supervisors as understanding, one Placid Sea worker told me how line supervisors would shout at workers, with one of the Latina supervisors remarking how she did not like how Anglo line supervisors treated her people.

\footnotetext{
${ }^{17}$ Sandra is the only one currently working at that Placid Sea plant, while the remaining three participants have been out due to and injury or household scheduling conflicts.
} 
Placid Sea supervisors may have the authority to hire someone, but their supervisory influence stops there. Their obligation is to create and present a certain product and to finish a certain quota and do not have the influence to negotiate working conditions or benefits for line workers. A Latino/a supervisor in this plant finds himself/herself in a difficult spot, having to answer to management while at the same time demanding certain work output from fellow co-ethnics. While most of the Placid Sea workers that I interviewed did not experience a direct wrong by their supervisors, they did not perceive them as potential allies or individuals with the ability to better their working conditions.

Interview participants brought up the issue of racism, but curiously the charge was often directed at those who where also Mexican, whether it was a supervisor or another worker. Even though interview participants attributed these acts to racism perpetuated by Mexicans, their words indicated highly contentious work relationships and not acts of racist behavior. Marta attributed what she feels one worker's disregard to the other workers' workload as a racist way of acting towards "your own people":

I think that Mexicans, the one that wants to have more power, and, the one who wants more, that wants to be more than others... like a certain woman, and she does more [she produces more, goes above quota], at that moment [that they see] that she does more than everyone else, the line supervisor requires that everyone does the same [as she is doing]... and that affects one as the worker... now one needs to work more, and within certain minutes you need to fill a bucket, and lets say, that she does them in less minutes than some other, so they force you to work at her pace...

Marta, aged 34, Michoacán

Here my participant saw this individual's lack of regard for the other workers as breaking the unspoken rule of not working too fast, her disregard was driven by the 
worker's desire to "have more power". Since pay is tied in to gallon productivity, some people will exert themselves in order to finish more gallons per hour, but in doing so they are alienating themselves from the others.

Every participant that worked at Placid Sea had suffered injuries, while one of them remarked that she could no longer use one of her shoulders due to a fall. Sandra showed me fresh and old injuries from having to work with defective knifes. Even when they showed me their work injuries, they tended to minimize what had happened, or the impact that it had on their everyday life. Sandra did not tell me how her hands were almost immobilized by the repetitive nature of the job, but during the focus group, she had to ask another woman to lift the soda can tab for her since her pain was obviously incapacitating. Marta showed me knife injuries where the fleshy part of her finger was now gone, but made a dismissive motion with her hand. Those in charge also had a dismissive attitude about workers' bodies. A focus group participant told me of a young man that had several pallets fall on his head and could not stand up or even stop feeling lightheaded. The line supervisor drove him to the hospital but retumed a few hours later, and made sure the young man went back to work.

Industries Employing Immigrant Working Women: Happy Cow Meat Processors

All but one of those participants working in Happy Cow were or are employed by Sanders \& Co., a third-party contractor, who recruits, hires, and assigns workers. The sole worker directly employed by Happy Cow is a machine operator. The contractor pays directly and two of those who have been there for six years or longer 
did not mention ever receiving any raises. When I asked Mina about this, she stated that the only time she saw an increase in pay was when Oregon raised the minimum wage.

According to the narrative of all the participants employed by Happy Cow, most of those contracted by Sanders are of Latin American descent, with a majority being of Mexican ancestry. Most of those working the machines and lines are women (according to the line operator, for each man there are 4 women that are employed). The few men employed during the day shift work in heavier pursuits, such as moving trucks or cutting larger pieces of meat into more manageable chunks. The night shift also employs males, mainly doing other work, such as clean up or operating the machines that process heavy meat carcasses into smaller pieces. All of my participants worked during the day in various areas of the plant, working with the smoking machines or in the packaging area.

Working the smoking machines involves either arranging meats to be smoked, or cutting smaller pieces to be processed by the machine. Machine operators usually select three to five people to help with a certain machine, with workers having the ability to sometimes choose what machine to work. Certain machines make a specialty product and workers refer to each of these machines by the name of the product. Packing requires heavy sanitation and requires workers to understand that they need to pack a certain amount of meat slices into each package, labeling them a certain way, and being cautious not to under count or over count. Socializing is not 
allowed and workers have been given written sanctions for talking while operating certain machines.

In addition to sex-differentiated duties, there was a high turnover of male workers, which was explained by an interview participant as "Mexican men and their desire to find higher paid jobs". Just like Placid Sea is seen as "the first place you go to work when you come here", Happy Cow seems to be the "place that men work until they get a higher paid job somewhere else". Contract work at Happy Cow is an extremely seasonal endeavor, with women line workers having their work hours cut by almost half during the slow months. Machine workers are not affected by the season since they perform line work duties during these months.

These workers also have the ability to choose what shift they want to work (all my interviewees currently worked during the day shift) and could leave and return in order to take care of sick family members, travel to Mexico, etc. One of my informants had left Happy Cow after her pregnancy required bed rest and another had left due to her childcare provider's illness. My informants spoke of the early morning start as difficult for mothers, since they could not be home to prepare kids to leave to school. However, the ability to be waiting at home when they arrive from school was seen as an added benefit of working at Happy Cow. One of the mothers has two adolescent boys, and she liked the day shift since it allowed her to monitor their afternoons and not be worried whether they did homework or whether they were getting into trouble. 
While many of the participants interviewed claimed to be civil towards coworkers, just as those employed by Placid Sea, there seemed to be a strong friction among workers. As one Happy Cow worker described it, "racismo esta entre nosotros mismos" (racism exists amongst us [as Latinos].) Except for one person who claimed to get along with everybody, as the focus group interview progressed, respondents generally used the term racism to describe feelings and actions motivated by envy, and not racist behaviors.

There are a couple of Latina supervisors with authority over machine operators and contracted employees, but line and floor supervisors are almost all female and non-Hispanic White. Views about these supervisors were varied. One of my informants valued an Anglo supervisor who understood her economic situation and tried to give her maximum hours during the slow season. Nevertheless, others who worked at Happy Cow did not have the same regard for their Anglo supervisors. One of the workers tells us what a line supervisor tells other workers who do pick up their pace:

The one in charge, tells them, "hurry up, because your [social] security [card] is no good, and if you have a [social] security that is not good you have to work hard"... like if they were slaves... they shout that to people... and people say "here, we are working not as contracted workers, we are working per hour" and working a machine, not making products

Ruby, aged 31, Guanajuato

Interestingly, many workers did not question why abuse was happening (since it seems that they are aware abuse will happen due to their perceived legal status vulnerability), 
but rather they questioned the need to shout when people are doing exactly what they were told to do.

Just like Placid Sea workers, every single person in this sample suffered a serious injury, and two were at home recovering after a major injury. One of my participants had fallen and pulled a back muscle, while the other had injured her right leg and her untreated diabetes was not allowing the injury to heal. When I asked this older participant why she was not going to the doctor or why she was not filing for workers compensation, she told me that she would not want to bother anyone. The other injured participant was able to take off from work and cited that this was her second fall this year. Other workers cited having doctors request for light working being downright ignored, while others mentioned needing the weekends to recover after working long hours with minimal breaks.

Women working in Happy Cow described their job as delicate and requiring a reasonable amount of dexterity and multitasking. Cynthia describes her role as a worker for the packing area; for example, she emphasized how important it is to be trained to operate a certain machine and to understand the larger role she plays when it comes to food processing.

My work requires extreme hygiene... you have to be well equipped with gloves, your hair covered, your uniform, because this is a company that requires extreme cleanliness, these are products that go to the public, right? So, you have to maintain a sanitary appearance because it is food [that you are handling] ... I pack bags I pack meat inside glass bottles, and we also weigh meat... very detailed, if you have a certain weigh of 98 or 99, this figure needs to be almost exact...sometimes if you see a certain bottle not weighing the exact 100, you have to promptly make sure you add or subtract... Cynthia aged 43, Michoacán 
Almost proudly, she describes herself as the last link between the consumer and the product she is packing. Her work is delicate because not only is she required to watch out for the consumer who will purchase a product that she packed but she needs to be cautious to be exact with her product weight and count.

Later on the interview retells how a supervisor prohibited her from working a certain machine that took her awhile to learn:

It's not fair, it was hard for me to learn that machine, and only because she did not like [me], she took me off, it was hard for me to work that machine, but I learned it well, and she told me "John says that he does not want you there"... so I got to talk to John, I brought an interpreter with me, [John] he was the one who taught me that machine... he said that he had nothing to do with that and did not tell anyone to take me away from that machine...

It seems that whether it was a petty decision from her supervisor or a legitimate need for her not to be working there, Cynthia's hard work in learning how to operate a certain machine compelled brave up and ask a higher up why he made that particular decision when she was certainly capable of doing the work. Cynthia spoke proudly of the skills learned at her position, and her experience may perhaps signal the formation of these women's identities as competent laborers. Some of Happy Cow's immigrant Mexican women workers had been there longer than six years, with some of them gaining the opportunity to understand how certain products are made, and some having experience operating the machines that produced all of the different Happy Cow products distributed in the area.

Ruby held a minor supervisory role as a machine operator, but she did not have much say on anything besides what goes on with her machine. However, she did have 
the authority to say whether people could talk or not since her product needed to be counted while being made. During the interview, she told me that people would get angry when asked to be quiet but complied in order not to anger the line supervisor. Having documentation and some command of the English language allowed her to apply directly to Happy Cow. She informs me that the pension benefits and insurance were a good incentive to keep on working, even when she wanted to finish her high school diploma in order further her education. A year ago she began training as a line supervisor but asked to be transferred back to her machine. The relationship of the main floor supervisor with the workers was a very tense one, with people practically bullied over product imperfections, and with junior supervisors being written up for the slightest of errors, or having their work sent back for reprocess.

\section{Other Industries Employing Immigrant Working Women}

Four of my participants worked for different area hotels. One was employed by chain hotel, two at a motel in the nearby town, and one who was working for a higher-priced inn. Their work duties consisted of cleaning a room with someone else, or cleaning a room alone. Those who worked in pairs were not forbidden to talk and were allowed (in one instance, encouraged) to turn the TV on, or listen to the radio while they cleaned. Most of the workers at these hotels were women of Mexican ancestry, except in the case of Julia who worked at the inn where a majority of the workers were either Filipino or South American. She stated being the only Mexican worker that worked there. Hotel work in Sea Prairie appeared to be female dominated, and in two of the instances, the work allowed for a flexible schedule that permitted two of the 
participants to drop their children off school. In all of these cases, these mothers were even able to get home just an hour after their kids arrived home from school. None of the workers in this sample complained about their supervisors and even one participant (Marisol) stated that Mexican workers fared well cleaning hotels because las Americanas se les van rapido (meaning that American [Anglo] women leave the hotel after a few days of working due to the heavy work). Marisol also informed me that if her Latina supervisor could better the other employees' working conditions, or had a say about pay or promotion, this supervisor would not hesitate in helping those working under her. In one case, a participant who is more fluent in English, worked three of the five days doing bookkeeping and her employer was planning on sending her to school in order to further improve her written English.

Marlena worked as a machine operator for a manufacturer of wood handles that had an evenly mixed workforce of men and women. Each worker specialized on a single machine and worked alone finishing wood handles. Although unable to socialize, since each of the workstations are separated from the other, the workers in that factory maintained offsite relationships, such as friendships and even formed godfathering/mothering and other fictive kin ties. Of all of those interviewed, Marlena was the one to express the most job satisfaction, even though she did not see avenues for advancement due to the place being family operated and extremely small. She did have medical benefits that covered most of her expenses after having been treated for breast cancer. Her schedule may not have allowed her to be there when her children left for school, but her four day, forty hour a week schedule meant that Fridays were 
part of her off days and she could stay with her smallest daughter at home or visit extended family members in the Portland area. She was also trained to operate and do basic maintenance on any machine used on site and since working there saw herself learning basic carpentry skills. Although she mentioned that socializing did not happen at the work site (due to workers working in a specific station), she did enjoy her working conditions.

One of my participants (the person that rented me a room in her house) worked for an area restaurant. Her sister also worked there part-time and indicated that worker socializing was not possible due to the language barrier. She expressed that her employer allowed the sisters to cover each others shifts, had hefty Christmas bonuses, and employees were allowed to take most of the leftover prepared food home. On many occasions, her older nephew could arrive at the restaurant after school, eat a snack, and do his homework while she was finishing up a shift. She was also able to receive discounted dinners when she brought family members from Mexico and California. Another added benefit was the distance from her job to her home (3 blocks), allowing her to not rely so much on her car and save money on gas.

\section{Industries Employing Immigrant Working Women: Patriarchal Behaviors and}

\section{Practices}

Except for the hotel workers, most of the Mexican immigrant women participating in this study worked for employers that hired workers of both genders. Due to legal prohibition of sexual harassment in the workplace, I expected that a U.S. 
work setting would be less sexually aggressive than a Mexican industrial setting. In this section, I describe Mexican immigrant women's experiences reconstructing patriarchy at work, by focusing on their perceptions and reactions to male and female behaviors in their worksites ${ }^{18}$.

While most of the women observed male attempts at behaviors that would have made them uncomfortable, sexual advances by male workers or male supervisors had not directly affected them. U.S. work was seen as pesado (heavy) and unpleasant, but it was not perceived to sexually threaten their reputation as "well-behaved" women. Episodes of women deviating from pre-migratory expected gendered roles did occur and were met with strong opposition and contempt. These narratives often point out to tales of women who came from Mexico and "misbehaved" once arriving to work at Happy Cow. Aside from these tales informing me of women's attachment to a certain patriarchal belief, I understood them to be gendered morality tales on how women avoided being involved in that situation:

This married woman who arrived [at the smoker] has three children., and guess what!? She got together [became intimately involved] with a younger man...she came very covered (bien tapada), very calm [in demeanor]...like I tell you, I did not want to get involved in their talks... because I did not want them [the couple] bringing me their arguments...I do not want to get involved.... and then getting into trouble myself...

Elisa, aged 39, Michoacán

Becoming involved in arguments may jeopardize a gain already made (entrance to the workplace) and this almost continues on what participant had to explain to her

\footnotetext{
${ }^{18}$ Since most of my interviewers worked for Placid Sea and Happy Cow, I only illustrate instances of patriarchal behaviors at these worksites.
} 
husband, that not all women "fly away", meaning, not all women breaking the patriarchal contract fail to uphold expected patriarchal roles. This participant having contact with that specific person may mean that she is also breaking her part of the contract and could have jeopardized her contract at home.

Women working either in Placid Sea or Happy Cow observed sexist behavior, mostly by other male workers, while one indicated that a male supervisor gave preferential treament to younger women, none of them saw this gendered risk to be solely the fault of males desires, but as women's own burden to avoid at all costs. One of the women saw men's attempts as almost natural, with one woman saying that men "'fish' for women, if they catch a 'fish' meant that this woman gave in to his advances..." and even citing that "...al hombre le fascina eso..." meaning that for a man, that the act of "fishing" for women is something that delights him. Part of the bargain at home is to avoid becoming involved in said situations and the bargain at work required her to shield herself from men's natural and acceptable attempts.

I do not want to give the impression of Mexican female workers at Happy Cow and Placid Sea as passive receivers of said acts. Most of the time, these advances were of men trying to flirt. Even so, none of them were so overtly aggressive as to touch women or publicly disrespect them. Some narratives indicated women that they knew experiencing sexually tense advances by a supervisor (younger women being treated nicer and given easier chunks of oyster to process, for example). However, these supervisors' position in the hierarchy of the industry is tenuous at best. Their duties change according to the labor needs of the day, therefore, they would not have the 
power to create an extremely sexually uncomfortable environment for women to work in.

Although women sanctioned those women who deviated from the expected female norm, they were not passive subjects that allowed sexists behaviors to continue. One of the workers at Happy Cow tells me of a certain young man who worked during the day shift:

One is used to be called "pretty" and many times, that bothers you, or... [sometimes]...not, but here, at best, it does not happen... they will tell you once [that you are pretty], to see, if you want to [she makes a motion as to suggest that I know what she means]... Also, they cannot behave like they do in Mexico... a young man came from Mexico, I do not know from what part, and he would tell you things like "love", but, they stopped his tongue, [some women informed him] that was not supposed to be said, everyone at the smoker got, well, angry, and then he understood, that he was not supposed to be...bothering, and he found out, that he wasn't in Mexico... but at the beginning, he wanted it like that, and he would not stop [bothering], and kept on going with that, or that he wanted to talk to a young Mexican girl, and according to him, since she was Mexican he could, but then ...[workers] ...got really angry...

Silvia, aged 37, D.F., Mexico

There appears to be a pattern of women sanctioning other women when they break the collective gendered norm of darse a respetar (to respect oneself in order to avoid male's sexual advances at work). It seems that darse a respetar to these women means advances by males are tolerated but only allowed up to a certain point. In this case, the female victim in this tale was not blamed for the male coworker's harassment; rather, it was the male worker that was blamed and sanctioned by the collective (mainly female) reaction to something that is not supposed to happen in the U.S. 
Whereas Mexican women working for pay in their areas origin experienced a range of both individual and institutionalized patriarchal behaviors, working for pay in Sea Prairie meant they would experience less individual arid institutionalized patriarchal behaviors. Nevertheless, Mexican immigrant women sanctioned other female workers who deviated from the patriarchal norm. The idea that one must protect oneself from individual patriarchal behaviors of male workers and supervisors rested on the contractual agreement between the immigrant couple, and these sanctions perpetuated traditional gendered behaviors in immigrant women and not men. Silvia's example of collective responses to continued patriarchal attacks might illuminate on possible challenges to the patriarchal bargain at work and the formation of gendered identities that question the current patriarchal order. In the case of Sea Prairie food processors, tense work relationships disallowed the formation of gendered work-based networks from forming. The context of these two industries negatively affected Mexican immigrant women: (1) Those working for Placid Sea did not see any avenues for advancement or the ability to gain any skills. Their work was perceived as a way to fulfill an immediate monetary need, and except for one of the participants, they all had left after a few months. Sandra, the only one remaining, did so out of economic need. (2) Those working for Happy Cow perceived it be a better working environment, but the work process disallowed Mexican immigrant women from finding task meaningfulness; it discouraged learning certain machines in depth, thus barring women from adding transferrable skills that may have made them employable somewhere else. Participants working in isolated contexts, such as housekeeping and 
wood handle manufacturing, enjoyed in-kind benefits arising from their employer's position as small business owners. Working for these employers meant that they could gain something from satisfactorily performing their duties, and it meant the development of transferrable skills. In sum, while a small number of Mexican immigrant women did see their jobs' as satisfactory, the majority felt that their work participation allowed them to earn an income that could satisfy family.needs, whether they were necessities or extras.

\section{Wage Earning}

Although immigrant couples have an specific understanding that in the U.S. two incomes are needed in order to successfully maintain the household, the more economically stable of the participants did not readily assert their earnings as satisfying basic financial obligations. Instead, these participants saw earnings as additions to the household income, and as a way to help the family. When I asked informants to describe where their income went to, they stated that their paychecks went to payments of a second mortgage, leases of new trucks and the accompanying payments, sending money to Mexico, paying credit card debt, etc.

Many women felt that their work was secondary to mothering. One of the women had quit her position at Happy Cow to wait until her daughter entered preschool while two others negotiated with the hotel managers to allow them to work part-time in order to spend time with young children. Those who may have depended more on their income did mention that the income was needed para sobrevivir (to survive), but later on in the interviews, they asserted that their entrance to the 
workplace was a way to provide for their children's needs. It was also the same case with those participants who stated that without two people working "en los U.S., no se la hace" (roughly translated: you cannot make it in the U.S.). The more economically stable women saw their earnings mainly as a way to provide their family with lujitos (small luxuries). Though they felt capacitated and that they were able to earn comparably more here than in the U.S. and could survive alone, when probed whether they saw their income as equivalent to that of their husband, everyone reverted to their status as secondary earners.

It could be argued that Mexican immigrant men's patriarchal control on wives' entrance to the workplace may be partly grounded on the U.S. wages and their monetary transferability to the Mexican peso. A section of my field dairy details the conversation I had with a woman from Michoacán, where she tells me how her earnings have allowed her to finish a home in Mexico. I had been invited for dinner and a certain soap opera ignited an animated discussion about the male protagonist and his constant infidelities. We discussed ways that we would react in that situation, I jokingly stated that I would probably "get back at him", while she would be more realistic about it. I write:

... Johana said that she would just keep the home that she is building in Michoacán [if she was the woman in that soap opera]. We laughed (while Luis, her husband, just looked over us, wondering what the commotion was). "your house?" I asked. She then told me how he did not want to deal [at first] with the hassle [of coordinating the building of a home], and it was most of her money [that went into the building of that house] and her effort (finding a contractor, calling people to help oversee said construction, sending money, making sure people sent her updates). ... I asked her to elaborate on how much of it really was hers, and she just said, "if I tell you he may get a bit mad" (she said this is a very joking manner). ... I [jokingly] told her I would 
make sure she was safe... [then] she said that although they are a marriage, most of her checks had gone to that house. He started putting a bit more [money] when he saw the pictures of the foundation laid out, that it was not something trivial, but her home, a home that she was able to build and something that would have been next to impossible with her earnings in Mexico. She then looked at him and shouted "Listen to me, if I find you playing around with some chiquilla [young woman], you cannot stay in my little house, I will only rent it to you". We both laughed. She then said how proud she felt que ella lo pudo hacer, todo sola (that she was able to do it, all alone).

Field dairy entry

Many of the participants spoke at length about how much more they "felt" their

incomes compared to what they would be in Mexico. Specifically, they explained how their earnings in Mexico did not allow them to even feed families adequately, while their income in the U.S. allowed them to have left over income:

In Mexico, even if you work, you cannot buy yourself a car... nor even a bicycle for your kids... things... we are five in this family... and what could my husband and I buy them? And that is how we didit, working everyday, both of us, without stopping, and it was not enough to even feed them, and here, almost all of them have their cars... and they have left over [money]..."

Focus group participant

I feel that, whatever happens, I could continue on alone, and in Mexico, without my husband, I could not afford to live by myself, could not continue on alone, and here I feel that I could do it alone" Focus group participant

Another focus group participant stated that her half of the income pays for the cars that they take to work, and she justified men's better treatment of wives as a result of the latter's income.

A focus group participant talks a bit more abstractly, about how the work that one does in Mexico and work that one does in the U.S compare: 
For me the positive [of being a working mother in Sea Prairie] is that you help the home. Right? Because you help with expenses, in some cases, men pay all of the bills, and one can buy their children clothes, or you have money to send to Mexico... so you are contributing with expenses, and expenses, they are seen, your work is seen, you understand? Because over there, [the] work [you do] in the fields, and still now, [work in the fields] is not seen like work that someone does...but here, it does

Here she stresses that since expenses are seen, the fruits of your labor are also seen, while work in Mexico, because of the low pay [this participant had stated earlier that she earned 25 pesos daily when working in the fields] work is not "seen". While we do not dwell much on the meaning of work during the focus group, many of the women in the focus groups saw earnings as a way to feeling more independent and capacitated. In another focus group, women said that with work there are "...mas cosas materiales, mas posibilidades, tienes carros, te respetan..." (more material things, more possibilities, you have cars, they respect you). When I asked to elaborate who respected them, the group said in unison "everyone". While they did not specify exactly who "everyone" was, whether everyone were other immigrant men, the nonimmigrant community or family members, there was consensus that women will be respected once they enter the U.S. workplace and earn income.

Although Mexican immigrant women working in Sea Prairie earn less than their male partners, their amount of earnings compared to what they may have commanded in Mexico is considerable. This is even more so when we compare the transferability of the U.S. dollar to the Mexican peso. With the opportunity to satisfy family material wants (such as cars, clothes, restaurant outings, trips to California, etc.), participants felt that they had more ground to renegotiate aspects of the 
patriarchal bargain. The idea of respect took on a new aspect in their lives. Their earnings and the possibilities of said earnings allowed them to respond to certain features of the patriarchal bargain, and as one woman passionately stated "he needs to let me work so we can have two nice cars, one of them being his car". Conversely, Mexican immigrant women's wages were restricted to satisfy household necessities beyond survival. While the entrance to a different set of patriarchal regulations (workplace) challenged household patriarchal control, the end result (wages) meant moderate advances to challenge the patriarchal bargain at home, since these wages would be needed for the household to begin with. Some of these women's earnings served as way to raise their household's status in the immigrant community, ergo household status meant a raise in the status of immigrant men. Thus, wages may have been a strong bargaining tool due to their monetary transferability, but the gendered . value of money skewed possible patriarchal advances.

\section{Men's Dairy Jobs}

While women's' income may also have disproportionally allowed for their male partners' raise of status in the U.S., since said additional income satisfied and justified the purchase of other objects, such as trucks or electronic equipment, it did not mean that income alone secured masculine identities. In this section I paint a detailed picture of immigrant males and their work for Sea Prairie's dairy farms, hinting at the possible effect on gendered roles, but also how Mexican immigrant 
males' work en las vacas ${ }^{19}$ (roughly translated for the cows) affected aspects of the patriarchal bargain.

Oregon's dairy farmers employ a large number of Latino workers (Nelson, 2007) and Sea Prairie's system of supporting small, family-owned farms attracts an eager Mexican immigrant workforce. Nelson (2007) suggests that dairy owners not only praised immigrant workers' superior work ethic compared to non-Hispanic White workers, but the authors indicated the support of farmers towards comprehensive immigrant legislative efforts in order to better attract this labor force.

Working for a dairy farm means year-round employment, long hours with no set schedule, and constant interruption of free time $\mathrm{e}^{20}$. For those who are employed en las vacas, they receive higher wages than those males employed in the other Sea Prairie industries hiring immigrant labor, and due to the nature of dairy work few women actually work in Sea Prairie's dairies. One of the participants tells me the workday of her husband:

He is the one in charge of a few farms, he is the supervisor for everyone else who works these farms, and it is very difficult for him to have the same hours as me... He wakes up quite early, at 3:00 am, because there was a problem with a certain cow, or that a yearling calf got stuck, and if they cannot take care of it themselves, he has to go and help them, since he is in charge, he is always on his telephone, sometimes he doesn't sleep, or sleeps for a few hours and then leaves again... Julia, aged 39, D.F.

\footnotetext{
${ }^{19}$ Thirteen of those participating in the interview had a husband employed in the dairy farnns. All of them had been in the area for more than 9 years and from this group, eight of the 13 interviewed lived in the property where their husband/partner worked.

${ }^{20}$ How long are these hours? Many of the women interviewed spoke of husband's work beginning at 2:00 a.m., ending at noon, and having to be available at all times. Another participant told me that when one worker left to another dairy job, her husband had to work two shifts, with three to four hours of sleep. This was still going one three months after I spoke with her over the phone.
} 
Except for three of the families ${ }^{21}$, ten of these families mentioned or displayed various ways that spoke to their economic stability. Some of them were building homes in Mexico, while one of them was able to purchase a second home in Sea Prairie. It was not uncommon to see a newer model car or truck parked in the driveway and all of their homes' furnishings were above modest.

Mariana tells me how her brother was hired for dairy work:

My brother came 9 years ago, he went around checking dairy farms, and he found an owner that needed someone, and he took him, and later on sent him to class [English classes], because he needed people, and so, like that, people that where here 10 years ago, they would take them even with no English...

Marta, aged 34, Michoacán

Her husband was also hired by one of the farms where her brother works, and their arrival 8 years ago may illustrate the availability of dairy jobs for immigrant men living here. While dairy industry jobs increased by almost 50\% in 2000 (Nelson, 2007), she informed me that farm owners are now requesting English skills from potential Latino workers.

During the interview, Marta's recently arrived family member was informally training to be "introduced" to the owner. He was currently working at Placid Sea but training for a potential job en las vacas was done during the weekends. It seems that dairy farm owners often prefer workers that they themselves can train (Nelson, 2007) instead of having to re-train a worker that may already bring previous bad habits or

\footnotetext{
${ }^{21}$ Three of these families had various reasons to be in financial straits: One woman had mentioned having to pay for her sister's cancer treatments in Mexico, the second one discussed her financial straits as the outcome of having a husband with a low earning position en las vacas, and the last one discussed the mismanagement of funds due to ignorance on how U.S. mortgage brokers operate.
} 
slightly different ways of doing the tasks required for the new position. The economic desirability of these dairy positions cannot be understated. Marisa, one of the sisters that were renting me a room, told me that when her husband died, there were already people asking whether his position was available.

The gendered nature of this job was also very clear, due to the physicality and the dirtiness attributed to farm work. During my stay in Sea Prairie, the son of the family I lived with worked part-time at one of the dairy farms. I always wondered why his mother allowed him to keep such a full schedule. Paulo was not only a B student but was also involved in high school sports and other extra curricular activities and was hardly ever home. His aunt told me that even though they did not want him working and would rather have him concentrating in other things, it kept him out of trouble and made him "trabajar como un hombre" (work like a man). They felt that now, without a father, work that emphasized masculine attributes would be good for him. It also assured him that he would have opportunity to be hired full time after he finished high school. The attributes of dairy work, as rancho work, trabajo de hombres, etc., was a salient theme in many of my conversations with families and individuals. They saw that for a man coming from a rancho, their dairy job was at times satisfying, even if it meant that their salary did not reflect their hard work.

Nevertheless, it was later when I interviewed Genera when I began to understand how men's labor.in Sea Prairie's dairy industry produced gendered relations everywhere else. Genera's husband had been working in the U.S. for almost three decades, and had recently arrived to Sea Prairie in order to reunite with her 
spouse. Although he had been always worked for wages in the U.S., he remained working the night shift at Happy Cow. This was the main source of her frustration with him, and this had emerged after asking her a bit more about Happy Cow: My husband is still there... he works another schedule...I do not know, that work, the meat, does not pay very well, I do not know why he is still there, and I think that is why I get furious with him... [Would you elaborate? If you want...] Well, I don't know, he has worked here [in the U.S.], and is not like we have small children that we [would] need different schedules, he has not made an effort to find something that gives him more money, because the men that work there [Smoker], they leave [Happy Cow jobs] for [other] jobs that pay much more, they only remain here [in the smoker] until they find [jobs]... [like what type of jobs?] Well, the cows or something like a milker, not this [job at the smoker], [something] that I could do... [but isn't working at the smoker a heavy job too?] Yes, of course, don't you see how bad I hurt my back... but like I tell you, it is a job [smoker] that is heavy for me, therefore it won't be heavy to him, correct? He is a man, I know his dad works there... but his dad is $65 . . . "$ Genera, aged 34, Michoacán

Working en las vacas meant more than just a job that would satisfy aspects of masculinities, it was almost expected to find work there. In this case, Genera felt that her husband failed to fulfill his side of the bargain, and remained in a job that a woman and elder could perform. His inability to make an effort fueled her dissatisfaction with him as a provider.

All of these women took pride in their husbands' dairy job routines. One participant animatedly told me about not interacting with her husband for two nights in a row (she would be sleeping when he arrived and he would then be asleep when she left for work) but would take Saturday as a day to spend time together. She stated that she would rather have a very good Saturday than many days of not really wanting time with each other. One of them equated their husband's hard work with responsibility 
and respect, and as one stated "el si lo hace, si lo puede, como un hombre debe" (rough translation: he does it and can do it, like a man should).

Not only were these dairy jobs gendered but also the specific skills of the job were transferrable. One of the participants in the sample had moved to Washington state due to her husband's long-time experience as a dairy worker. She told me that leaving Sea Prairie would mean having to leave family members and friends, especially her parish activities as a lector. After living in Sea Prairie for over 15 years, she felt that she would have a hard time getting used to Washington. Her husband's new wage was substantially higher than what the dairy owner in Sea Prairie was offering, and even though he trained his brother to take his old position, the dairy owner eventually offered him almost the same amount of money he would have earned in his new position. What attracted her husband was the ability to work as the overseer of the new place, to learn new things, and to move to an area with educational options for his children. Although this scenario may be atypical, it may not be as uncommon as one would think, and some jobs are offering immigrant men with certain human capital attributes the ability to find meaning to their workforce participation.

Sea Prairie's dairy industries supplied Mexican immigrant males with highly paid and year round stable jobs that stimulated masculinities. At the same time, immigrant males were positioned to further develop and gain skills that made them more employable. While workforce participation allowed men to successfully fulfill aspects of the patriarchal bargain, the work of women did not. Interestingly, the 
fulfillment of masculine behaviors in the workplace may have allowed for men's more lax view of their participation in household labors.

\section{Men's Participation in Domestic Activities}

Almost all women participating in both interviews and focus groups agreed that men changed once migrating to the U.S. While some did say that men had previously helped with household chores, most of the women indicated that their husbands and partners were not only helpful, but also understanding of their wives' household duties. The majority saw their willingness to help or for those who had been here for longer, as one of the most welcoming aspect of U.S. living. While women's responsibilities in both private and public spheres made them feel overwhelmed, the changes in the majority of their men (whether gradual or sudden) were seen as significant and welcoming. A participant tells me how her husband changed his attitude towards the complete care of children, by contrasting his experience taking care of his first infant (now oldest) son, to the later experience of taking care of two infants:

[Did he help in Mexico?] In Mexico? No, no. [She laughs] Nothing. [I ask her to compare him in Mexico and now here]... when my oldest son [19 years old] was barely a year, he was really sick with vomiting and diarrhea, he has to take him to the doctor...so for three hours, that he was with the child, he did not put a diaper on the baby, he felt incapacitated, he did not know how to put a diaper on him [She laughs even more] and the child had diarrhea... it wasn't that he didn't want to, but that he didn't know where to begin, and now, my girl, he took care of her since she was 4 months old. And we had another one that was almost a year and 9 months when she was born, meaning, both of them in diapers, and he took care of all of their needs quite well, diapering, bathing, feeding, because he worked at night and I worked during the day... [why do you think he changeg?] Necessity...two small 
children, and if we sent them to be taken care of, we would have to pay, there would be no money, he had to take care of them...

Veronica, aged 42, Michoacán

Veronica later details that her spouse's change was not only when it came to

household duties, but his perceptions of women's roles as "servers" were no longer

there. She suggested his was a gradual change of what is expected of women to do for men as well:

He is very understanding ... but also it has been because he understands a bit more, because before I had him accustomed to have the glass of water right next to his plate of food, and he would get annoyed if I did not serve him his glass of water, and one day I told him, "if someone prepared me food, I would be happy, even if they did not bring me the water"... now he says that he doesn't worry if I serve him [food] or not, he goes and does it himself, it was gradual, I think...

While each and everyone mentioned their husbands and partners constant help with different chores, a minority did mention that their help was occasional at best:

My husband is the type that will not help, but I am also the type that I do not like to have him help me, meaning, I will not demand, like saying "you do not help me wash even one plate"... he is understanding, that he won't be asking a lot, with what there is to eat around the house... he will not demand extremely prepared plates of food... when I can I make him a few little things, but I do not want him to help because he is from a rancho, you know how they are raised, like men are not supposed to do anything, sometimes he helps with picking up stuff, or make the bed, but doing it together, if we are talking, but that I catch him doing anything, no, nothing like that... there is an understanding that I am not going to kill myself, but that there will be beans and eggs [to eat], somewhat picked up, but that he is machista and he demands, no...

Marta aged 34, Michoacán

Even if many women did mention that men helped at home even when they were a married couple in Mexico, the help received was not an equal division of 
constant duties. For those that did elaborate on what their spouse helped with in Mexico, it was mostly taking care of children.

At the sarne time, while women praised their men in their interviews, I suspected that their household output was overwhelmingly their responsibility. During one of my fieldwork weeks, I decided to help my host with her daily work. Although at first she was bothered having me do anything, I explained to her that as a guest I should also help. During a morning, I helped her care for three toddlers, bathed and fed said three toddlers, cooked for three nights (she freezes her meals), picked up around the house, cleaned bathrooms and decorated the yard for Christmas. When I asked her to subtract my help from what she usually does every day, she told me that being able to clean the toilets and putting up the Christmas lights ended up being the surplus. In her regular day (before leaving for one of her jobs), she does all of these duties every single day, yet at the same time, she tells me that her husband helps. The help that my host's husband provided was making sure the kids ate dinner (she worked at night) and putting all of the plates in the dishwasher.

While women viewed their job as heavy, when asked to compare theirs with their husbands, they knew that their male partner's job was possibly hardest. Not only was it time demanding, but it meant working outside no matter what the weather dictated.

This perception of their job never being as heavy as dairy (male) jobs indicated that they rationalized men willing to assist in household labor, but realistically being unable to do so. Some of these male dairy workers arrived at noon time and meant that 
they would need to sleep during the day or early evening, while other women said that their husbands were comprensivos (understanding) that household and waged duties were heavy burdens to their wives.

However, Mexican immigrant women's labors in the U.S. did not resemble housework in the places of origin, and neither did men expect for that to happen. Take the previous example of Manuela, who animatedly stated that she would not let her husband do any of the housework because he was raised in a rancho, and she was not going to battle that aspect of the patriarchal bargain. Neither would she labor over elaborate food dishes and he would not force her. Other women stated that their household output meant being able to take care of the house but it did not mean that they would make tortillas by hand.

Marisol details what how her husband reacted to her brother's more machista ways:

I have a brother and he is machista in every sense of the word... Would he help his wife with washing a dish? No. Even if she worked he would be like that, he says he does not like to eat alone, or serve himself...my husband helps me, even when my brother was [visiting] here... my brother said "why am I going to be helping, she has to do it" and my husband tells him "no man, but sometimes you have to help..." Marisol, aged 31, Nayarit

Not only is he showing a more progressive view of understanding that his help is needed inside the household, he is making an almost public statement of participating in unpaid labor. While many of the participants spoke of their partners' participation in household chores, they still felt compelled to assure partners and other males that 
helping out did not mean being a mandilon, (roughly translated as a man wearing an apron).

Here Marisol continues with what his participation in household chores meant:

Because in Mexico [if they help] they are already mandilones, they say "that one is a mandilon" and that "he has to do what the wife says" and I say that they are not mandilones, I feel that helping one another is something that comes from oneself, is not that he is a mandilon, is that he is solidario (in solidarity)...

In the experiences of Mexican immigrant women living in Sea Prairie, immigrant men's contribution to domestic affairs may be the result of the fulfillment of masculinity in the work sphere. Even when there was the fear of being branded a mandilon, occasionally helping one's wife was not seen as threatening to masculinities. In addition to being seen as a good provider, it meant that you satisfied the role of being comprensivo. In one of my visits to Veronica, an interview participant, I found myself talking to her husband. After many of the usual pleasantries, I lightly directed the conversation to that of Mexican men helping wives. Her husband then stated that Mexican men living in the U.S. "eran mas modernos" (are more modern in behavior) and that is why they sometimes help around the house. While dairy jobs exempted men from constantly taking a share of the household labor, responses like the one above, suggest the possibility a more complex and progressive way of thinking about gender roles that Mexican men residing in the U.S. may be figuring out for themselves. 


\section{Using Features of Life in the U.S. to Fight Back Patriarchy}

Like in Mexico... it was not my case... but there are people that they need to bear that their husbands are having affairs with other women, or that they drink a lot, or that he does not pay attention to you, and you have to resign yourself to this because you are $100 \%$ dependant on him... and here, you can work, there is money left over and you are able to feed your children, and here the government supports women... Rita, aged 33, Nayarit

Migration to the U.S is not only driven by the needs of individual actors and economical forces, but also by the perception of relative gains in the U.S. compared to those in Mexico. I suggest that this perception is heavily gendered, as immigrant women perceive the U.S. state as beneficial to women, a place where unacceptable pre-migratory patriarchal behaviors of Mexican men are deterred. Women's access to resources creates the ability to either challenge patriarchal bargains or replace an adverse one. It could expand the obligations of an already satisfactory bargain and allow for the creation of alternative spheres of autonomy for women. Resources will serve as a form of capital, increasing the overall wellbeing of women by giving them something to bargain with. In this section, I emphasize the complex role of institutions in reorganizing aspects of the patriarchal bargains. While a certain U.S. institution may offer women the opportunity to challenge the old bargain in the household and in the immigrant community, another may bind them to different forms of patriarchal control. 
Negative Masculinities ${ }^{22}$ in the U.S. Context: Un Buen Lugar Para Todas ${ }^{23}$

During the focus groups, and later on while conducting interviews, participants became animated when speaking of gender and patriarchal behaviors of immigrant men. A strong pattern surfaced: the U.S. discouraged immigrant males from acting in ways that negatively affected women. This was a question that brought the quietest of participants to speak up or join in the conversation. In order to understand why they strongly perceived the U.S. as un buen lugar para todas (a good place for all women), I must draw attention to their view of the Mexican state and women as gendered citizens. This particular informant echoed other participants' perception of Mexican society, and in her case, the Mexican state, as a force that encouraged forms of irresponsible behavior in males:

In the case of being alone, or if you have a child from here [U.S. born child], they help you with food, or they make sure your husband is giving you a portion of his income, and they make sure he does it, in Mexico, they only tell him that he needs to give money to your children, but it doesn't reach you, it's by law but they won't make an effort that it gets done... or your husband's family will not encourage it... even the Mexican government is for the man and not for the woman... here, they cannot snub you like they do in Mexico... that is what I think Focus group participant

A number of women saw that male partners that were once socialized to stay out in the public sphere and engage in negative masculinities (with friends or others),

\footnotetext{
${ }^{22}$ I label "negative masculinities" 22 " those behaviors that run the gamut such as alcoholism, spousal abuse, and extramarital affairs to any form of accepted gendered behaviors that are less extreme such as an unequal household division of labor. These various sending area patriarchal practices may have diminished or even brought to an end in the receiving area.

${ }^{23}$ Translation: A good place for all women
} 
were compelled to radically change their ways once in the U.S. A focus group

participant speaks on how her brother changed his behavior:

[Speaking of her sister in law's fears]...she tells me that she is really concerned and afraid if they return to Mexico, because, her husband drives a taxi and over there ... [everyone nods their head, agreeing, almost silently]...over there, he was a person that was always having affairs, always on the streets, and he did not care about his family's wellbeing... he would be having the time of his life with women and here, everything is the opposite, he doesn't go out, he takes care of his children very well, and you can see that he is very affectionate with his children, it was a change that I saw, a 360 degree change, she fears going back to Mexico

Focus group participant

Many women saw that the receiving area's economic demands on immigrant men

discouraged or left no time for men to "misbehave":

He changed, even more so now than in California, because in California, there was a lot of things like they do in my town, he was prone to going out, and he liked it, and here, because of his job he is not permitted of taking days off, since here, he always needed to be working, and they have those types of things [celebrations, parties] in Salem and Portland, but you have to drive two hours, and if he gets out at 7 , he did not have enough time to get there.

Veronica, aged 42, Michoacán

Because of work [in Sea Prairie compared to Mexico] they are more attached, it makes family anew, and because they do not rest since they work weekends, so there is not the going out all the time, so he needs to go out with family and kids

Focus group participant

Many of the other respondents spoke about Sea Prairie's remoteness and the lack of

places for immigrant males to socialize:

Because is so small, the place is very calm, they misbehave when there is something, like where people can dance, seeing something like this, they leave and change the relationship between husband and family, but not, there isn't.

Focus group participant 
Over there in Mexico, there are a lot of perdiciones [roughly translated as places that leads people to ruin], there are night clubs, I went two years ago and I was aghast, I am old, and have some innocence left, I said "my God"... in the past, there was not a lot of them, and there are now, and over there, are no rules or authority, men, who makes them leave those places? No one, no authorities, and here, there are not many clubs, and if there are, they have rules, hours.

Focus group participant

A strong pattern that emerged from interviews and focus group meetings was women's perception of men's performances as guarded due to their fear of law enforcement in the receiving area. Many women testified that immigrant males knew that behaviors such as spousal abuse were dealt with differently in the U.S.

Men behave differently because they are afraid of the police, because they [the police] have more power than them here, I think that's it, and I could call the police if he was hitting me... I think...

Trina, aged 33, Aguascalientes

Here, they can't hardly do anything, like, a man cannot hit a woman, I do not know, even if the man wanted to hit the woman, he cannot, and for a woman I think that is...good... good for her, because they won't hit you... because they know that she can call the police...not like in Mexico, where the [police] won't pay attention to you Herminia, aged 26, Michoacán

Patriarchal structures such as waged labor impinged on individual patriarchal behaviors that affected Mexican immigrant women. In addition, an environment allowing women to feel more entitled to call on police and the remoteness of Sea Prairie, were perceived to be a great benefit. Others felt that the public sphere discouraged negative behaviors, such as alcoholism, due to bars closing early. Some participants expressed the lack of spaces that encouraged the substance abuse of 
Mexican immigrant males as extremely beneficial, not only to family's emotional wellbeing, but also their economical interests.

I also argue that many of the same factors that put a check on traditional oppressive behavior may compel men to find and nurture alternative masculinities.

My brother, he smoked, drank, not like those that end up drunk on the streets, but he drank and smoked and gambled, and did not take care of family stuff... we all thought when he arrived here he would get worse, especially since he would have money [to spend], but everything changed... and the temptations are there... but I felt that in Mexico... since he did not work a lot, he would find [work]... but here, he works and he can give to his family

Veronica, aged 42, Michoacán

Here not only did she emphasize that a change occurred, but that economic opportunities replaced one form of behavior for the other one. His ability to provide economically to the family was enough to deter him from old behaviors such as drinking and gambling.

Others felt that men in their family were more open to display a more caring attitude towards their children:

Because over there, you wouldn't tell your dad "daddy, I love you" and hug him, a kiss, one was always fearful of their father, my nieces are not like that, and here my girls get on top of their dad, hug him, kiss him, tell him that they love him, and I wasn't like that with my dad... and when my parents came to visit me and they saw that ...they felt strange...

Sandra, aged 33, Jalisco

Another participant said that neighbors thought her husband was "a very dedicated single father", since he was always spending time with his children, and they did not see her around long enough to deduct she lived there. My participant was working during the day while her husband spent time with the youngest at home. 
Whether there is a burgeoning understanding among immigrant males that fatherhood is a source of positive male identities or that structures such as wage labor or the State leave men no other options, women see these changes as an added benefit to more egalitarian gender relationships inside the home. These emergent positive male behaviors in the receiving area seem to dictate a more flexible male identity that allows for men's participation in household affairs without compromising their masculinity.

While women did see changes in male partners and male family members, a small number of interview participants felt that some men were not prone to these negative masculinities in Mexico. These interview participants were either extremely young and had married here in the U.S. One had come from a large urban area and had attained a moderate amount of work experience under her belt. They explained that men were socialized to be machistas and that they would behave the same no matter were they resided.

I am not sure if he would change if he lived in Mexico... we already lived there [as a couple], and no, he was the same, the same he was here ... That of men being machistas, is how they are raised, if they see, for example, that his dad is a machista, he act like that, and there are some that are born like that, violent, or something like that, and they feel like themselves when they act like a machista, you make them or they are born aggressive and become machistas, I think.

Trina, aged 33, Aguascalientes

I have another opinion, the one who enjoys going out, the man, husband who enjoys being out, he will go out, even if it's a ghost town, whatever he needs to do to get there, he will get there, and he will go out

Focus group participant 
Well, there are also those who like that, and you cannot stop them, and cannot tell him "stay at home"... that depends on the person.

Silvia, aged 37, D.F.

The community also provided women with "normative resources", more intangible resources that allowed them to press for equitable relationships in the home. One of these institutions was the church. Whereas in Mexico the Catholic church may have not been perceived as an enthusiastic ally and would disapprove of women's demands on husbands, certain activities facilitated by the Sea Prairie church supported women's gendered interests. Some of my participants attended the weekly couple's study group facilitated by an outside paid coordinator. This coordinator held several groups throughout the week, denoting each of the stages the participants had completed, with new groups opening every year for new participants. Those Mexican immigrant women attending the group meetings felt that the teachings challenged their husbands' patriarchal views and behaviors. Even though these study gatherings were spiritual in nature, at the same time, they promoted a more egalitarian view of marriage and family dynamics. One of the focus group participant talks about an interchange between the facilitator and one of the male members:

Well let me tell you, let me tell you one thing, last time in one of the religious retreats... the facilitator [woman] that was giving the talk, said, "the woman is the same as the man", that first, is that they are a couple and then they are a family... so this man says "over there in Mexico, if you are seen with your spouse, your friends immediately call you a mandilon... " and the facilitator said to him "and what do you prefer, to be a happy mandilon or an unhappy macho? Happy with your family?"

Focus group participant 
The perception of males being discouraged from engaging in patriarchal acts, like interpersonal violence, does not mean that the problem disappears. For women experiencing abuse in the sending area, migration might make the situation even more precarious (Family Violence Fund). Most of those participating in the interviews and focus groups did not report experiences with physical abuse and only one person was currently involved in a mentally abusive marriage. Her inability to access social resources stemmed from having to make known to male members of her family that this, her second marriage, also failed. She was also not aware of resources that existed in the area. This participant attended one of the focus groups, and while bursting out in tears had made this known to others. In addition, while many women offered their knowledge on resources that could help her get away from her abuser, their help was not specific enough to pinpoint or direct her to resources that could help her at the moment. During my time collecting data, Sea Prairie's Women's Center did not have bilingual staff working for them, and women who may have sought assistance, were given the number of the nearest metro area crisis line in Salem. Federal laws protecting immigrant women from abuse limit who is eligible for protection and undocumented immigrant women are not be able to access or even be aware that a legal recourse exist. For example, the Violence Against Women Act (VAWA), limits the number of undocumented immigrant women who may petition for help. Specifically, those undocumented women eligible for protection need to be married to a permanent resident or U.S. citizen, or had to have arrived in the U.S. with the intention to escape an abusive situation. VAWA does not offer assistance to 
undocumented Mexican immigrant women married to men that are also in the country without legal documentation.

Women did not access resources such as TANF and any other state or federal benefit that could be have been used to renegotiate their position at home. They were either ineligible for them or felt uncomfortable giving information to social workers. Immigrant women's access to U.S. state benefits was restricted to Women, Infant and Children (WIC) benefits for their small children, and the use of the County Health Department Clinic. These two resource bases did not offer ways to challenge aspects of the old patriarchal bargain.

With various levels of documented or undocumented status, U.S. antiimmigrant vitriolic and its effect on the ongoing legal consequences for undocumented status may negatively affect immigrant families. Here a participant speaks about her fears and the effect they have had on daily activities:

You know that there has been a lot on the raids, and people say " we will not go out because maybe la migra [Deparment of Homeland Security] is there"... but one gets mad being at home... you cannot stay at home your whole life, you are anxious, but you have to live life, go to the grocery store, visit family in Portland, you cannot stop your life from happening, even if the migra is there...

Focus group participant

Because we do not now the day, for example, that la migra will come for us and we will leave our old people here, and what would be of our children... what would happen to the children if they take us, all mothers worry about the raids, very hard, they are on the verge of a nervous breakdown, what would happen to the kids, would they take him to an orphanage? Or who they would stay with? Especially the ones who where born here...one always has that on their mind, what would happen on the way to work, or on the way to Safeway... Mina, aged 35, Tlaxcala 
Mexican immigrant women attributed Sea Prairie's remote location and tranquility as a strong detractor of negative masculinities. The lack of a public spaces for immigrant males, demanding work schedules, and the threat of law enforcement were also perceived as factors that pushed men to perform a more devoted role as husbands and fathers. In the case of solo male immigrants, existing literature suggests men seizing opportunities to have extramarital sexual affairs in the U.S., and seeing themselves as single. In the case of men with partners in the U.S., opportunities for cultural machismos diminished, leaving men with few outlets to affirm their masculinity. Women in the focus groups were conscious of all of these reasons, and understood the unbalanced dynamics of power as women. The affirmation that "I could call the police if he wanted to hit me" existed, and though it may have restricted men from actually acting out on patriarchal abuses, women did not capitalize on this resource. Although it was not specifically stated, women in the focus groups became uncomfortable when they thought that someone would actually call the police to solve marital problems. In many cases, this intangible benefit of "tamed machos" was cautiously acknowledged as a positive, not be exploited, or even called upon.

The perception that the U.S. helps mothers by allowing them to take advantage of some state programs is only partially correct. Mexican immigrant women in this sample chose not to apply for anything besides WIC. Moreover, their position as "protected" gendered citizens is merely a construct that hinders men from enforcing parts of the old bargain. In sum, U.S. context provides some relief to patriarchal 
behaviors, but it does not always challenge or transform the pre-migratory bargain to a more woman-friendly bargain.

\section{Conclusion}

Migrating to the U.S. meant a rapidly changing environment for these women, both as paid laborers and household caretakers. Immigrant Mexican women in Sea Prairie perceived gains associated with that eventual entrance to the U.S. labor force. These gains included the perception of their wages as positively affecting their ability to negotiate for a more equitable marriage, for example. The material tangibility of wages compared to their earnings in Mexico empowered them to feel more capable and autonomous. Nevertheless, it was men's increased participation in the private sphere and their flexibility on the amount and standard of household labor demanded from female partners, what was perceived to be the significant gain.

While these negotiations were grounded on a certain gendered script founded on traditional views of women's behaviors and expected roles, and even if the gains in favor of Mexican immigrant women were substantial, various factors associated with this entrance also encouraged pre-migratory patriarchal practices. Women subjected other women to extremely traditional standards of female behavior and ignored men's as a mere understanding of "men act like they always do". Their perception of men's paid labor efforts also prevented women from demanding husbands to perform an equal share of the household labor, even if their own jobs were as heavy and possibly more dangerous than that of immigrant men. And even though the attempts or occasional help of male partners with domestic work were seen as positive by 
Mexican immigrant women, it seems these efforts may have not been substantial, and as their narratives indicated, the participation of malespouses in the domestic realm was not constant, and in some instances, a source of tension

The U.S. state and its benefits to mothers and children were perceived as protective of Mexican women and their wellbeing. A Mexican immigrant woman, living here felt better protected from negative patriarchal behaviors practiced in Mexico. In spite of this, participants did not use the resources from the U.S. state by as a lever to fight male dominance. The few other resources offered by the social service net (mainly WIC and medical attention for U.S. born children) were seen as aiding them in being good, competent mothers. As I will discuss in the next chapter, the possibility of furthering a more just post-migratory patriarchal bargain may first require changes in the identity formation process of Mexican immigrant women. 


\section{CHAPTER VI}

\section{GENDERED NEGOTIATIONS AND IDENTITIES}

Migration reorders the pieces of the patriarchal bargain, and as stated above, often with mixed results for either men or women. The products of said renegotiations affect ideological positions on women and men's identities. In this section, I emphasize not only possible outcomes of the U.S. patriarchal bargain on women's identities, but also hint at pre-migratory changes on gendered subjectivities. I posit that these changes further affect subsequent renegotiations and patriarchal institutional practices.

\section{Acoplacion: To Connect}

During one of the focus group meetings, my co-moderator felt the need to interrupt the flow of conversation by posing a question to the group. As we had previously discussed, her role as co-facilitator would be limited to the taking of notes and the streamlining of the informed consent process. She was not there to moderate the group. At the time, I had been bothered by her interruption, but as I reflect on how the participants responded, I am thankful that she did interrupt.

[Co-moderator: A lot of young couple say that they need to acoplarse... or she and her boyfriend are very acoplados... my boyfriend is Mexican and he said something like that...]

The way I understood acoplar (roughly translated, to connect) was in the most formal of ways, such as the connection of one piece to the other as to fit them perfectly, or having had heard it as a young girl in Honduras, to yoke two animals in order to plough a field. I was not accustomed to understand the term colloquially, as the way 
these women's attributed meaning to this term. As many women did show, acoplar meant to think as one, to know one another, to become a couple:

Participant 4: It means that they know one another, they know each other well, that they will know how to reach to each other...

Participant 3: To unite in ways of thinking and doing, how are you going to solve a problem, unite... to solve it together... I never had that experience and I did not have a partner like that ... if the young lady allows me [moderator: you can do whatever you want... you are the boss]... Does everyone here think that this union gets stronger in the U.S., more united?

Participant 4: couples are closer here...

Participant 1:... one gets used to that life of partnering... you spend time with family...

One of the very salient narratives in the interviews and focus groups was the change of the immigrant couple in light of the challenges posed by the receiving area. Many of those saw that their male partners changed not only when it came to household labor but also were more open to giving affection to their children. When it came to Mexican immigrant women, the essence of acoplacion, meant that the couple understood what was expected of them in the U.S. Even though women had to negotiate entrance to the U.S. workplace, they understood that wage earning activities would be part of their role as partners. Many women indicated what could be explained as male partners and their reluctance to their wives' labor participation. Nevertheless, economic conditions compelled male immigrants to grant their female parmers permission to enter waged labor. As I described previously, old gendered ideologies may force women to reverse to a more traditional script in order to remain 
in the workforce, and in this case, men may revert to the same beliefs before letting women work.

\section{Ayudarse (To Help One Another)}

Women's labor participation and eventual financial contributions many times may have been relegated to the supplementary realm. However, these additions to household income were entrenched in the idea of ayudarse (help each other).

We are together, here [in the U.S.] or over there [Mexico], we have to fight the fight together, so we have to work so we can help each other more...

Sandra, aged 33, Jalisco

To help each other, mutually... they help each other more than in Mexico...here there is a lot to pay for, so you have to help each other... I think that eventually they will have to resign themselves to the idea that women will work, and that she will earn money, almost the same [as he does].

Focus group participant

To me the positive things [of being a working mother] is what she said, to help the family, it would unfair if I stayed at home all that time, maybe some men earn more, I don't know... but it would be unfair to stay at home the whole day when he is working such a heavy job... Focus group participant

He says, ."it is good to help one another", and I tell him that we also need the money, and he knows that we need the money, that we need two incomes or we cannot do it...

Marisol, aged 31, Nayarit

Well, we come here [to the U.S.] for that, the sacrifice to come here, to do better than before, to better ourselves, right? I need to do it or we cannot better our situation... we need to both make the effort, because we are like a team...

Hernanda, aged 38, Michoacán

During a focus group meeting, a participant mentioned that she did not feel the need to work and could stay at home with her children. Since most of those participating were 
selected because of their participation in waged activities, this specific person did not work but had attended the focus group with one of the invited participant. Although there was no tension in the group when she made this statement, it resurfaced on a later interview. Here Veronica brings the incident back during one of our interview sessions:

Why do those women, those women think like that? If they are not doing it [working]... we are here to better our situation, because we do not have the opportunity to do so in our countries, towns, because the husband and the wife, they support each other... and I know that earnings are never enough... and we were also chatting at work, that many women think, the feel that they are superior to men, that they can do it themselves, alone, and I say, that for me is not, it should not be, it just doesn't go...

Veronica, aged 42, Michoacán

Here she not only echoes participants' opinion on work participation in the receiving area but disapproved of women that think they can "do it all". Immigrant women's work participation may introduce some egalitarianism due to the financial impact of an increase in household wages, or the amount of finances when compared to the their earnings in their regions of origin. My participants were cautious and remained separated from those women that overtly challenged the bargain. U.S. facilitated some bargaining due to said wages, but many of the women in my sample reacted negatively to thinking que ellas las pueden solas (that they can do it àne).

Other negative reactions came from women using whateve resources the U.S. provided in order to greatly upset the gendered bargain. In a focus group, a mildly humorous comment turns to a more serious conversation on the subject of Mexican immigrant women "abusing" their position in the receiving area: 
Participant 1: What I like here... what I like from the U.S. is that they do whatever you want [laughter from everyone]... they do more things here, things that they would not do over there...

Participant 5: [after the laughter has died out] Many times, we know, we know of women that abuse that, meaning, we need to see both sides, because it's true, in Mexico we did not have anyone to give women any support, but here, when the woman arrives here, and the man hits you, or the man says some profanity, right there she calls the police, yes, there is that support, that is good, but because men would rather not get in any trouble, they do what women say...

Participant 2: So are we abusing them or what? [Note: This participant was very animated and somewhat of a humorous person, but here she said this very seriously, matter of fact even] No, really, this is something that we should reflect on...

Participant 3: Not all $\ldots$

Participant 8: Don't exaggerate... [small laugh]... those are cases, very extreme cases, of women who are like that [that abuse men]

Participant 5: Not all of them... not all of the women in general... I have heard from other people, other women, other men, or the case of my brother... so, they let themselves [be talked down to]... I am not saying that women are hitting them, but that many times, women do what they want... There are even cases of women who take a lover and the husband, afraid of the police, doesn't act like they would do in Mexico...

Participant 3: The only thing I see here... that they have a husband, immediately they separate, it's the same, whether they separate or not, so easily they decide to get separated... if the woman here has a job, they tell him "I can't stand you" for the smallest of things...

The ability of ayudarse was seen by these women as a positive trait that allowed them to negotiate entrance into the workplace with their spouses and solidified their role in the receiving area. Data suggested that ayudarse was not a receiving area phenomenon, but one that reflects gendered changes slowly occurring 
in Mexico. Earlier on, participants recalled their fathers' experience as circular migrants and their mothers' role of the Mexican head of households. Theirs was a great contrast to that of a more recent phenomenon: couples who negotiate and plan on the journey. Rita stated how her husband rationalized their plans to leave to the U.S. together and work: "pues si trabajamos los dos, es mas rápido... compramos casa en Méjico y nos regresamos después..." (If we both work together, it's faster... we buy a home in Mexico and then we return afterwards.)

Marta speaks about making decisions to work and why:

Ever since we lived over there, that is the way we were, since we had been newlyweds, if there was a way that I could work, I would work, I would work or he would work, and when he wanted to save for a truck... we both started working picking fruit... we came to an agreement in Mexico that I would work to help us, (para ayudarnos), there are no arguments over that ... and if I do not work for a time, he doesn't tell me anything, he does not demand that of me either... Marta, aged 34, Michoacán

Narratives of women's pre-migratory experiences showed certain aspects of the patriarchal bargain. The idea of ayudarse as part of an economic strategy in Mexico intensified and became a supporting factor when negotiating entrance to the U.S. workforce.

\section{Immigrant Motherhood}

Women's participation in the labor force may be tied to a notion of solidarity and mutual goal making, one that positively enforced some egalitarian ideas without overtly challenging aspects of the patriarchal bargain. But when we bring motherhood into this identity forming process, Mexican immigrant women's workforce 
participation may counter with a culturally essential aspect of their identity: motherhood.

Just as with their educational and regional backgrounds, women's experiences with motherhood were diverse. For example, the women's ages when their first child was born varied, with one woman having had her child as early as 14 while another having her first child at age 28. Five of those participating were former transnational mothers, bringing sons and daughters to the U.S. years later after their own migration North.

While living in Mexico, mothering was perceived as a hard task due to lack of economic resources or a social service net. Except for one participant, no one was eligible or even informed of any social services provided by the Mexican government. A number of participants saw that their children were better positioned to receive an education in the U.S. than in Mexico. While many women saw the positives of sending children to school without having to worry about additional costs such as uniform and books, they did not perceive U.S. education as superior to that of Mexico. During one of my interviews I asked a participant her opinion on having her children schooled here compared with in Mexico, and while she agreed that sending children to school in the U.S. was made easier to immigrant mothers, Mexican education was superior to that of the U.S. She also elaborated why women may want to migrate as a family:

We decided to come here, and make the sacrifice, but if we were living in Mexico, we would all be working, and my children not going to school, and we see that we do not want our kids to be working in the fields, and because of that [economic] necessity, children start 
working... even if schools are better in Mexico... if I brought my kids

[to the U.S.], was to have the family together...I could leave them studying over there, and I am working over here, and I send them money... but I would rather not have that ...

Marta, aged 34, Michoacán

Not only does the U.S. provide a way to maximize resources for mothering, family reunification was perceived as a process that benefited children, and one that normalized their lives. More than half of the participants and their eligible children were participating in the special supplemental nutrition program known as WIC (Women Infant and Children), while only one was participating in the federal food stamp program and three had enrolled their kids in the Oregon Health Plan prograrn. All of the women participating had children enrolled in the local public schools.

Most of the participants spoke at length of the difficulty of receiving any social service aid in Mexico and the majority of them agreed that the extra help provided in the U.S. was great help to their children:

Here it becomes so much easier for someone, because you can get WIC, food stamps, some, if they don't work enough hours, here it gets easier for me, especially since I have my son going to school, and in the case that the mother works, they don't have to worry to pack a lunch because the school makes sure they give [the child] a lunch... Marta, aged 34, Michoacán

The ability to access free and reduced lunch was perceived by the participants to be extremely beneficial. Some recalled the difficulty of sending a child to school in Mexico without food or money for food:

If there is no money, then the child doesn't eat, so what are you going to choose, you choose either the education of your child or that he eats, that is what gets easier for mothers here, your son attends school, they feed him well, breakfast and lunch... and no uniform... [and in Mexico] 
if you do not have money to buy the uniform, is like a type of discrimination for your child in [Mexican] schools...

Focus group participant

Over there they ask for uniform, shoes, toilet paper, and more, and you have to pay other fees, and if they have money to eat they eat, if not, they won't eat, and [the school] won't be feeding them, and over there isn't any government help, that the government will be helping you, so you can get fiee food for school, over there you either have food to take or not...

Focus group participant

Participants were also very well informed on the various ways of obtaining help for their household:

Here there are food banks, that if people do not have [food], they go to the food bank, sometimes they can even go once a month, there is also an office near Oyster Street, that they also have food, once a month, and there is another office that give you CARE, and sometimes they even give you diapers... so there are places that you can go and get food that in Mexico there would not be...

Focus group participant

While a large majority spoke positively of the help available to families, such as schooling, supplemental food programs and community aid, a few stated that those living here were misinformed about the way the Mexican welfare system operates. It is interesting to note that these three participants came from urbanized areas and their reasons to migrate in part deviated from what I saw as the family reunification norm ${ }^{24}$.

The majority of my participants were not eligible to participate in Mexican state aid programs such as the Sistema Nacional para el Desarrollo Integral de la Familia (National System for the Integral Development of the Family, DIF for short)

\footnotetext{
${ }^{24}$ One participant had migrated in order to prevent his spouse from divorcing her and the other came here after being abandoned by her spouse. The third woman, who was born and raised in the capital, spoke at length of Mexican state benefits for elderly and abused women.
} 
due to income requirements being too low. Here a participant describes this "catch-22" requirement:

Well, DIF, ends up being like [social] help, but there are more requirements [in order to partake in] DIF... if your children are going well in school, or if they are given a scholarship, they can receive food... but when one can't send children to school, when one needs the help, it isn't there... and you have to be extremely poor [to get DIF]... if they see you eating more than beans they will not give you DIF...

Veronica, aged 42, Michoacán

Other forms of aid that women used were those provided by political parties during election time:

P4: When politicians are campaigning, they give you your box, with stuff, with over the counter pills, some foods

P1: Yeah, a box that comes with oil, sardines, a bit of everything, beans, rice, some soap

P4: If PRI wins they give you...

$\mathrm{P} 1$ : If they win...

[Moderator: How long does that last?]...

P1: Like 5 or six months, candidates are in their "revolution", going from pueblo to pueblo, in their revolution, and they know if they give our kids food, then we will vote for them...

[Laughter from all]

While most of the mothers participating mentioned advantages of mothering in the U.S., a strong pattern was salient when it came to describing things that immigrant mothers do give up: the ability to completely immerse themselves in mothering. Even if some women participated in income earning activities in Mexico, their ability to have extended family nearby allowed them to go into the work sphere without feeling that their kids were not being taken care of. While many people mentioned having 
trusted U.S. childcare providers, their inability to make time for children due to early work hours, compounded feelings of missing important activities and milestones in their children's lives.

Women's experiences with daily mothering activities suffered as well, with many of them elaborating on their inability to dedicate time to the appearance of children, or even being aware when their children leave or return:

Sometimes I fall asleep, I am not even aware how they leave, dirty clothes or not, with or without their snow jackets, sleep wins over that, and sometimes I am telling them "get nicely dressed" and then I know it, it is already 8:40, I wake up all startled, they left to school... and sometimes they come from school all dirty... with clothes that were in the laundry basket to be washed... but I fell asleep and could not supervise them...

Sandra, aged 33, Jalisco

While income earning activities were perceived as negatively impacting women's roles as good mothers, financial security softened this. In many of my conversations with these mothers, food insecurity may have been expected in their lives:

[In Mexico] what you earn is very little, you earn 80 pesos each day, and meat is 90100 pesos, so there is not enough to eat meat, only rice, beans and bit of egg...

Focus group participant

Others saw that their income meant children having more than the basics. In the case of one participant, she stated that husbands might think that a pair of socks is enough for a child, and never understand that kids grow up and have a need for adequate clothes. 
While women saw earned income activities both negatively and positively affecting their lives, there was a strong belief that mothers must do whatever is possible to fulfill both material and emotional necessities. In some instances, women who could not fulfill the role were seen negatively by others, when it came to some of the food processing work schedules, working at night might automatically mean your children were neglected.

\section{Women's Experiences with and Responses to Patriarchal Behaviors}

Aside from a small number of participants, most of those interviewed had never been directly confronted with extreme forms of patriarchal behaviors, while others had been so indirectly affected by them that they only heard about them from their family members or other females.

Most of the women spoke of either friends or family members having had experienced patriarchal behaviors: husbands going out alone to bars, having the occasional sexual encounter, gambling, cases of public drunkenness, etc. Most of them recalled a certain woman friend seeing her male partner improve his behavior in the U.S. Another spoke of a woman in Sea Prairie whose husband's doubts about her fidelity forced her to quit her job. While there may always remain instances of rigid patriarchal behaviors in the receiving area, my interest was the reaction of these women to these indirect accounts: 
I think those women, they suffer... there are women... that have husbands that demand to know who they are with and where they are at ... and I feel that they are fearful... there are still women here in Sea Prairie that are afraid to go out, that they won't learn how to drive... because they have husbands like that... that there are women like that, there certainly are...

Veronica, aged 42, Michoacán

That I have seen and heard, a lady that was working [the night shift at Happy Cow], and it was pretty late that we arrived at home, and then gossip reach men, some gossip, and they say "you can't work anymore" and it happened to that young woman, they told her husband that she was [misbehaving]... with some young man... "What misbehavior?" I said... you were working, we were all together and we were working, we are seeing what we are all seeing ... but her husband doesn't know how to act here... [Moderator: Would you elaborate?]... Two things, he can't be going around being machista, because their three kids are going to suffer, they are suffering, and also because Sea Prairie is not Mexico, and many men understand that when they come for work here, the woman will also try to find work...

Genera, aged 34, Michoacán

Of course there is machismo! I have heard of women [in Sea Prairie?] yes... that have arrived, well for me, that is a machista, to even forbid you what you wear or what you won't wear, understand? Or if you go out or not, or who are you out with, or if you are with other women and where...

Trina, aged 33, Aguascalientes

The one that needs to be going to parties, he will go out and find them... I have heard, where I work, you can hear comments from people, of, about a lot of women, people, they say that so and so left to some place to see certain things, but yes, there are things like that. Herminia, aged 26, Michoacán

Three of the women in my sample had either married here or did not experience married life in Mexico (many of them had married and migrated to Sea Prairie shortly after). Many times their experiences were so far removed that indirect 
experiences with patriarchal behaviors in Mexico served as a way to compare their experiences to their husbands' gendered behaviors:

[In Mexico] is very difficult, the man, he hardly ever lets the woman work, I remember that my dad never let my mom work, and my mom wanted, and also over there men are more, prone to parranda (carousing), going out for awhile...

Ruby, aged 31, Guanajuato

This same time she talks about her husband's limited help in the household:

[Researcher: So how does he help around the house] [She laughs] Well, he doesn't, let's say he takes off a sock here and then another one... nothing...he tells our girls... "girls, start cleaning up"... But he does take care of the girls, takes care of the baby, he took care of him since he was three months and I would go to work, and he, when he came back from work, he would pick him up from the sitter and would take care of him the rest of the day... I know of men, in Sea Prairie, that instead of coming home and helping, they leave with friends to drink, or they go out and drink, or they go out looking for women... but it depends on the man's part if he wants to change...

While we see in this exchange that some Mexican immigrant women may make sense of the amount of gendered behaviors that may be part of the gendered bargain, some others may not be accepted, such as those behaviors that extremely tilted the balance of the patriarchal bargain.

In another exchange, Amalia told me about what her husband's attitude would be if she had been a wife in Mexico and had wanted to enter the workplace, she stated, "I do not think it would have happened, it would have been almost impossible".

Other women clearly articulated what they thought of patriarchal behaviors:

Participant 4: I have seen friends' marriages, I would see them, and their husbands, they would leave, that was when I was single, they would leave to go out with friends, or with other women, and they would not care, here, you husband's doesn't leave you to go out ... 
Participant 3: I do not know why one stays quiet over there, you do not stay quiet here, your tongue loses its stiffness (you are more prone to speak up) and over there you have to be submissive...

Participant 2: In Mexico, it is very different, over there, the husband can be hitting you, leaving you all bruised, you have to go out looking like that, you go to the church and the priest doesn't reprimand the macho...

Focus group participants

[Men need to see] that things change, but they need to let them [work], they have to leave the machismo, I think, they need to come to terms that women also have the right to work, and that is it... no more... they have to leave the machismo...

Mina, aged 35, Tlaxcala

\section{The Modified Patriarchal Bargain}

Throughout my analysis of all the interview material, there was a strong pattern of what was an accepted gendered behavior and one that violated the new bargain. This was true when it came to how women modified household routines in the receiving area, with women describing what was part of this bargain (even though it was still somewhat biased), to what it may have been - an unfair, demanding, and almost unrealistic request.

Veronica states what she would see as an unfeasible expectation of a working immigrant woman:

I know many men here that their women goes out to work, and say, that they do not care how tired she is, they have to make tortillas, and my husband no... of course, he was used to that in Mexico, but he would never demand that, "make me tortillas", I make them, but when I have a craving for them...

Veronica, aged 42, Michoacán

Many husbands' housework contributions attested to their being comprensivos (roughly translated as sensitive and aware of a wife's double burden) and this was also 
noticed when it came to women's description of husbands now and husbands then.

Some of the older women spoke about men's old expectations before they learned to understand the terms of a new patriarchal bargain:

Participant 3: Over there, you have to serve them, and if his spoon fell to the floor [they would tell you]. "get it for me"... not anymore... he serves himself, I make the food and is there...

Participant 2: I would ask him, "have you eaten?" and he would say, "You have not served me"...

Focus group participants

While above I describe impractical (but very real) requests of women's household labor, three of those interviewed had left their jobs due to their inability to fulfill their part of the bargain. Rosa details why she left her work:

[He wasn't pleased] that is what I had to get out [leave Placid Sea], because he did not... I would get home at 5:30 p.m., and as soon as I came, it was already 6:00 p.m., and as soon as I got home, I would cook, so when he got home, he could eat, and while they ate [children] I would wash dishes or whatever that needed to be done, and I was extremely tired. So I would sleep, and when he came like around 8:00 p.m. I was already asleep and never had a chance to talk to him... Rosa, aged 28, Michoacán

The problem here was not that she was not fulfilling her part of household duties, since she did the washing, cooking, caring of children, and the rest of the daily list of duties. It was that the more affective part of the bargain may not have been fulfilled, the one that equates housework and domestic acts such as preparing a meal as a demonstration of love. In the case of immigrant households, this affective part of the bargain may be most important. In many cases, my participants lamented nót fulfilling the affective part of the patriarchal bargain: 
There were times... that he wanted me to stay at home, waiting for him with a plate of hot soup, and I leave him food, but it is not the same... he eats alone... so I make it easy for him to eat hot food... alone... but he has that... he doesn't have to be out in the street eating burritos or food that needs to be reheated...

Julia, aged 39, D.F.

When one comes back from the smoker, one does not come back home in a good mood, and those small things, and sometimes my husband wanted to find me home, he would prefer me to be in a good mood... and I understand him, since I would come so tired that I would not want to cook for him and he worked so hard to not have food waiting for him at home...

Marisol, aged 31, Nayarit

He liked me having me at home... even though I leave him food, I do not serve him, he serves himself and eats alone, and he would say, "I guess it's ok, that way you are not in a bad mood"...

Rita, aged 33, Nayarit

Women participating in the focus group also lamented children getting ready for school without their help, and felt guilty when a child forgot to eat breakfast or wear an extra layer of clothes during the winter. Even though they had prepared children the night before by choosing what they would wear, and packing lunch and leaving breakfast utensils and cereal boxes out in the counter in the morning, they felt this was not satisfactory. Even when said child wore what was picked up, took that prepared lunch, and ate the breakfast that was left in the counter, these mothers felt that they did not meet their own standards of what a family caretaker was required to do.

Pessar stated that Latina immigrants might see the domestic sphere differently than White women because of the race/class/ethnic location of the social actor. For the immigrant women in her sample, domestic work was a way to not only show their 
them. While a participant stated that the U.S. "allows you to do things you thought you could not do", it was not solely living in the U.S. what may have triggered a multifaceted identity. Data showed that those pre-migratory instances of egalitarianism, such as husbands being open to pitch in with household duties or allowing wives to work in Mexico, were also affecting women's identities.

I have described women's decisions to enter the workforce as a way to ayurdarse, as a pre-migratory pact in the marriage. The U.S. becomes the stage to facilitate egalitarian practices and put into practice what they saw as gendered possibilities. Women's narratives of their lives as wives in Mexico pointed to specific goal making with male partners, and even those women coming from modest educational backgrounds and nural sending areas, articulated sophisticated plans to satisfy objectives:

One always comes to the U.S with that illusion, no, not an illusion... you have goals, as a couple you have goals, things that you must do... money to save in order to build a home, or get a car...

Rita, aged 33, Nayarit

When I asked Rita to describe how this was different from doing it the way her father and grandfather (who had migrated here while wives stayed in Mexico) did she had this to say:

Like my dad would come [to the U.S.] like I toldyou, but his goals and his plans, he made them for his family... and now, that is not the way it's done, you make those plans together as a couple, and it gets easier...

She continues by explaining the difference between older women in her family: 
The father would leave to work, for years, without coming to visit you, no one felt sad or like women 30 years ago, if the men came to work here, mothers, I am not sure, I do not think they could tell their husbands "the child needs you, takes us [to the U.S.] ... with you" or tell them "the baby" or "I miss you, do not leave, let us see what we can do instead"...

Amalia, a recent arrival to Sea Prairie, was telling me how her husband wanted her to join him in Texas, but she refused, deciding to stay in Michoacán instead. During my interview she became extremely animated:

We have more freedom... I am not sure why we have changed... I am not sure what has happened in our country, our mothers would not say that, so husbands would force them and hit them, I don't know, well, that is what my mom told me, and now, the time that we are now, [women] become rebellious, [if men] tell you "you are going to do this" [you reply] "I am not going to do it"... but then when you get married men say "where I am, you will be as well" so you have to go...

[Researcher: But you said you would not go to Texas?]

Well, if you do not want to do, they can't force you, if I was older, I would have gone without protest, but women already know that is not like that.

Amalia, aged 20 Michoacán

While younger women echoed disassociation from past generations of solo male migration and even as I illustrated above, even indirect experiences with extreme forms of female subjugation (such as wife beating), an older cohort of women equated migration with family reunification:

So he would stay most of the time in the U.S. working, and then five years had passed, and then I said, no, well, I told him that there was nothing good of me being here alone, with my children ... it is better to have the whole family together...

Silvia, aged 37, Morelia 
When I asked Silvia to tell me about those women that were left in Mexico, she stated that they were always filled with ancias de venirse (desire to come) and she proceeded to tell me how she waited for her husband to agree to family reunification.

When he said, "would you like to come here with the children?"... I said "Yes!"... Quickly I organized everything... I needed to follow my husband, because we were already a big family, so I came...

Although her bargaining may have been subtler, unlike the direct statements or demands of younger participants, I am not arguing that gendered identities and the questioning of gendered bargains and roles are generationally distinctive. Instead, I suggest that older women in my sample were less likely to instantly see the possibility of radical changes to gendered practices, or were less likely to immediately consider different possibilities and alternative identities for themselves. However, as stated below, they wished for a different gendered path for their daughters or younger female kin. While Silvia continues on about her family ties and her 13 years in Sea Prairie, I ask her to reflect at a passing statement:

Since we have been here, my daughter married, I have two grandsons, and my son is 13 and the other girl is 8, and two grandkids, so life changed completely, I was not hoping to become a grandmother so soon, well, that is life...

[Researcher: You said "grandmother so soon"... What was so different about you becoming a grandmother when your mother became a grandmother when you had your first child?]

[After smiling at me and pausing] Well, it took me by surprise [she laughs]. I don't know, when one comes to the U.S., one thinks their children, I don't know, they will try to do something, like buying a car, or save money, before they get married... I am not sure how to tell you... 


\section{Conclusion}

Data showed identity formation as the outcome of migratory influences but also as pre-migratory echoes of more progressive ideas about gender. Women's concepts of acoplacion y ayudarse did not occur automatically in the U.S., but before migration, as part of women's renegotiation of patriarchal bargains in Mexico. These concepts may have been muted in light of other pre-migratory patriarchal forces, such as sexism and machismo, but U.S. living allowed them to emerge, and be further equipped to successfully renegotiate their positions of power. As a result of financial uplift, mothering may become a source of positive identity formation, encouraging women's further renegotiation of the bargain. Women are faced with various structural obstacles to mothering, such as limited time with children, which may subtract from said positive identity formation. However, I wish to emphasize the importance of these identity formation processes and the resulting possibilities for Mexican immigrant women, as it amounts towards a more multifaceted view on the roles of men and women. 


\section{CHAPTER VII}

\section{DISCUSSION}

Migration is decisively gendered, as it informs who migrates and dictates the roles of those that stay in the community. The act of crossing borders, both physical and symbolic, shapes how men and women think of themselves in the new area. It also rapidly redefines the character of institutions, such as the labor market, the family, or other cultural institutions, which are constitutive of patriarchal forces that dominate women collectively, and benefit a large majority of men. However, patriarchal bargains change in light of migration: they provide social actors with a new set of resources and strategies that may aid in restructuring pre-migratory forms of male domination.

This study examined how migration forces women and men to reorganize their gendered lives, how Mexican women living in new immigrant destinations renegotiated patriarchy in the domestic sphere, and what the rearrangements of various patriarchal practices meant to the identity formation of these Mexican immigrant women. It also demonstrated how pre-migratory changes in patriarchal ideologies and practices altered the patriarchal bargain in the U. S.

I framed changes in the Mexican patriarchal bargain as a mixed bundle of gains and losses that occurred within contexts. The context where bargaining occurred — whether it was the home, the community, or the workplace - informed women of what strategies to use in order to claim their end of that bargain. Migration 
reorganized the specific bargain by informing women of new alternatives to the old bargain, new forms of resistance, and new forms of capital that may have increased bargaining outcomes. At the same time, institutional forces altered aspects of pre and post migratory bargains, limiting some gains, magnifying some losses. In this case, women's gains of modified household duties may have given them some relief and a way to juggle public sphere demands, but the "affective" aspect of housework was lost. The ability to perform acts of caring via acts of domesticity was replaced by material concessions to children. The question remains of how this will affect mothering as a source of identity and individuation for Mexican immigrant women.

Entrance to the U.S. workplace compelled women to reenact old patriarchal practices reminiscent of early $20^{\text {th }}$-century Mexico: asking the permission of their male partners or guardians in order to participate in income-eaming activities. In the case of immigrant men living in Sea Prairie, it was those culturally-entrenched attitudes of women's behaviors that allowed them to justify, at least symbolically, why female partners should dedicate themselves solely to the home sphere. This aspect of the U. S. patriarchal bargain may have resembled the pre-migratory patriarchal bargain, and women's tactics in this aspect of the bargain may not have differed; however, the potential gain of entering the U. S. workplace did. In this case, it was not how women negotiated entrance that was important, but the specific gains that could be reaped from U. S. employment compared to employment in Mexico. This specific process of denying, strategizing or resistance, and eventual consent plays out in order to maintain cultural aspects of gender. For men, their masculinity is measured 
on this performance, not only as providers, but as controllers of women's movements in the public sphere. Consent by "letting" women participate in wage eaming activities is rationalized as a way to avoid household conflict only or become eventually accepted once women's wages aid in the purchase of status markers (automobiles, homes, electronics, etc.) Moreover, as I found in this research, it was women and their protection, adherence, and promotion of highly patriarchal rules that justified their continued participation in Sea Prairie's industries, and disallowed the formation of work-related networks. Thus, the absence of networks was indicative of the lack of female solidarity in these industries.

Income eaming as gains happened to uplift women, but these gains also had certain stipulations attached to them. In both the pre-migratory and the post-migratory gender contract, monetary gains were for ayudarse $e^{25}$, and not to be used as to gain more control over the relationship. Income earning was an acceptable way to be a better mother or a good partner, but it did not permit one to think that one "could do it alone". Women may have seen the influence and the new possibilities that their earnings brought when it came to bargaining, but they were still required to follow certain rules, and attaching eamings to motherhood assured them the continuation of that bargain.

Findings agree with Wilson's (2001) position of women's transition from one aspect of patriarchal control (home) to another (work). Women's experiences with patriarchal behaviors in Mexico's workplaces may lessen economic and subjective gains, since their positions as women dictate that they be controlled via their sexuality, 
and generally eam less than Mexican men. However, I argue that Mexican immigrant women's position in the U. S. workplace lessens their control as sexualized bodies, but forces women to call upon patriarchal practices in order to maintain and maximize their gains outlined in the gendered contract. These practices, such as the policing of other women, keep aspects of the pre-migratory bargain alive. In the case of Sea Prairie Mexican immigrant women, this gender policing may have prevented the creation of female work and work-related networks, thus snuffing out any additional resources to be used against patriarchy. Their adherence to the portarse bien ${ }^{26}$ rule may blind them to questioning the restrictions imposed on them because of their role as sexual bodies.

Sea Prairie Mexican immigrant men are better positioned in the workplace compared to their female counterparts. Not only are Sea Prairie immigrant men enjoying economic and career advancements, but the nature of dairy jobs may be fulfilling aspects of a positive masculinity that could enforce various pieces of a more traditional gendered bargain in the household. Their positions as highly paid, highly overworked household members allowed them to avoid a substantial portion of household duties, and thus overburdened women who were also doing a fair share of paid work that was physically demanding. While the net result indicates women are still doing more than a fair share of the work, their perception of men as comprensivos and men's willingness (even if not always acted upon) to help with household labors, points to the future formation of a more enlightened view of women and men's roles.

\footnotetext{
${ }^{26}$ Behaving well
} 
Resources are crucially important to bargaining parties. In the case of Mexican immigrant women's strategies, networks were an initial form of capital, but not a constant one. They could be summoned at first, as an example of bargains gone right, when it came to female in-laws taking charge of a female newcomer. However, networks are not endless resources, and their upkeep requires constant acts of reciprocity in order to maintain their "freshness". On the other hand, there were more intangible resources that challenged patriarchal ideas of public male space, such as the perception of the U.S. as protective of women. This feature of the U.S. as an ally when it came to men's public space performance of destructive gendered behaviors was attractive to women, one that may have allowed them to expect responsible behaviors from their men, so as not to renege on the new patriarchal bargain at home. Reorganization of the household bargain may mean new ways of thinking about gender. For Mexican immigrant women, it meant an affirmation to gendered changes that were already in flux in their places of origin, and some of their "indirect" experiences with machismos attest to this. The idea of ayudarse $y$ acoplarse takes a new dimension when coupled with women's substantial income earning abilities. It is no longer a supposition, but a possible avenue to a more egalitarian view of gendered norms. The idea of having more resources to bargain with (especially when it came to the U. S. as beneficial) was seen by women as advantageous, but with an added dose of caution.

The patriarchal bargain within a specific institution, the household, is transformed by men's flexibility with household chores and their eventual 
permissiveness of female partners' workforce participation, the perception of the U.S. state as "protective of women but not men," and women's pre-migratory blossoming ideas on gender. Nevertheless, this patriarchal bargain needs to allow for lost masculinities to be recouped in other areas, such as work or the public sphere. This last component allows for a sense of balance to men's lost power and position, in light of negative changes to male status brought on by migration. In the case of Sea Prairie men, it was the dairy industry's influence on masculinities that allowed for those men's more relaxed attitude about housework participation.

The household patriarchal bargain may revert to a pre-migratory and/or more rigid version when some factors are absent, such as pre-migratory progressive ideas on women's and men's roles and practices, or areas that allow immigrant males to recoup lost masculinities without reneging on the patriarchal bargain. In other locales, the inability to restore aspects of masculinities via employment may indeed effect bargaining for immigrant women. A woman may find herself employed and assuming all of the housework while weathering conflict (economic or otherwise) brought on by an unemployed or underemployed spouse.

In light of these findings, I propose that the patriarchal bargain in the household is successfully renegotiated in favor of women by the accumulation of various factors, including entrance to the workplace, earnings of both men and women, the type of jobs men and women do, identity formation processes, and their access to economic, in-kind, and/or normative resources. In addition, the patriarchal bargains of another structure may affect what and how factors are accumulated, and 
even if they accumulate at all. Women's acceptance of an unfair bargain in one area may increase their gains in another. At the same time, this acceptance may undermine overall gendered gains. Mexican immigrant women acknowledging earnings as supplementary and perceiving their husbands' jobs as mas pesado que el mio (heavier than mine), meant that their husbands would be comprensivos and not demand household labors from them, and they might even be available to take on some of their female partners' household chores on occasion. Men's higher paid positions in the dairy industry may have afforded the immigrant family some level of comfort and economic satisfaction, but it also caused women to ignore their double burden at home.

I build upon the work on current migration scholars' view of the U. S. as a mixed arena of gains and losses for immigrant women, or as gains in some spheres, and not others. However, I argue that women's gains in any patriarchal context should be recognized as the sum of certain negative and positive factors, or as cumulative gains in light of the different patriarchal practices that constitute each of these structures. Sea Prairie immigrant dairy workers' wives have accumulated enough gains to off set losses, and have a satisfactory net result. In the household, they are solely responsible for all of the labor, but they are also afforded a few luxuries that some other immigrant women in Sea Prairie may not have. They are also afforded comprensivo_husbands who do not demand that they make tortillas by hand if they are working for pay, or they enter the work sphere if they are not. For women with an unemployed or underemployed spouse, her gains may counteract with her 
responsibility of both work and the home, and the conflict that may arise from her partner's inability to affirm his masculinity due to restrictions imposed by U. S. society.

\section{Final conceptual thoughts}

Kandiyoti proposed that patriarchy should be seen as distinct across cultures, with gendered practices and forms of male domination affecting women differently. However, she detailed the complexity of power in gendered relationships by suggesting that women strategize and arrange to take full advantage of their options for autonomy around the boundaries of their subordinated position. These women's strategies to resist complete loss of power in male-female relationships take varied forms, ranging from complete passive responses to extreme forms of apparent resistance. Her conceptualization of gendered relationships as the result of a constant state of negotiation between two individuals, where one party may hold a lesser share of the bargaining chips and the more advantaged party still resist compromising, established the conceptual framework to understand Sea Prairie's Mexican immigrant couples and their experience with new gender roles and responsibilities. Her assessment of patriarchal bargains as vulnerable and changeable, and the outcomes of these affected bargains as being uncertain — sometimes detrimental or sometimes favorable to women - effectively illustrated the complex result of gendered changes due to the crossing of physical borders. However, Kandiyoti's lacks the specificity to describe the way this renegotiation takes place within the different contexts of Mexican immigrant women's lives (such as negotiations with patriarchy at work, etc.) 
In order to incorporate these different contexts into the idea of women as negotiating within existing patriarchal boundaries, my research incorporated Walby's ideas of how patriarchy affects spheres of women's lives differently and how these spheres may causally affect each other. While this theoretical addition may have refined how I applied Kandiyoti's model to understand how Mexican immigrant women respond to, strategize, and resist patriarchal domination within these different sites, synthesizing both models did not clarify the identity formation processes that I encountered. Kandiyoti's model focuses on understanding gender as a result of changes in the economic realm, leaving the question open when it came to women's feelings, wants, beliefs, understandings, and explanations of their gendered worlds. Kandiyoti later revisited her patriarchal bargain argument and recognized that “. . . the messiness of social reality has always exceeded the explanatory power of conceptual frameworks . . . the more so in the area of gender" (p. 147). While recognizing that her model had validity when it came to understanding the power of market forces on the lives of women, identity and how it shapes how women in different cultures respond and recognize their own subjugation and the web of power, remains to be developed. In order to enhance Kandiyoti's ideas of the patriarchal bargain, I briefly discuss the idea of the patriarchal bargain as susceptible to identity transformation; how new patriarchal bargains may be affecting how men strategize new ways to maintain a position of power, how new ideas of gender bolstered by past bargains may be pointing towards more concrete ideological changes; and lastly, how patriarchal 
bargains should be understood as the result of a former bargain gone awry and as the process of constant and aggregated renegotiated bargains between gendered players.

My fieldwork problematized the idea of bargaining when it came to identity. I realized that identity was as a strong bargaining chip as wage earning was, and the further questioning that arose from these new ways of thinking about gender allowed for further bargaining. While the failure of the old patriarchal bargain allowed women to see themselves as migratory actors, the idea of entering the U. S. paid labor force was met with resistance from immigrant males. It was the cultural strength of Mexican motherhood that restricted but also justified women's wage earning activities. Mexican immigrant women in Sea Prairie felt that this cultural given of motherhood may have limited their entrance to the workplace due to the lack of childcare, but it justified their entrance as a "way to help out or provide," comparing the economical insecurity of "back home" to the possibilities in this new place. However, the result of the increased value of wages in the U. S. allowed for an increased view of themselves as better positioned to further bargain in the future, since their economic participation perrnitted immigrant males to raising their status in the new community via the display of material tokens of masculinity, such as cars and home ownership. Maintaining femininities and masculinities thriving in the new area allowed for a more balanced negotiation that would not have been possible otherwise.

The new nature of the patriarchal arrangement in these immigrant households consisted of an understanding that "we are no longer in Mexico," and both men and women (the latter more enthusiastically than the former) accepted the new 
arrangement. However, the openness of males to seeing themselves as modernos does not mean that they are no longer benefiting from patriarchal control of immigrant women. The ideological permeation of gender role socialization remains strong, and in this case, became a way not to tilt the negotiated balance. Mexican immigrant women felt that they needed to abstain from seeing themselves que las pueden solas, and that stepping from that new patriarchal boundary meant destroying the fragility of this new bargain. In this case, Sea Prairie Mexican immigrant men gained not only new forms of positive identity (fatherhood and "modernity") but greatly benefited from women reproducing cultural vestiges of femininity. These new masculinities also allowed them to re-evaluate ways to maintain some form of gendered advantages without discounting their wives' claims for egalitarian arrangements. In the case of Sea Prairie men, their denouncement of outmoded forms of machismo by occasionally helping out in domestic affairs meant that Mexican women would maintain their part of their bargain by keeping some cultural semblance of "back home" intact. This, in turn, did not benefit women as it decidedly placed them in a situation of constant labor, both domestic and waged.

While Mexican immigrant women in Sea Prairie are seeing a positive effect on motherhood being bolstered economically, they are still at odds with new forms of thinking about gender. However, these new forms of thinking are furthering negotiation and increasing Mexican immigrant women's claims for egalitarianism when it comes to intimate and other personal relationships between the sexes. Most of the Sea Prairie women interviewed currently subscribed to some traditional behaviors 
and practices, but from the depth of their interviews emerged the impossibility of these behaviors reversing to unreasonable states. While my participants understood that their male partners' views of gendered behaviors may have been somewhat progressive and accepted lighter aspects of machismo that dictated daily discourses, they all stated a disdain towards flagrant machismos and suggested that they would not allow them to happen, would not see themselves in that depowering situation, or would actively resist allowing outmoded (and restrictive) male gendered behaviors to affect the gains already made.

While Kandiyoti suggested breakdown of a particular patriarchal bargain did not mean a smooth transition to a newer patriarchal instance, she stated that women responded either passively (by yearning for the old order) or by active and open resistance. However, she does not allude to how the accumulation of various renegotiations affects future bargains, and does not inform us whether women on the losing end of a certain bargain find ways to renegotiate when the time is right. In the case of Mexican women, their participation in unremunerated and remunerated activities began when the old arrangement of a working spouse failed to successfully meet the economic needs of the Mexican family unit. Their entrance to formal employment began as a series of renegotiations (with Mexican institutions and individual men) and throughout the last two centuries, the cumulative effect of this renegotiation normalized women's participation in the Mexican workforce while still enforcing the essentiality of unequal gender roles and responsibilities. The failure of the old solo migrant did not immediately inform Mexican women of the new ways to 
renegotiation (in this case, joining spouses) but it took an understanding and absorption of their losses relative to what they were expecting to gain. Migrating with your spouse "to help each other out" was another cycle of renegotiations that has built upon that past renegotiation of entering remunerated activities.

Reframing the patriarchal bargain as an evolutionary compound of past bargains affected by old and new ways of constructing masculinities and femininities, men's reactions to women's claim making and the ensuing strategies that maintain patriarchal control, and understanding how ideological changes in gendered roles and performances are continuously affected by bargaining in different contexts can allow us to flesh out Kandiyoti's position. Bargaining also affects the gendered consciousness of both parties, and the renegotiated results are but a glimpse of what further changes may look like.

\section{Strengths and Limitations}

This study has several strengths. It collected information using multiple methods, such as in-depth interviews, focus groups, and ethnographic immersion. Therefore, it focused on the individual lived experience of participants, but also took into account the context of their experiences as immigrant mothers accessing institutions. The short ethnographic immersions allowed me to intensely reevaluate preliminary findings and learn from those being interviewed. Constant questioning of my role as an insider/outsider allowed me to address bias issues by evaluating how this position may have influenced data collection and findings. 
I made a big effort to have participants amend transcripts. Although many were satisfied with how I captured their words, those who did amend parts (and in some cases larger portions) of the transcripts supplied me with valuable direction and suggestion for change.

Some limitations were present in the study. The sample of Mexican immigrant women interviewed was small $(n=20)$ and quite diverse. Portions of those interviewed were educated and may differ from participants with more modest educational backgrounds. The focus groups $(n=23)$ were also made up of extremely diverse women and included voices of women who did and did not work. Some women participating in the focus groups were reticent and shy, and did not feel comfortable enough to voice everything. I was also looking at women who are participating in waged labor, thus already experiencing a degree of autonomy in their households and social spheres.

The present findings included women's voices only, and in no fact does it reflect what Pessar (1999) called the "common fallacy of equating gender with women ... [or ignoring the fact that] ... immigrant males may be stripped of patriarchal status and privilege by white men and women" (p. 578 as noted in Espiritu, 1997). To be more precise, women's experiences were central in understanding change because of their position vis-à-vis immigrant males, and their experiences with diverse forms of male domination in both the sending and receiving area.

The distinctiveness of Sea Prairie as a high immigrant destination also limits these findings to this setting, therefore the validity of findings in a different high 
immigrant destination is not known. Sea Prairie's dairy cooperative model may not reflect the nature of many dairy producing areas and their effects on immigrant workers' lives. Women's work narratives in the Happy Cow industries are also unusual, due to the private nature of Happy Cow compared to other corporate run meat processors that operate in other new destination areas.

\section{Further Recommendations}

Cohort studies of newcomers and more established immigrant women should be conducted to better understand how networks are formed and used. What are the specific attributes of women who were forced to find and/or create networks? How did they mother in areas with no support or resources? How do their experiences compare with those of women settling in an area with solid female networks?

Finally, more studies of these new emerging forms of Mexican immigrant masculinities should be prioritized. These studies should make an effort to incorporate voices of Mexican immigrant women's understanding of masculinities in their lives and communities (both origin and transnational). I feel that this may begin to break down the residual academic view of the stereotypical macho, the one that may still unconsciously affect how we label cultural performances of gender. 


\section{REFERENCES}

Baker, Phyllis L. (2004). 'It is the Only Way I Can Survive: Gender Paradox Among Recent Mexicana Immigrants to Iowa. Sociological Perspectives 47(4), 393408.

Casique, Irene. (2001). Power, Autonomy and Division of Labor in Mexican DualEarner Families. New York: University Press of America.

Cerruitti, Marcela and Douglas S. Massey. (2001). On the Auspices of Female Migration from Mexico to the United States. Demography 38(2), 187-200.

Chant, Sylvia. (1991). Women and Survival in Mexican Cities. Manchester: Manchester University Press.

Chavez, Leo R. (1998). Shadowed Lives: Undocumented Immigrants in American Society. In George and Louise Spindler (Eds.), Case Studies in Cultural Anthropology. Irvine: University of California Press.

Curran, Sara R. and Estela Rivero-Fuentes. (2003). Engendering Migrant Networks: The Case of Mexican Migration. Demography 40(2), 289-307.

Curran, Sara R. and Abigail C. Saguy. (1999). Migration and Cultural Change: A Role for Gender and Social Networks? Paper presented to the Culture and Inequality Workshop, Princeton University.

Davis, Benjamin and Paul Winters. (2001). Gender, Networks and Mexico - U.S. Migration." Journal of Developmental Studies 38(2), 1-26.

De La Torre, Adela. (1993). Hard Choices and Changing Roles among Mexican Migrant Campesinas. In Adela De La Torre and Beatriz M. Pesquera (Eds) Building with Our Hands: New Directions in Chicana Studies, (pp. 168-180). Berkeley: University of California Press.

Donato, Katharine M. (1993). Current Trends and Patterns of Female Migration: Evidence from Mexico. IMR 27 (4), 748-771.

Durand, J., Massey, D. S., \& Charvet, F. (2000). The Changing Geography of Mexican Immigration to the United States: 1910-1996. Social Science Quarterly (University of Texas Press), 81(1), 1-15. 
Easter, M. M., Linnan, L. A., Bentley, M. E., DeVellis, B. M., Meier, A., Frasier, P. Y.; et al. (2007). "Una Mujer Trabaja Doble Aqui": Vignette-Based Focus Groups on Stress and Work for Latina Blue-Collar Women in Eastern North Carolina. Health Promotion Practice, 8(1), 41-49.

Fink, Deborah. (1998). Cutting into the Meatpacking Line: Workers and Change in the Rural Midwest. Chapel Hill, NC: University of North Carolina Press.

Fix, M., \& Zimmermann, W. (2001). All Under One Roof: Mixed-Status Families in an Era of Reform. International Migration Review, 35(2), 397-419.

Fontes, L. A. (2002). Child Discipline and Physical Abuse in Immigrant Latino Families: Reducing Violence and Misunderstandings. Journal of Counseling \& Development, 80(1), 31 .

Gouveia, L. (2005). Latinos in Rural America and U.S. Agriculture: From Pioneers to New Arrivals. Journal of Latino-Latin American Studies (JOLLAS), 1(4), 1-24.

Gutmann, Matthew C. (1996). The Meaning of Macho: Being a Man in Mexico City. Berkeley: University of California Press.

Hancock, T. U. (2007). Sin Papeles: Undocumented Mexicanas in the Rural United States. Affilia, 22(2), 175-184.

Hirsch, Jennifer S. (2000). En el Norte La Mujer Manda: Gender, Generation and Geography in a Mexican Transnational Community. In Forner (ed) Immigration Research for a New Century (pp. 369-389). New York: Russell Sage.

Hondagneu-Sotelo, Pierrette and Ernestine Avila. (1999). "'I'm Here, but I'm There"': The Meanings of Latina Transnational Motherhood. In Pierrette HondagneuSotelo (Ed.) Gender and U.S. Migration: Contemporary Trends" (pp. 317340). Berkeley: University of California Press.

Hondagneu-Sotelo, Pierrette. (1994a). Gendered Transitions: Mexican Experiences of Immigration. Berkeley: University of California Press.

Hondagneu-Sotelo, Pierrette. (1994b). Regulating the Unregulated?: Domestic Workers' Social Networks." Social Problems 44(1):50-64.

Hondagneu-Sotelo, Pierrette. (1995). Beyond 'The Longer They Stay' (and Say They Will Stay): Women and Mexican Immigrant Settlement. Qualitative Sociology 18(1), 21-43. 
Hondagneu-Sotelo, Pierrette. (1999). Retrospectives. In Gender and U.S.

Migration: Contemporary Trends" edited by Pierrette Hondagneu-Sotelo.

Berkeley: University of California Press.

Kanaiaupuni, Shawn Malia. (2000). Reframing the Migration Question: An Analysis of Men, Women, and Gender in Mexico. Social Forces 78(4), 1311-1347.

Kandel, William and Emilio A. Parrado. (2005) Restructuring of the US Meat Processing Industry and New Hispanic Destinations. Population and Development Review 31(3), 447-471.

Kandiyoti, Deniz. (1988). Bargaining with Patriarchy. In Gender and Society 2(3), 274-290.

Kandiyoti, Deniz. .(1998). Gender, Power and Contestation: Rethinking Bargaining with Patriarchy. in C. Jackson and R. Pearson (eds.), Feminist Visions of Development: Gender Analysis and Policy. London and New York: Routledge.

Kandiyoti, Deniz. .(2002). Bargaining with Patriarchy (Afterword). In Nancy Holmstrom (ed.)

The Socialist Feminist Project: A Contemporary Reader in Theory and Politics. New York; Monthly Review Press.

Kibria, N. (1990). Power, Patriarchy, and Gender Conflict in the Vietnamese Immigrant Community. In Gender and Society, 4(1), 9-24.

Kurien, Prema. (2003). Gendered Ethnicity: Creating a Hindu Indian Identity in the United States. In Pierrette Hondagneu-Sotelo (Ed.) Gender and U.S. Migration: Contemporary Trends" (pp. 151-173). Berkeley: University of California Press.

Le Espiritu, Yen. (2003). "Gender and Labor in Asian Immigrant Families. In Pierrette Hondagneu-Sotelo (Ed.) Gender and U.S. Migration: Contemporary Trends" (pp. 101-126). Berkeley: University of California Press.

Livingston, Gretchen. (2006). Gender, Job Searching and Employment Outcomes among Mexican Immigrants. Population Research and Policy Review 25, $43-$ 66.

Madriz, E. I. (1998). Using Focus Groups With Lower Socioeconomic Status Latina Women. Qualitative Inquiry, 4(1), 114-128.

Martin, J. (1990). Motherhood and Power: The Production of a Women's Culture of Politics in a Mexican Community. American Ethnologist, 17(3), 470-490. 
McClenaghan, S. (1997). Women, work, and empowerment: Romanticizing the reality. In E. Dore (ed.) Gender politics in Latin America: Debates in theory and practice, (pp.19-35). New York: Monthly Review Press.

Menjivar, Cecilia. (1997). Immigrant Kinship Networks and the Impact of the Receiving Context: Salvadorans in San Francisco in the early 1990's. Social Problems 44(1), 104-123.

Menjivar, C. (1999). The Intersection of Work and Gender: Central American Immigrant Women and Employment in California. American Behavioral Scientist, 42(4), 601-627.

Menjivar, Cecilia. (2003). "The Intersection of Work and Gender: Central American Immigrant Women and Employment in CaliforniaIn Pierrette HondagneuSotelo (Ed.) Gender and U.S. Migration: Contemporary Trends" (pp. 151173). Berkeley: University of California Press.

Nelson, Jessica. (2007). Oregon Dairy Industry Mooving Forward. In Oregon Labor Market Information System. Retrieved July 15, 2008 from http://www.qualityinfo.org/olmisj/ArticleReader?itemid $=00005675$

Neuhouser, K. (1989). Sources of Women's Power and Status among the Urban Poor in Contemporary Brazil. In Signs, 14(3), 685-702.

Mills, Mary B. (2003). Gender and Inequality in the Global Labor Force. In Annual Review of Anthropology 32, 41-62.

Mummert, Gail. (1994). From Metate to Despate: Rural Mexican Women's Salaried Labor and the Redefinition of Gendered Spaces and Roles. In Heather FowlerSalamini and Mary Kay Vaughan, (eds.), Women of the Mexican Countryside, 1850-1990, (pp.192-209). Tucson: University of Arizona Press.

Parrado, E. A., \& Flippen, C. A. (2005). Migration and Gender among Mexican Women. American Sociological Review, 70, 606-632.

Pedraza, S. (1991). Women and Migration: The Social Consequences of Gender. Annual Review of Sociology, 17(1), 303-325.

Perreira, K. M., Chapman, M. V., \& Stein, G. L. (2006). Becoming an American Parent: Overcoming Challenges and Finding Strength in a New Immigrant Latino Community. Journal of Family Issues, 27(10), 1383-1414. 
Pessar, Patricia R. (1988). The Constraints on and Release of Female Labor Power: Dominican Migration to the United States. In A. Home Divided: Women and Income in the Third World, (pp. 195-215). California: Stanford University Press.

Pessar, Patricia R. (2003). Engendering Migration Studies; The Case of New Immigrants in the United States." In Pierrette Hondagneu-Sotelo (Ed.) Gender and U.S. Migration: Contemporary Trends, (pp. 195-215). Berkeley: University of California Press.

Ramirez E. \& Barajas M. (2008). Transnationalism, Mexican Communities \& the Shaping of Perceptions of Gender Equality \& Inequality Across Borders. Paper presented at the $79^{\text {th }}$ Annual Convention of the Pacific Sociological Association Meeting, Portland, Oregon.

Roldan, Marta. (1988). Renegotiating the Marriage Contract: Intrahousehold Patterns of Money Allocation and Women's Subordination Among Domestic Outworkers in Mexico City." Pp. 229-247. in A Home Divided: Women and Income in the Third World . California: Stanford University Press.

Segura, D. A. (1991). Ambivalence or continuity?: Motherhood and employment among Chicanas and Mexican immigrant women workers. Aztlan, 20(1\&2), 119-150.

Toro-Morn, Maura I. and Marisa Alicea. (2003). Gendered Geographies of Home: Mapping Second and Third -Generation Puerto Ricans Sense of Home.In Pierrette Hondagneu-Sotelo (Ed.) Gender and U.S. Migration: Contemporary Trends, (pp. 194-216). Berkeley: University of California Press.

Walby, S. (1991). Theorizing Patriarchy. Oxford: Blackwell

Wilson, T. D. (2003). Forms of Male Domination and Female Subordination: Homeworkers versus Maquiladora Workers in Mexico. In Review of Radical Political Economics, 35(1), 56-72.

Williams, Susan L., Sandra D. Alvarez and Kevin S. Andrade Hauck. (2002). My Name is Not Maria: Young Latinas Seeking Home in the Heartland. In Social Problems 49(4): 563-582.

Ybarra, L. (1982). When Wives Work: The Impact on the Chicano Family. Journal of Marriage and the Family, 44(1), 169-178.

Zavella, Patricia. (1987). Women's Work and Chicano Families. Ithaca: Cornell University Press. 